\title{
Ancestral reconstruction of tick lineages
}

Ben J. Mans ${ }^{1,3,4^{*}}$, Minique H. de Castro ${ }^{1,2,4}$, Ronel Pienaar ${ }^{1}$, Daniel de Klerk ${ }^{1}$, Philasande Gaven ${ }^{1,4}$, Siyamcela Genu ${ }^{1,4}$ and Abdalla A. Latif ${ }^{1,5}$

${ }^{1}$ Parasites, Vectors and Vector-borne Diseases, Agricultural Research CouncilOnderstepoort Veterinary Institute, Onderstepoort 0110, South Africa

${ }^{2}$ The Biotechnology Platform, Agricultural Research Council-Onderstepoort Veterinary Institute, Onderstepoort 0110, South Africa

${ }^{3}$ Department of Veterinary Tropical Diseases, University of Pretoria, Pretoria, South Africa

${ }^{4}$ Department of Life and Consumer Sciences, University of South Africa, South Africa

${ }^{5}$ School of Life Sciences, University of Kwa-Zulu Natal, Durban, South Africa

*Corresponding author: mansb@arc.agric.za 


\begin{abstract}
Ancestral reconstruction in its fullest sense aims to describe the complete evolutionary history of a lineage. This depends on accurate phylogenies and an understanding of the key characters of each parental lineage. An attempt is made to delineate our current knowledge with regard to the ancestral reconstruction of the tick (Ixodida) lineage. Tick characters may be assigned to Core of Life, Lineages of Life or Edges of Life phenomena depending on how far back these characters may be assigned in the evolutionary Tree of Life. These include housekeeping genes, sub-cellular systems, heme processing (Core of Life), development, molting, appendages, nervous and organ systems, homeostasis, respiration (Lineages of Life), specific adaptations to a bloodfeeding lifestyle, including the complexities of salivary gland secretions and tick-host interactions (Edges of Life). The phylogenetic relationships of lineages, their origins and importance in ancestral reconstruction are discussed. Uncertainties with respect to systematic relationships, ancestral reconstruction and the challenges faced in comparative transcriptomics (next-generation sequencing approaches) are highlighted. While almost 150 years of information regarding tick biology have been assembled, progress in recent years indicates that we are in the infancy of understanding tick evolution. Even so, broad reconstructions can be made with relation to biological features associated with various lineages. Conservation of characters shared with sister and parent lineages are evident, but appreciable differences are present in the tick lineage indicating modification with descent, as expected for Darwinian evolutionary theory. Many of these differences can be related to the hematophagous lifestyle of ticks.
\end{abstract}

Keywords: Blood-feeding, Evolution, Genomics, Phylogenetics, Molecular systematics, Next-generation sequencing 


\section{Ancestral Reconstruction}

Ancestral reconstruction aims to provide an accurate history of changes that occurred in a lineage during the course of evolution and to determine which characters were present in the last common ancestral lineage. Zuckerkandl and Pauling elaborated on the basic idea in a series of papers which aimed to establish a theoretical basis for the reconstruction of amino acid positions in protein sequences, based on the molecular clock hypothesis (Zuckerkandl and Pauling, 1965a, 1965b, 1962). In this form it has been successfully used to reconstruct and characterize ancient "extinct" proteins at functional level, thereby gaining insight into the evolution of protein function (Liberles, 2007). However, ancestral reconstruction as a discipline spans much more than reconstruction of protein sequences and has been present at least as long as the idea of evolution by descent (Darwin, 1859).

In its most encompassing form it aims at the total description of the evolutionary history of an organism and include all levels of biological complexity, from sub-cellular to cellular to multi-cellular organization, developmental biology, morphological and physiological adaptations, gene duplication and gene loss, functional acquisition, loss, modification or exaptation, differential gene expression, complex interaction networks, divergence and extinctions of species or lineages, lineage specific innovations or losses, acquisition via horizontal gene transfer, pathogen and symbiont interactions and the microbiome of a species. In fact, it may be argued that ancestral reconstruction lie at the heart of all biological disciplines and that without it a full understanding of biology and the evolution of a lineage cannot be attained. To paraphrase Dobzhansky (1973): Nothing in evolution makes sense, except in the light of ancestral reconstruction. 
Ancestral reconstruction serves to provide a perspective on the proper place that function, biological process, phenotypic trait or a species may have in the intrinsic nature of a lineage. The intrinsic nature of a lineage is those properties that allow us to classify it as unique in relation to its closest relatives. For example: Ticks are monophyletic hematophagous parasitiform Acari, a trait that distinguish them from most other Arachnids.

Correct phylogenies are crucial for accurate ancestral reconstruction (Cunningham et al. 1998; Ronquist, 2004), whether this is for protein sequences, domains or families, morphological characters, biological processes or species relationships, since the identification of homologous characters lies at its heart. Ancestral reconstruction can therefore not be considered without reference to the systematics of a lineage and its place within the larger Kingdom of Life.

Reconstruction of the evolutionary history of the tick lineage (Ixodida) in broad terms have previously been addressed on various levels (Barker et al. 2014; Barker and Murrell, 2004, 2002; Black et al. 1997; Burger et al. 2014a, 2013, 2012; de la Fuente et al. 2015; Dobson and Barker, 1999; Durden and Beati, 2014; Hoogstraal, 1985; Klompen and Oliver, 1993; Klompen et al. 2000, 1996a; Mans, 2014; Mans, 2011; Mans and Neitz, 2004a; Mans et al. 2015; 2014, 2012, 2011, 2008a, 2008b, 2003a, 2002a; Murrell et al. 2005; Oliver, 1989), but no critical review regarding progress in this field in recent years exist. The current review will assess our knowledge regarding ancestral reconstruction of the tick lineage, as well as challenges faced for successful reconstruction in the future. It is our contention that accurate ancestral reconstruction will allow understanding of tick biology in its entire complexity. This will allow knowledge-based hypotheses on a far grander scale than is the current case and will allow for a targeted approach to tick control. 


\section{The place of ticks in the Tree of Life}

It is of interest to define the place of ticks in the Tree of Life, the certainty of this placement and its implications for the understanding of tick biology with respect to ancestral reconstruction (Fig. 1). Life may be classified into Archaea, Bacteria and Eukaryotes (SAR, Archaeplastida, Excavata, Amoebozoa, Opisthokonta) (Adl et al. 2012). Within the Opisthokonta the Animalia (animals, Metazoa) are multicellular heterotrophic eukaryotes divided into the Bilateria, Calcarea (Calcareous sponges), Ctenophora (comb jellies), Cnidaria (sea anemones, corals, jellyfish), Homoscleromorpha (encrusting sponges), Placozoa and Silicea (siliceous sponges) (Edgecombe et al. 2011). Bilateria (animals with bilateral symmetry) includes Acoelomorpha and Nephrozoa. The latter includes Deuterostomia (vertebrate and their ancestral lineages), Ecdysozoa (animals able to molt) and Spiralia (including molluscs, annelids and platyhelminths). Ecdysozoa include the Arthropoda, Nematozoa (nematodes), Onychophora, Scalidophora and Tartigrada (Philippe et al. 2009). The Arthropoda are invertebrates with exoskeletons, segmented bodies and jointed appendages and subphyla include Chelicerata (Arachnida, Xiphosura and Pycnogonida), Crustacea (crustaceans), Hexapoda (insects) and Myriapoda (centipedes and millipedes) (Edgecombe, 2010; Edgecombe and Legg, 2014). Within this scheme ticks are part of the Arachnida; a distinction shared with other Acari (mites), Amblypygi (tailless whip scorpions), Araneae (spiders), Opiliones (harvestmen), Palpigradi (microwhip scorpions), Pseudoscorpionida (pseudoscorpions), Ricinulei (hooded tick-spiders), Schizomida (split middle whip scorpions), Scorpiones (scorpions), Solifugae (sun spiders) and Thelyphonida (whip scorpions). The Acari is composed of the Acariformes 
Figure 1: The lineage specific history of the Ixodida. Indicated are a current phylogenetic relationships for Eukaryotes (Adl, et al. 2012), Metazoa (Edgecombe et al. 2011), Arthropoda (Giribet and Edgecombe, 2012), Acari (Klompen et al. 2007) and Ixodida (Mans, 2011; Mans et al. 2015). Numbers in brackets indicate current number of species according to Guglielmone (2010) as updated (Mans, 2011).

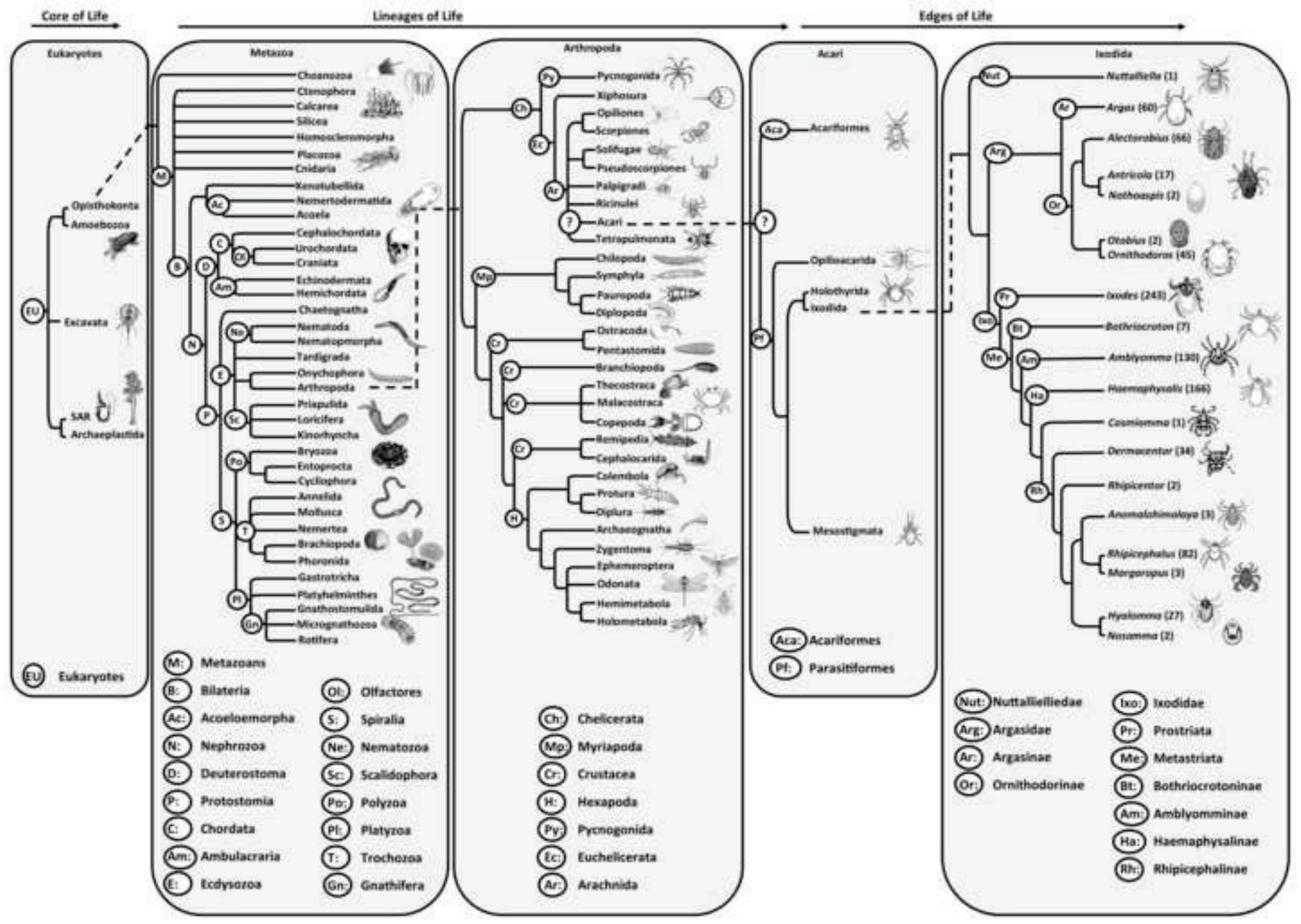


and the Parasitiformes, the latter divided into Opilioacarida, Holothyrida, Ixodida and Mesostigmata (Fig. 1).

\section{Core, Lineage and Edges of Life processes}

Our confidence that ticks fall within this classification scheme (Eukaryotes, Metazoa, Bilateria, Nephrozoa, Protostomia, Ecdysozoa, Arthropoda, Chelicerata, Arachnida, Parasitiformes, Ixodida) is fairly robust based on morphological and molecular evidence (Dunlop, 2010; Edgecombe et al. 2011; Edgecombe and Legg, 2014; Garwood and Dunlop, 2014; Giribet and Edgecombe, 2012; Legg et al. 2013; Philippe et al. 2009; Shultz, 2007, 1990). This phylogenetic placement allows us to make some generalized statements with regard to ancestral reconstruction, with the understanding that there is a gradation of lineage specific conservation. As such, conservation phenomena may be divided into Core of Life, Lineages of Life and Edges of Life processes. Core of Life processes are those conserved in all Eukaryotes and evolved in the Last Eukaryotic Common Ancestor (LECA) (Koonin, 2015; Penny et al. 2014). Lineages of Life processes refer to those that characterize a lineage in relation to other lineages, with the implication that those characters that define the ancestral lineage will be conserved among sibling lineages. Edges of Life processes refer to those adaptations that make lineages unique with respect to their biology and ecology. Whereas Core of Life and Lineages of Life deal mainly with processes that ensures functionality at cellular and developmental level, Edges of Life deal mainly with those processes that allow organisms to interact and engage with their environment. This is also the space where lineage specific innovation and adaptation occurs and where organisms find different solutions to the same problem, for example, the way that different bloodfeeding arthropods adapted independently to the vertebrate host-interface using similar 
anti-defence mechanisms via convergent evolution (Mans, 2011). In this space, closely related lineages can have very different biology. These broad classifications can overlap and a central theme that emerges is that of modification of existing features with descent, i.e. organisms use existing characters for innovation. The remainder of the review will discuss the evolution of ticks and their ancestral reconstruction within this framework.

\section{Core of Life processes}

The core eukaryotic set of orthologous housekeeping genes

It may be reasonable to expect that the Core of Life processes will be conserved in ticks. These include metabolic pathways, sub-cellular organization and cellular processes such as cell division, protein degradation, secretory pathways, replication, transcription, translation, cell trafficking and transport (Koonin, 2015; Penny et al. 2014). Knowledge that these characters are conserved allows functional annotation of transcriptome or genomic databases with some degree of confidence (Gabaldón and Koonin, 2013), even if most of these functionalities have never been empirically tested in ticks. Databases that may serve as gateways to discover Core of Life processes are the COG (Tatusov et al. 2003), KOG (Koonin et al. 2004), KEGG (Ogata et al. 1999) and Biosystems (Geer et al. 2010) databases. In the KOG database for example, 3413 core genes were conserved in all eukaryotes and 5210 in the Ecdysozoa (Koonin et al. 2004). Approximately 70000 tick proteins from Genbank can be annotated as housekeeping using the KEGG database (B.J. Mans, personal observation). More specifically, 14000, $\sim 15000$ and $\sim 5000$ can be annotated as housekeeping, respectively, for the three species with the highest number of genes available at present, namely Ixodes scapularis, I. ricinus and Rhipicephalus microplus (Table 1). The scorpion Mesobuthus martensii, with a genome size of $\sim 1.3 \mathrm{Gbp}$ and an estimated 32016 genes, is the only chelicerate genome 
Table 1: A summary of transcriptomes sequenced from ticks and other mites. Protein sequences were retrieved from the NR protein database where available, otherwise nucleotide and EST data were retrieved from Genbank or Vectorbase $(*)$. Open reading frames $(>240 \mathrm{bp})$ were extracted and translated to protein sequences. A nonredundant dataset was analyzed by BLAST analysis against an in-house curated tick database. C: conventional sequencing; N: next-generation sequencing; SG: salivary gland; WB: whole body; HL: hemolymph; SYN: synganglion; OV: ovaries; G: gut; SEC: secretory; HK: housekeeping; KI: kunitz/BPTI inhibitor; BT: basic tail; LC: lipocalin; 5NT: 5' nucleotidase/apyrase; MP: metalloprotease. Missing data or unavailable data in Genbank is indicated by - .

\begin{tabular}{|c|c|c|c|c|c|c|c|c|c|}
\hline Species & $\begin{array}{l}\text { Type } \\
\text { Source }\end{array}$ & SEC & HK & KI & BT & $\mathbf{L C}$ & 5NT & MP & Reference \\
\hline \multicolumn{10}{|l|}{ Argasidae } \\
\hline A. monolakensis & $\mathrm{C}, \mathrm{SG}$ & 137 & 83 & 8 & 21 & 32 & 1 & 21 & Mans et al. 2008b \\
\hline O. coriaceus & $\mathrm{C}, \mathrm{SG}$ & 123 & 102 & 13 & 19 & 39 & 1 & 12 & Francischetti et al. $2008 \mathrm{~b}$ \\
\hline O. porcinus $*$ & $\mathrm{C}, \mathrm{WB}$ & 20 & 139 & 2 & 2 & 4 & 0 & 2 & Neilan et al. 2003, unpublished \\
\hline O. parkeri & $\mathrm{C}, \mathrm{SG}$ & 132 & 161 & 15 & 20 & 48 & 0 & 7 & Francischetti et al. 2008a \\
\hline O. rostratus* & $\mathrm{N}, \mathrm{SG}$ & 396 & 5600 & 21 & 22 & 34 & 8 & 60 & Araujo et al. 2015, unpublished \\
\hline \multicolumn{10}{|l|}{ Ixodidae } \\
\hline I. pacificus & $\mathrm{C}, \mathrm{SG}$ & 66 & 36 & 9 & 16 & 10 & 0 & 1 & Francischetti et al. 2005 \\
\hline I. ricinus $*$ & $\mathrm{C}, \mathrm{SG}$ & 129 & 135 & 18 & 47 & 6 & 0 & 8 & Chmelar et al. 2008 \\
\hline I. ricinus & $\mathrm{N}, \mathrm{SG}$ & 3882 & 3537 & 512 & 310 & 564 & 60 & 564 & Schwarz et al. 2013 \\
\hline I. ricinus & $\mathrm{N}, \mathrm{SG}$ & 3670 & 9891 & 478 & 406 & 568 & 41 & 427 & $\begin{array}{l}\text { Kotsyfakis et al. 2015a; Schwarz et al. } \\
\text { 2014a }\end{array}$ \\
\hline I. ricinus & $\mathrm{N}, \mathrm{HL}$ & 625 & 1712 & 47 & 66 & 126 & 2 & 48 & Kotsyfakis et al. $2015 b$ \\
\hline I. ricinus & Total & 8401 & 15360 & 1058 & 834 & 1283 & 103 & 1054 & Databases* \\
\hline I. scapularis & $\mathrm{C}, \mathrm{SG}$ & 274 & 147 & 44 & 42 & 40 & 0 & 1 & Ribeiro et al. 2006 \\
\hline I. scapularis & Genome & 1368 & 13042 & 99 & 49 & 65 & 38 & 342 & Hill et al., unpublished \\
\hline I. scapularis & Total & 1795 & 13283 & 176 & 123 & 119 & 39 & 348 & Databases* \\
\hline A. americanum $*$ & $\mathrm{C}, \mathrm{SG}$ & 193 & 133 & 65 & 6 & 69 & 0 & 8 & Aljamali et al. 2009 \\
\hline A. americanum $*$ & $\mathrm{C}, \mathrm{SG}$ & 104 & 859 & 8 & 9 & 31 & 0 & 4 & Gibson et al. 2013 \\
\hline A. americanum & $\mathrm{N}, \mathrm{SG}$ & 849 & 1814 & 110 & 34 & 213 & 6 & 71 & Karim and Ribeiro, 2015 \\
\hline A. americanum & Total & 1173 & 2982 & 184 & 49 & 314 & 6 & 83 & Databases* \\
\hline A. maculatum & $\mathrm{N}, \mathrm{SG}$ & 886 & 3325 & 88 & 24 & 304 & 8 & 147 & Karim et al. 2011 \\
\hline $\begin{array}{l}\text { A. variegatum } \\
\text { A. variegatum }\end{array}$ & $\mathrm{C}, \mathrm{SG}$ & $\begin{array}{l}- \\
140\end{array}$ & $\begin{array}{l}- \\
526\end{array}$ & $\overline{7}$ & $\begin{array}{l}- \\
5\end{array}$ & $\begin{array}{l}- \\
12\end{array}$ & - & $\begin{array}{l}- \\
18\end{array}$ & $\begin{array}{l}\text { Nene et al. } 2002 \\
\text { Ribeiro et al. } 2011\end{array}$ \\
\hline A. cajennense & $\mathrm{N}, \mathrm{SG}$ & 1362 & 3479 & 187 & 125 & 275 & 18 & 109 & Garcia et al. 2014 \\
\hline A. parvum & $\mathrm{N}, \mathrm{SG}$ & 476 & 1977 & 61 & 19 & 109 & 4 & 38 & Garcia et al. 2014 \\
\hline A. triste & $\mathrm{N}, \mathrm{SG}$ & 1761 & 4991 & 135 & 87 & 589 & 13 & 115 & Garcia et al. 2014 \\
\hline H. flava & $\mathrm{N}, \mathrm{SG}$ & - & - & - & - & - & - & - & $\mathrm{Xu}$ et al. 2015 \\
\hline H. longicornis & $\mathrm{N}, \mathrm{SG}$ & - & - & - & - & - & - & - & Tirloni et al. 2015 \\
\hline H. longicornis* & $\mathrm{C}, \mathrm{SG}$ & 796 & 878 & 85 & 22 & 133 & 0 & 22 & Tsuji et al. 2015, unpublished \\
\hline D. variabilis* & $\mathrm{C}, \mathrm{G}$ & 63 & 368 & 3 & 0 & 6 & 0 & 2 & Anderson et al. 2008 \\
\hline D. variabilis* & $\mathrm{N}, \mathrm{SYN}$ & 29 & 36 & 4 & 0 & 0 & 0 & 0 & Donohue et al. 2010 \\
\hline D. variabilis $*$ & $\mathrm{~N}, \mathrm{WB}$ & 44 & 180 & 1 & 1 & 1 & 0 & 1 & Jaworski et al. 2010 \\
\hline R. appendiculatus $*$ & $\mathrm{C}, \mathrm{SG}$ & 107 & 709 & 4 & 6 & 5 & 0 & 24 & Nene et al. 2004 \\
\hline R. appendiculatus & SG & 2134 & 8237 & 236 & 90 & 516 & 16 & 193 & de Castro et al. 2016 \\
\hline R. microplus & $\begin{array}{l}\mathrm{HC}, \mathrm{SG} \\
\mathrm{OV}\end{array}$ & - & - & - & - & - & - & - & Santos et al. 2004 \\
\hline R. microplus* & $\mathrm{C}, \mathrm{WB}$ & 699 & 3897 & 50 & 21 & 81 & 8 & 100 & Guerrero et al. 2005 \\
\hline R. microplus* & $\mathrm{C}, \mathrm{GOL}$ & 62 & 768 & 6 & 0 & 0 & 0 & 0 & Heekin et al. 2012, 2013a, 2013b \\
\hline R. microplus* & $\mathrm{N}, \mathrm{SG}$ & 93 & 55 & 2 & 0 & 49 & 0 & 2 & Tirloni et al. 2014 \\
\hline R. microplus & Total & 917 & 5088 & 64 & 21 & 134 & 9 & 107 & Databases \\
\hline R. pulchellus & $\mathrm{N}, \mathrm{SG}$ & 1414 & 8160 & 196 & 39 & 331 & 13 & 107 & Tan et al. 2015 \\
\hline R. sanguineus & $\mathrm{C}, \mathrm{SG}$ & 102 & 163 & 10 & 10 & 31 & 0 & 0 & Anatriello et al. 2010 \\
\hline Total & & 22757 & 77033 & 2604 & 1578 & 4378 & 247 & 2456 & \\
\hline \multicolumn{10}{|l|}{ Mesostigmata } \\
\hline M. occidentalis & $\mathrm{N}, \mathrm{WB}$ & 334 & 9075 & 6 & 8 & 5 & 5 & 45 & Hoy et al. 2013 \\
\hline D. gallinae* & $\mathrm{N}, \mathrm{WB}$ & 303 & 5142 & 18 & 7 & 8 & 2 & 27 & Schicht et al. 2014 \\
\hline S. scabiei & Genome & 386 & 6973 & 8 & 0 & 1 & 5 & 23 & Rider et al. 2015 \\
\hline
\end{tabular}


sequenced to date that approaches the size of tick genomes (Cao et al. 2013). Reciprocal best BLAST hit analysis of M. martensii, I. ricinus and I. scapularis gave 3312 shared proteins, 5455 for I. scapularis/M. martensii, 4403 for I. ricinus/M. martensii and a total of 6546 that can be classified as housekeeping. This indicate that some of the core genes may still be missing from the I. scapularis genome and I. ricinus transcriptome and that chelicerates may have up to $\sim 7000$ shared core housekeeping genes. This core set codes for various basic processes central to cellular biology, including metabolism of amino acids (239), carbohydrates (350), energy (112), lipids (185), nucleotides (108), detoxification (10), replication (373), transcription (798), translation (633), protein folding, degradation and sorting (756), transport (433), cell division (128), cell communication (43), cell motility (190), signal transduction (746) and signalling (193).

Gene losses and duplication account for differences in the rest of the housekeeping complement where M. martensii retrieve 16078 genes from I. scapularis and 14905 from I. ricinus using BLAST analysis, of which 6749 and 6186 are nonredundant, respectively and $\sim 90 \%$ are housekeeping. This indicated that $M$. martensii has a significant portion of duplicated housekeeping genes, which may account for the high gene number observed in the genome. Conversely, I. scapularis retrieved 12032 BLAST hits (6883 non-redundant) and I. ricinus 14372 (5566 non-redundant) of which $\sim 90 \%$ are housekeeping. BLAST analysis of the non-redundant proteins from I. scapularis against its own database indicated that $95 \%$ of these proteins have at least one gene pair in the rest of the genome (BLAST E-value $<10^{-10}$ ). This may suggest that each gene has underwent at least a single duplication, or that one genome duplication event occurred in the past.

Moonlighting of housekeeping proteins at the tick-host interface 
Conserved proteins may have moonlighting functionality at the tick-host feeding interface (Tirloni et al. 2015, 2014). For example enolase, a glycoolytic enzyme may act as plasminogen activator (Díaz-Martín et al. 2013a). An interesting phenomenon in this regard, is the proteomic detection of high numbers of housekeeping proteins in tick salivary secretions, even though the majority do not have secretory signals (DíazMartín et al. 2013b; Oliveira et al. 2013; Tirloni et al. 2015, 2014). The presence of housekeeping proteins in saliva may be explained by conservation of apocrine secretion in metazoans (Farkaš, 2015). As opposed to exocytosis (merocrine secretion), where secretory granules that derive from the Golgi network, fuse with the cell membrane and selectively secrete its contents externally, apocrine secretion consists of shedding of whole pieces of cellular material (granular and cytoplasmic content) into a lumen (Farkaš, 2015). Apocrine secretion of large granules and merocrine secretion of small granules have been described in soft ticks (Balashov, 1972; Coons and Roshdy, 1981), as well as hard ticks (Gill and Walker, 1987; Shaw and Young, 1995). Merocrine secretion most probably occurs for dopamine vesicles that have a paracrine role in secretion ( $\breve{S i m o}$ et al. 2011). Direct evidence of apocrine secretion in the soft tick O. savignyi is presented in the current study for the first time (Fig. 2). Apocrine secretion may explain why not all granular content are secreted during feeding (Balashov, 1972; Coons and Roshdy, 1981), why housekeeping proteins show up in saliva (Díaz-Martín et al. 2013b; Tirloni et al. 2015,2014 ) and why saliva proteomes may in general show high levels of diversity between feeding stages, sexes and individuals (Díaz-Martín et al. 2013b).

The detection of high numbers of housekeeping proteins in salivary secretions may indicate a function in tick-host interactions (Tirloni et al. 2015, 2014), making the accurate annotation of housekeeping proteins an important aim in ancestral reconstruction. However, the inconsistent nature of apocrine secretion necessitates 
Figure 2: Apocrine secretion in the soft tick Ornithodoros savignyi. Indicated are unfed acini (top left) and acini day 0 after feeding (top right). Arrows indicate signs of broken cells that secreted material into the lumen. Graphical representations of unfed (bottom left) and acini after apocrine secretion (bottom right).
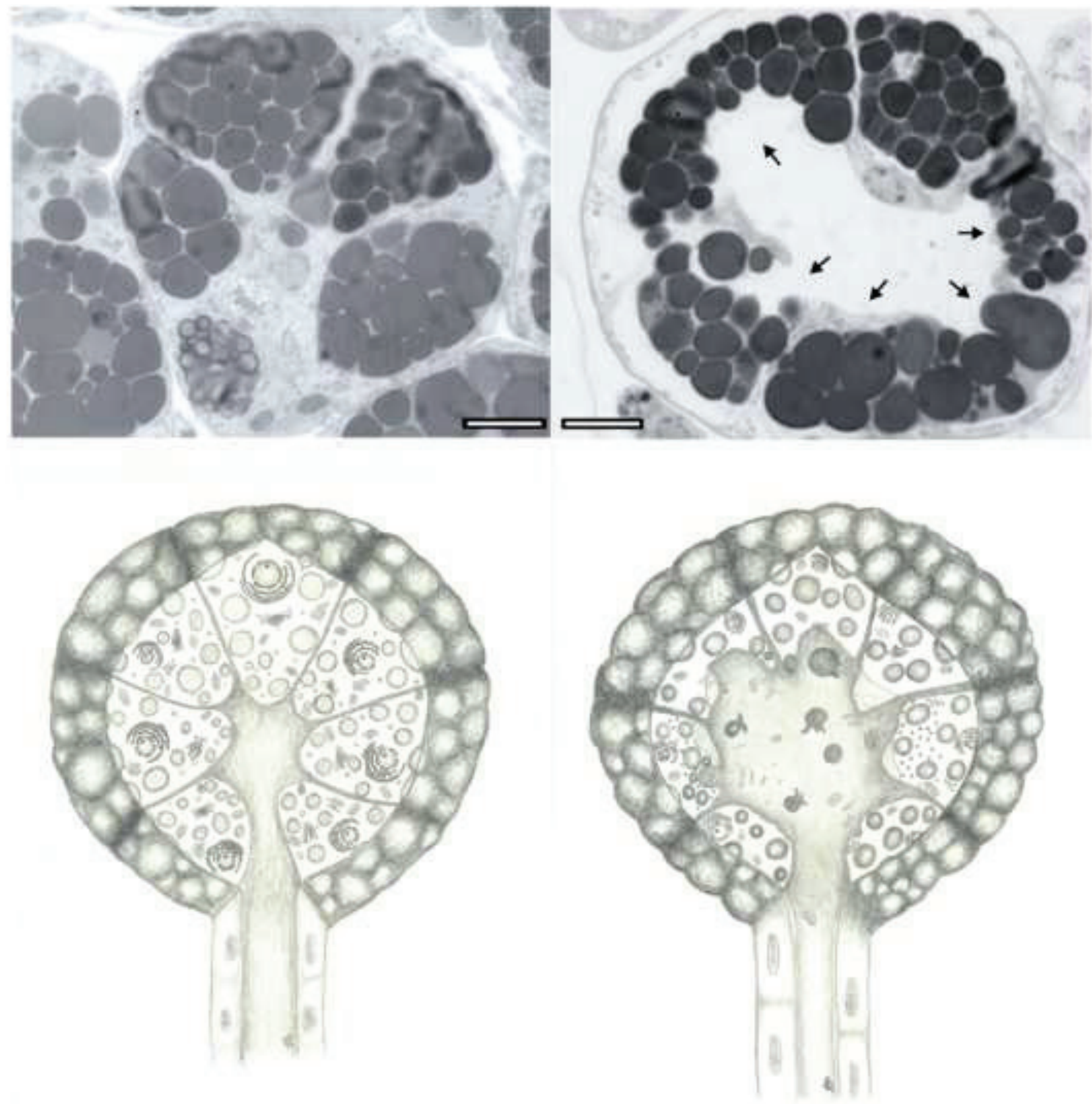
Table 2: Platelet aggregation inhibitors from ticks. Adapted and updated from Mans and Neitz (2004a).

Sequences were analyzed by BLASTP analysis against an in-house curated tick database (Table 1) to identify potential orthologs. Those highlighted in grey are considered to be present in the ancestral tick lineage.

\begin{tabular}{|c|c|c|c|c|c|c|}
\hline Species & Name & Target & Mr & Family & Orthologs & Reference \\
\hline O. moubata & Apyrase & ATP, ADP & 63291 & $5-\mathrm{NT}$ & Ixodida & Ribeiro et al. 1991; Díaz-Martín et al. 2015 \\
\hline O. savignyi & Apyrase & ATP, ADP & 63102 & $5-\mathrm{NT}$ & Ixodida & Mans et al. 1998a, 1998b; Stutzer et al. 2009 \\
\hline A. monolakensis & Apyrase & ATP, ADP & ND & $5-\mathrm{NT}$ & Ixodida & Mans et al. 2008a; Mans et al. 2008b \\
\hline I. scapularis & Apyrase & ATP, ADP & 61841 & $5-\mathrm{NT}$ & Ixodida & Ribeiro et al. 1985; Stutzer et al. 2009 \\
\hline O. moubata & Moubatin & TXA2 & 16756 & Lipocalin & Ornithodoros & $\begin{array}{l}\text { Waxman and Connolly, 1993; Keller et al. } \\
1993\end{array}$ \\
\hline O. savignyi & TSGP2/3 & TXA2 & 15878 & Lipocalin & Ornithodoros & Mans and Ribeiro, 2008b \\
\hline O. moubata & TAI & Collagen & ND & ND & ND & Karczewski et al. 1995 \\
\hline O. moubata & Disagregin & GPIIbIIIa & 6956 & BPTI & Argasidae & Karczewski et al. 1994 \\
\hline O. savignyi & Savignygrin & GPIIbIIIa & 6966 & BPTI & Argasidae & Mans et al. 2002b \\
\hline A. monolakensis & Monogrin & GPIIbIIIa & 9817 & BPTI & Argasidae & Mans et al. 2008a \\
\hline D. variabilis & Variabilin & GPIIbIIIa & 4986 & Ixodegrins & Ixodidae & Wang et al. 1996; Francischetti et al. 2005 \\
\hline A. americanum & AamS6 & Plasmin & 52000 & Serpin & Metastriates & Mulenga et al. 2013 \\
\hline A. americanum & AAS19 & Thrombin & 46638 & Serpin & Ixodidae & Kim et al. 2015 \\
\hline H. longicornis & Longicornin & Collagen & 16000 & ND & ND & Cheng et al. 1999 \\
\hline I. ricinus & IRS-2 & Cathepsin G & 41900 & Serpin & Prostriates & Chmelar et al. 2011 \\
\hline I. scapularis & YY-39 & GPIIbIIIa & 4432 & Ixodegrins & Ixodidae & Francischetti et al. 2005; Tang et al. 2015 \\
\hline D. reticulatus & SHBP & Serotonin & 22065 & Lipocalin & Ixodida & Sangamnatdej et al. 2002 \\
\hline O. savignyi & TSGP1 & Serotonin & 18614 & Lipocalin & Ixodida & Mans et al. 2008c \\
\hline A. monolakensis & Monotonin & Serotonin & 16559 & Lipocalin & Ixodida & Mans et al. 2008c \\
\hline I. scapularis & $\begin{array}{l}\text { IS-14 } \\
\text { IS-15 }\end{array}$ & $\begin{array}{l}\text { Serotonin } \\
\text { Serotonin }\end{array}$ & $\begin{array}{l}20318 \\
21343\end{array}$ & $\begin{array}{l}\text { Lipocalin } \\
\text { Lipocalin }\end{array}$ & $\begin{array}{l}\text { Ixodida } \\
\text { Ixodida }\end{array}$ & Mans et al. 2008c \\
\hline
\end{tabular}

ND - not determined 
Table 3: Blood clotting inhibitors from ticks. Adapted and updated from Mans and Neitz (2004a). Sequences were analyzed by BLASTP analysis against an in-house curated tick database (Table 1) to identify potential orthologs. Those highlighted in grey are considered to be present in the ancestral tick lineage.

\begin{tabular}{|c|c|c|c|c|c|c|}
\hline Species & Name & Target & Mr (Da) & Family & Orthologs & Reference \\
\hline O. moubata & ND & Thrombin & ND & ND & ND & Hellmann and Hawkins, 1967 \\
\hline O. moubata & Ornithodorin & Thrombin & 12620 & BPTI & Argasidae & van de Locht et al. 1995 \\
\hline O. savignyi & Savignin & Thrombin & 12430 & BPTI & Argasidae & Nienaber et al. 1999; Mans et al. 2002c \\
\hline A. monolakensis & Monobin & Thrombin & 13663 & BPTI & Argasidae & Mans et al. 2008a \\
\hline A. americanum & Americanin & Thrombin & 12000 & ND & ND & Zhu et al. 1997 \\
\hline I. ricinus & Ixin & Thrombin & 7000 & ND & ND & Hoffmann et al. 1991 \\
\hline I. holocyclus & ND & Thrombin & ND & ND & ND & Anastopoulos et al. 1991 \\
\hline R. microplus & BmAP & Thrombin & 60000 & ND & ND & Horn et al. 2000 \\
\hline R. microplus & BmGTI & Thrombin & 26000 & ND & ND & Ricci et al. 2007 \\
\hline$R$. microplus & Microphilin & Thrombin & 1755 & ND & ND & Ciprandi et al. 2006 \\
\hline A. variegatum & Variegin & Thrombin & 3609 & Hirudin-like & Metastriates & Kazimírová et al. 2002; Koh et al. 2007 \\
\hline H. longicornis & Madanins & Thrombin & $\begin{array}{l}6771 ; \\
7122\end{array}$ & Madanin & Metastriates & Iwanaga et al. 2003 \\
\hline H. longicornis & Chimadanin & Thrombin & 7472 & Madanin & Metastriates & Nakajima et al. 2006 \\
\hline H. m. rufipes & Hyalomin-1 & Thrombin & 6386 & Madanin & Metastriates & Jablonka et al. 2015 \\
\hline I. scapularis & Ixophilin*1 & Thrombin & 14112 & BPTI & Ixodidae & Narasimhan et al. 2013 \\
\hline H. longicornis & Hemalin*1 & Thrombin & 14246 & BPTI & Ixodidae & Liao et al. 2009 \\
\hline R. microplus & Boophilin*1 & Thrombin & 13980 & BPTI & Ixodidae & $\begin{array}{l}\text { Macedo-Ribeiro et al. 2008; Soares et al. } \\
2012\end{array}$ \\
\hline R. microplus & RmS-15 & Thrombin & 42643 & Serpin & Ixodidae & Rodriguez-Valle et al. 2015 ; Xu et al. 2016 \\
\hline A. hebraeum & Amblin*1 & Thrombin & 17400 & BPTI & Ixodidae & Lai et al. 2004 \\
\hline R. calcaratus & Calcaratin & Thrombin & 14500 & ND & ND & Motoyashiki et al. 2003 \\
\hline H. dromedarii & NTI-1 & Thrombin & 3200 & ND & ND & Ibrahim et al. 2001a \\
\hline H. dromedarii & NTI-2 & Thrombin & 14900 & ND & ND & Ibrahim et al. 2001a \\
\hline O. moubata & TAP & fXa & 6979 & BPTI & Ornithodoros & Waxman et al. 1990 \\
\hline O. savignyi & fXaI & $\mathrm{fXa}$ & 7193 & BPTI & Ornithodoros & Gaspar et al. 1996; Joubert et al. 1998 \\
\hline R. appendiculatus & fXaI & fXa & 65000 & ND & ND & Limo et al. 1991 \\
\hline H. truncatum & fXaI & fXa & 17000 & ND & ND & Joubert et al. 1995 \\
\hline H. dromedarii & fXaI & fXa & 15000 & ND & ND & Ibrahim et al. 2001b \\
\hline I. scapularis & Salp14 & fXa & 11933 & BTSP & Prostriates & Narasimhan et al. 2002 \\
\hline A. americanum & AAS19 & fXa, fXIa & 46638 & Serpin & Ixodidae & Kim et al. 2015 \\
\hline A. cajennense & Amblyomin-X & fXa & 12504 & BPTI & Metastriates & Batista et al. 2010 \\
\hline H. longicornis & HLS2 & Thrombin & 44000 & Serpin & Metastriates & Imamura et al. 2005 \\
\hline I. scapularis & TIX-5 & fXa-fV & 22757 & PLUNC*2 & Prostriates & Schuijt et al. 2013 \\
\hline H. longicornis & Longistatin & Plasminogen & 17800 & EF-hand & Ixodida & Anisuzzaman et al. 2011,2012 \\
\hline O. moubata & rOmEno & Plasminogen & 46959 & Enolase & Ixodida & Díaz-Martín et al. 2013a \\
\hline I. scapularis & MP1 & Fibrin & 53756 & Metalloprotease & Ixodida & Francischetti et al. 2003 \\
\hline R. bursa & TCI & $\begin{array}{l}\text { Carboxy- } \\
\text { peptidase B }\end{array}$ & 7923 & Beta-defensin & Ixodida & Arolas et al. 2005a, 2005b \\
\hline H. longicornis & HITCI & $\begin{array}{l}\text { Carboxy- } \\
\text { peptidase B }\end{array}$ & 8400 & Beta-defensin & Ixodida & Gong et al. 2007 \\
\hline R. microplus & BmTI-A & Kallikrein & 18000 & BPTI & Metastriates & Tanaka et al. 1999 \\
\hline R. microplus & BmTI-D & Kallikrein & 8000 & BPTI & Metastriates & Sasaki et al. 2004 \\
\hline H. longicornin & Haemaphysalin & Kallikrein & 16222 & BPTI & Metastriates & Kato et al. 2005 \\
\hline I. ricinus & Ir-CPI & $\begin{array}{l}\text { Kallikrein- } \\
\text { fXIIa-fXIa }\end{array}$ & 7653 & BPTI & Prostriates & Decrem et al. 2009 \\
\hline I. scapularis & Ixolaris & fXa-TF-VIIa & 15657 & BPTI & Prostriates & Francischetti et al. 2002 \\
\hline I. scapularis & Penthalaris & $\mathrm{fX}, \mathrm{fXa}$ & 35000 & BPTI & Prostriates & Francischetti et al. 2004 \\
\hline O. moubata & TAM-a & Vasodilation & 8602 & Calcitonin & $\begin{array}{l}\text { Ornithodoros } \\
- \text { HGT }^{3}\end{array}$ & Iwanaga et al. 2014 \\
\hline O. savignyi & $\begin{array}{l}\text { BSAP1 } \\
\text { BSAP2 }\end{array}$ & PT pathway & $\begin{array}{l}9196 \\
9199\end{array}$ & ND & ND & Ehebauer et al. 2002 \\
\hline
\end{tabular}

*1 The inhibitors are all non-salivary derived and found in the hemolymph or gut.

*2 Family assignment was based on a Phyre search and the model confidence was $99.2 \%$. The PLUNC superfamily includes Der f7 allergens (Tan et al. 2012).

*3 HGT - horizontal gene transfer from mammals. 
Table 4: Immuno-modulators from ticks. Sequences were analyzed by BLASTP analysis against an in-house curated tick database (Table 1) to identify potential orthologs. Those highlighted in grey are considered to be present in the ancestral tick lineage.

\begin{tabular}{|c|c|c|c|c|c|c|}
\hline Species & Compound & Target & Mr (Da) & Family & Orthologs & Reference \\
\hline I. scapularis & Isac & Complement C3 & 18132 & Isac & Prostriates & Valenzuela et al. 2000 \\
\hline O. moubata & OmCI & Complement C5 & 16779 & Lipocalin & Ornithodoros & Nunn et al. 2005 \\
\hline I. ricinus & Iris & Elastase & 41358 & Serpin & Prostriates & Prevot et al. 2006 \\
\hline R. microplus & BmTI-A & Elastase & 18000 & BPTI & Metastriates & Tanaka et al. 1999 \\
\hline O. savignyi & TSGP4 & LTC4 & 17141 & Lipocalin & Argasidae & Mans and Ribeiro, 2008a \\
\hline A. monolakensis & AM-33 & LTC4 & 18427 & Lipocalin & Argasidae & Mans and Ribeiro, 2008a \\
\hline I. ricinus & IRS-2 & Chymase & 41900 & Serpin & Prostriates & Chmelar et al. 2011 \\
\hline I. scapularis & $\begin{array}{l}\text { ISL929 } \\
\text { ISL } 1373\end{array}$ & Neutrophils & $\begin{array}{l}10224 \\
11584\end{array}$ & ADAMTS & Prostriates & Guo et al. 2009 \\
\hline R. appendiculatus & $\begin{array}{l}\text { HBP1 } \\
\text { HBP2 } \\
\text { MS-HBP }\end{array}$ & $\begin{array}{l}\text { Histamine } \\
\text { Histamine } \\
\text { Histamine }\end{array}$ & $\begin{array}{l}19438 \\
19467 \\
21021 \\
\end{array}$ & Lipocalin & Ixodida & Paesen et al. 1999 \\
\hline D. reticulatus & SHBP & $\begin{array}{l}\text { Histamine } \\
\text { Serotonin }\end{array}$ & 22065 & Lipocalin & Ixodida & Sangamnatdej et al. 2002 \\
\hline O. savignyi & TSGP1 & $\begin{array}{l}\text { Histamine } \\
\text { Serotonin }\end{array}$ & 18614 & Lipocalin & Ixodida & Mans et al. $2008 \mathrm{c}$ \\
\hline A. monolakensis & Monomine & Histamine & 15725 & Lipocalin & Ixodida & Mans et al. 2008c \\
\hline A. monolakensis & Monotonin & Serotonin & 16559 & Lipocalin & Ixodida & Mans et al. 2008c \\
\hline I. scapularis & $\begin{array}{l}\text { IS-14 } \\
\text { IS-15 }\end{array}$ & Serotonin & $\begin{array}{l}20318 \\
21343\end{array}$ & Lipocalin & Ixodida & Mans et al. 2008c \\
\hline R. appendiculatus & Japanin & DC modulation & 17574 & Lipocalin & Metastriates & Preston et al. 2013 \\
\hline O. moubata & Moubatin & LTB4 & 16756 & Lipocalin & Ornithodoros & Mans and Ribeiro, 2008b \\
\hline O. moubata & OmCI & LTB4 & 16779 & Lipocalin & Ornithodoros & Roversi et al. 2013 \\
\hline O. savignyi & TSGP2/3 & LTB4 & 15878 & Lipocalin & Ornithodoros & Mans and Ribeiro, $2008 \mathrm{~b}$ \\
\hline I. ricinus & Ir-LBP & LTB4 & 21834 & Lipocalin & Prostriates & Beaufays et al. 2008a \\
\hline I. ricinus & Tryptogalinin & Tryptase & 8452 & BPTI & Ixodidae & Valdés et al. 2013 \\
\hline R. appendiculatus & TdPI & Tryptase & 11093 & BPTI & Metastriates & Paesen et al. 2007 \\
\hline R. appendiculatus & Ra-KLP & maxiK channels & 8542 & BPTI & Rhipicephalus & Paesen et al. 2009 \\
\hline$R$. sanguineus & Evasin-1 & $\begin{array}{l}\text { CCL3, CCL4, } \\
\text { CCL18 }\end{array}$ & 10458 & Evasin-1 & Metastriates & Frauenschuh et al. 2007 \\
\hline R. sanguineus & Evasin-3 & CXCL1; CXCL8 & 6999 & Evasin-3 & Metastriates & Déruaz et al. 2008 \\
\hline R. sanguineus & Evasin-4 & CCL5; CCL11 & 11176 & Evasin-1 & Metastriates & Déruaz et al. 2008 \\
\hline R. microplus & BmTI-2 & Elastase & 17000 & BPTI & Metastriates & Sasaki et al. 2004 \\
\hline R. microplus & BmTI-3 & Elastase & 15000 & BPTI & Metastriates & Sasaki et al. 2004 \\
\hline R. microplus & Boophilin & Elastase & 13980 & BPTI & Ixodidae & Soares et al. 2012 \\
\hline R. microplus & RmS-3 & Elastase & 41534 & Serpin & Metastriates & Rodriguez-Valle et al. 2015 \\
\hline$R$. sanguineus & RsTIQ2 & Elastase & ND & BPTI & ND & $\begin{array}{l}\text { Sant'Anna Azzolini et al. } \\
2003\end{array}$ \\
\hline I. scapularis & Sialostatin L & Cathepsin L, V & 12399 & Cystatin & Prostriates & Kotsyfakis et al. 2006 \\
\hline I. scapularis & Sialostatin L2 & Cathepsin L, V & 12654 & Cystatin & Prostriates & Kotsyfakis et al. 2007 \\
\hline O. moubata & $\mathrm{OmC2}$ & $\begin{array}{l}\text { Cathepsin B, C, } \\
\text { H, L, S }\end{array}$ & 13054 & Cystatin & Ornithodoros & Salát et al. 2010 \\
\hline A. americanum & MIF & Macrophages & 12605 & MIF & Ixodida & Jaworski et al. 2001 \\
\hline D. variabilis & HRF & Basophils & 19724 & HRF & Ixodida & Mulenga et al. 2003 \\
\hline R. appendiculatus & $\begin{array}{l}\text { IGBPA } \\
\text { IGBPB } \\
\text { IGBPC }\end{array}$ & Immunoglobulins & $\begin{array}{l}35214 \\
18141 \\
17236 \\
\end{array}$ & $\begin{array}{l}\text { IGBPA } \\
\mathrm{ML} \\
\mathrm{ML}\end{array}$ & $\begin{array}{l}\text { Ixodida } \\
\text { Ixodidae } \\
\text { Ixodidae } \\
\end{array}$ & Wang et al. 1998 \\
\hline I. scapularis & Salp15 & CD4+ T cells & 12459 & Salp15 & Prostriates & Anguita et al. 2002 \\
\hline D. andersoni & p36 & T lymphocytes & 22837 & ETX_MTX2 & Metastriates & Bergman et al. 1998; 2000 \\
\hline I. scapularis & $\begin{array}{l}\text { Metallo } \\
\text { Dipeptidyl } \\
\text { Carboxypeptidase }\end{array}$ & Bradykinin & ND & $\mathrm{ND}$ & ND & Ribeiro and Mather, 1998 \\
\hline R. microplus & Bookase & Bradikinin & ND & ND & ND & Bastiani et al. 2002 \\
\hline R. microplus & $\mathrm{ACE}$ & Bradikinin & 72472 & M2_ACE & Ixodida & Jarmey et al. 1995 \\
\hline I. scapularis & PGE2 & Inflammation & ND & ND & Ixodidae & Ribeiro et al. 1985 \\
\hline
\end{tabular}


accurate quantification when claims are made regarding functionality at the tick-host interface. It should also be considered that ticks show an impressive extent of lineage specific secretory protein family expansion (Mans and Neitz, 2004a; Mans et al. 2008b), which has been linked with specific anti-hemostatic and immuno-modulatory functions (Table 2; Table 3 and Table 4). Secretory proteins are also generally more stable and may be stored in secretory granules for extended periods, while housekeeping proteins have higher turnover rates (Bošnjak et al. 2014). Housekeeping functions that act at the tick-host interface may therefore be short term and incidental, compared to secretory proteins that evolved specifically for the purpose of feeding. Moreover, secretory proteins show on average higher rates of non-synonymous versus synonymous substitutions suggesting positive selection of secretory proteins compared to housekeeping proteins (Kotsyfakis et al. 2015a).

The possibility that overabundance of housekeeping proteins in saliva may be an artefact of artificial stimulation using chemical stimulants such as dopamine and pilocarpine, should as yet not be discounted, since natural salivary secretion has not yet been analysed. In this regard, the high levels of host proteins observed in tick saliva are of interest, ranging from $\sim 2 \%$ in argasids to $24-36 \%$ in ixodids (Díaz-Martín et al. 2013b; Tirloni et al. 2015, 2014), since apocrine secretion cannot account for their presence. Regurgitation of gut-derived blood meal content during feeding has been suggested for both hard and soft ticks (Brown, 1988; Connat, 1991). Even so, host IgG secretion via the salivary glands was shown to be specific (Wang and Nuttall, 1994), while transport of intact host-derived proteins across the gut epithelium of insects and ticks seem to be a general non-specific phenomenon (Jeffers and Roe, 2008), suggesting that host-derived proteins may end up in the salivary glands. The recent extent of detection in saliva is, however, remarkable and warrants further analysis. 
Heme, the centre of Life

The central role that heme plays in oxidative phosphorylation and respiration makes its biosynthesis a conserved feature of all life forms including eukaryotes and prokaryotes (Hosler et al. 2006; Panek and O’Brian, 2002). The first metabolite in the heme pathway, $\delta$-aminolevulinic acid (ALA), is synthesized by $\alpha$-proteobacteria and metazoans in the $\mathrm{C} 4$ pathway from succinyl-CoA and glycine by ALA synthase (hemA), or by archae and other bacteria in the C5 pathway from glutamyl-tRNA ${ }^{\text {Glu }}$ involving a two-step synthesis by glutamyl-tRNA reductase (gtrA) and glutamate 1-semialdehyde amino transferase (hemL) (Kořený et al. 2013). The biosynthetic pathway from ALA to protoheme is generally conserved in all organisms, and includes seven enzymatic steps catalysed by seven enzymes (ALA dehydratase: hemB, porphobilinogen deaminase: hemC, uroporphyrinogen synthase: hemD, uroporphyrinogen decarboxylase: hemE, coproporphyrinogen-III oxidase: hemF, protoporphyrinogen oxidase: hemG, ferrochelatase: hemH) (Panek and O'Brian, 2002). It was therefore quite surprising to find that $R$. microplus lacks the hemB enzyme, cannot synthesize heme and is therefore dependent on host-derived heme (Braz et al. 1999). BLASTP analysis of hemB in 2011 indicated that no hemB homologs could be found for ticks, but were found in acariform mites (Mans, 2014). Revisiting this, using the hemA-hemH genes from the honey bee Apis mellifera, the total complement of the heme biosynthesis pathway could be obtained for the predatory parasitiform mite Metaseiulus occidentalis (hemA: 391339730; hemB: 391332178; hemC: 391347560; hemD: 391331139; hemE: 391332650; hemF: 391341014; hemG: 391332341; hemH: 391348503), that has the smallest chelicerate genome to date (Jeyaprakash and Hoy, 2009a). This indicates that the ability to synthesize heme existed in the ancestral parasitiform lineage. 
The question that remains is that of the extent of loss of the heme biosynthetic pathway in the Ixodida. Loss of components of the heme biosynthetic pathway is a common occurrence among obligatory parasites that uses host-derived heme (Kořený et al. 2013). Other blood-feeding arthropods such as mosquitoes probably retain their ability to synthesize heme, since not all lifestages are obligatory blood-feeding. Assassin bugs are obligatory blood-feeders, but did not lose their ability to synthesize heme, although they may also utilize host-derived heme (Braz et al. 1999). All stages of ticks (with some derived exceptions: see ecdysis section) are obligatory blood-feeders and could potentially derive all of their heme needs from their diet (Donohue et al. 2009). If ticks lost their ability to synthesize heme during evolution of blood-feeding, because they utilized host-derived heme, this could be an important character to support a monophyletic origin for blood-feeding in the ancestral lineage (Mans, 2014).

BLAST analysis using the hemA-hemF genes from M. occidentalis indicated that no orthologs could be found for hemA, hemC, hemD and hemE in current tick databases or in-house transcriptome databases. HemB could not be found in any ixodid databases, but a sequence was found for $O$. rostratus and in in-house Argasidae databases (B.J. Mans, unpublished observation). HemF, hemG and hemH homologs were found in public and in-house ixodid and argasid databases. Ixodids lack hemAhemE, but retained hemF-hemH, while argasids show the same pattern as ixodids, but also retained hemB. This would suggest that all ticks lack key early components of the heme biosynthesis pathway, with no ability for de novo synthesis, requiring host-derived heme. Retention of hemB in argasids may indicate that this enzyme has been exapted for another function.

The loss of early stage enzymes could have occurred to prevent build-up of toxic precursors due to the presence of excess dietary heme (Chiabrando et al. 2014). 
The presence of late stage enzymes, all mitochondrial (Severance and Hamza, 2009), suggest that these are needed for a specific purpose and also suggests that part of the pathway may be rescued if sufficient precursors are available. In this regard, HeLp, a heme transporting protein in the hemolymph of $R$. microplus, has been shown to bind heme species with different Soret bandwidth compared to other proteins that bind heme, suggesting multiple quantum states for bound heme (Maya-Monteiro et al. 2000). The hemosome, a special organelle in ticks where excess heme is stored for detoxification purposes, also has a supramolecular structure that differs from that of hemozoin (Lara et al. 2003). However, the mechanism of transport of heme from the gut to other tick tissues, across cell membranes and into the mitochondria is not yet clear. The mitochondrial enzymes may function in this capacity as part of substrate channelling, or may have other non-heme related critical functions in the mitochondria (Chiabrando et al. 2014; Severance and Hamza, 2009). If the different tick families utilize the same heme transporters this would be a strong argument for the monophyletic origin of hematophagy in ticks.

\section{Lineages of Life processes}

Bilateria

Conservation of Lineages of Life processes may be expected in ticks. In the Bilateria this includes multicellularity, body symmetry, three germ layers, neuro-sensory system, muscle cells, digestive system, mesoderm and bilaterality (Philippe et al. 2009). These are encapsulated by modern studies of embryonic development in ticks (Santos et al. 2013).

\section{Ecdysozoa}


The Ecdysozoa encompass all animals that shed their exoskeleton (molt) during growth and/or different life stages (Aguinaldo et al. 1997; Borner et al. 2014). Conservation includes a three-layered cuticle involved in the ecdysis process, the lack of locomotory cilia, production of amoeboid sperm and no spiral cleavage in the embryo as seen for other protostomes (Telford et al. 2008; Valentine and Collins, 2000). In ticks the cuticle is comprised of an epicuticle and a procuticle, the latter divided into an exocuticle and endocuticle (Hackman, 1982; Hackman and Filshie, 1982). The epicuticle (1-4 $\mu \mathrm{m}$ thick) is composed of a wax and cuticulin layer and serves to protect the tick against water loss (Balashov et al. 1972; Hackman, 1982; Hackman and Filshie, 1982). In the Argasidae, a cement layer $(<0.5 \mu \mathrm{m}$ thick $)$ is also secreted over the wax layer for protection, similar to cuticles from other arthropods (Balashov et al. 1972; Hackman, 1982; Hackman and Filshie, 1982). The exocuticle is composed of sclerotized chitin and protein, which is broken down by chitinases during the molting process, while the endocuticle is also composed of chitin and protein, but not sclerotized (Kaufmann, 2014). Chitinases are regulated by ecdysteriods, which is a conserved feature among Ecdysozoa. Ecdysteriods (20-hydroxyecdysone) is synthesized in the epidermis of argasids and ixodids from dietary precursors (Kaufman, 2014; Roe et al. 2014). In contrast to insects, juvenile hormone $(\mathrm{JH})$ does not seem to be present or required by ticks for ecdysis, perhaps because ticks do not undergo metamorphosis (Roe et al. 2014). 20-Hydroxyecdysone is, however, central to the molting process of all arthropods (Nijhout, 2013). In ixodids, sclerotized cuticle includes the capitulum, scutum, legs, spiracular plate, anal valve and ventral plates, while in argasids it includes the capitulum, legs, spiracular plate and small disks that serves as muscle attachment sites (Hackman, 1982). 
Molting allows for continued growth by shedding of the rigid exoskeleton, but also allows for progression through the lifecycle. In ticks, molting occurs after feeding events. Most parasitiform mites have a larval, several nymphal and an adult stage. In the case of hard ticks, single larval, nymphal and adult stages occur. This is followed by oviposition, laying of a large egg mass and female death. Soft ticks have single larval, several nymphal (4-8 instars) and a single adult stage that can feed several times and lay small egg batches after each feeding event (Hoogstraal, 1985). Deviations from this general pattern occur in a number of argasid lineages. As such, larvae from the subgenus Ornithodoros molt to first instar nymphs (Hoogstraal, 1985) and nymphs from the tick Ornithodoros peropteryx molt to adults (Venzal et al. 2013) without feeding. Conversely, adults from the genera Antricola, Nothoaspis and Otobius are autogenous and can produce egg batches without feeding (Oliver, 1989). In the case of N. namaqua, a single larval and adult stage have been recorded (Mans et al. 2012). It is not yet known whether the number of nymphal stages correspond to that of argasids or ixodids. However, based on size comparisons of adults and nymphs and expected increases in size based on blood meal volume, it is likely that $N$. namaqua only have a single nymphal stage comparable to ixodids (B.J. Mans, unpublished observation).

\section{Arthropoda, Chelicerata and Arachnida}

The Arthropoda are characterized by symmetrical form, jointed limbs and a central nervous mass of ganglia that surrounds the esophagus (Von Siebold, 1848). Most arthropods are segmented into a head, thorax and abdomen linked by the hemolymph, in an open circulatory system. The Chelicerata differ from other arthropods in having a prosoma (fusion of the head and thorax) and opisthosoma (abdomen), as well as chelicerae in front of their mouths and pedipalps (Sonenshine and Roe, 2014). The 
Chelicerae and pedipalps may be modified to various extents as pincers, claws or fangs (Ruppert et al. 2003). In the Acari, the mouthparts are beared by the capitulum, while the prosoma and opisthosoma are fused into a non-segmented idiosoma (Sonenshine and Roe, 2014). However, segmentation in embryos, body pattern of setae, fissures, folds and festoons, support a more ancient arthropod segmentation plan in ticks (Klompen et al. 2015, 1996b; Santos et al. 2013). Further, opisthosomal segmentation during the germ band stage is observed in ticks (and other Parasitiformes?), but absent in Acariformes (Santos et al. 2013), arguing against a monophyletic origin for these lineages. The Arachnida include all chelicerates with eight legs in the nymphal or adult stages. Arachnid larvae have six legs, while some derived Acari may have less than eight legs in the adult stages (Ruppert et al. 2003). Their monophyly is supported by morphological and molecular data (Garwood and Dunlop, 2014; Sharma et al. 2014; Shultz, 2007, 1990; Wheat and Wahlberg, 2013).

\section{Arthopod limbs}

The majority of arthropods have side-by-side or uniform flexible articulation joints (Tajiri et al. 2011), as found in all argasids and ixodids. Of interest is that $N$. namaqua is the only chelicerate thus far identified where leg segments are articulated by ball and socket jointed legs (Keirans, 1976). This is only observed in nymphs and adults, while larvae have flexible articulation joints as found in argasids and ixodids (Latif et al. 2012). In the Arthopoda, the only other lineages that possess ball and socket joints are members of the Neoptera, and this is considered a derived trait (Tajiti et al. 2011). Development of ball and socket joints in the Neoptera has been linked to Notch signalling and consequent cell differentiation and movement (Tajiri et al. 2011, 2010). The Notch signalling pathway is highly conserved in all Metazoa and functions in cell 
differentiation and development processes (Artavanis-Tsakonas et al. 1999). The ball and socket joints of nymphal and adult Nuttalliella may therefore be a lineage specific derived trait linked with expression changes in the Notch pathway, raising the question whether this confers any survival advantage to this species. Ball and socket joints confer a wider range of movement which may allow better traction for nymphs and adults when feeding on "scaled" reptiles such as lizards, skinks and geckoes (Mans et al. 2014, 2011). Larvae have been shown to feed on rodents (Horak et al. 2012; Mans et al. 2012), and may as such not require ball and socket joints. Ixodid ticks that feed on reptiles (Amblyomma, Bothiocroton and Ixodes spp.) do not possess ball and socket joints, which may indicate that adaptation to reptilian hosts occurred independently in these lineages.

\section{The arthropod nervous system and salivary secretion}

The central nervous system of most arthropods is composed of a brain located in the head with three pairs of ganglia (proto-, deuto- and tritocerebrum) that is anterior to the mouth and esophagus. A subesophageal pair of ganglia links up with the ventral nerve cord that links paired ganglia specific to each segment that bear the nerves for the appendages in that segment (Loesel et al. 2013). In ticks, the ganglia have fused to form a single synganglion mass that is divided into a supra and subesophagael region. The supraesophageal region contains three pairs of ganglia that may be homologous to the insect brain (Sonenshine and Roe, 2014). A fused synganglion is also found in most other arachnids and is located within the prosoma, with ganglion absent in the opisthosoma. Conversely, scorpions and primitive spiders (Mesothelae) possess unfused ganglia in the abdomen and opisthosoma, respectively (Ruppert et al. 2003).

A complex network of peptidergic neurons has been identified in the tick synganglion with at least 34 neuropeptides in the $I$. scapularis genome using 
bioinformatics, of which 20 neuropeptides could be confirmed using mass spectrometry and localized using antibodies (Christie, 2008; Neupert et al. 2009; Šimo et al. 2014, 2009a). More recently, using transcriptome sequencing of the synganglion, 15 neuropeptides and 14 neuropeptide receptors were detected in I. scapularis, while genome screening detected 51 neuropeptides (Egekwu et al. 2016; 2014), 16 neuropeptides and 15 neuroreceptors in the argasid O. turicata (Egekwu et al. 2016). Next-generation sequencing of the synganglion of $D$. variabilis detected 9-14 neuropeptides (Bissinger et al. 2011; Donohue et al. 2010). Comparison of the neuropeptides and neuroreceptors of $I$. scapularis and $O$. turicata suggest overall similarity in neuropeptide signaling. As such, 51 neuropeptides were found in the genome of the acariform mite Tetranychus urticae (Veenstra et al. 2012). These neuropeptides are homologous to other insect neuropeptides suggesting that all evolved within the common arthropod ancestral lineage (Šimo et al. 2014).

However, while the neuropeptides may be very similar to their insect counterparts and some neurons resemble those of other arthropods, unique neuronal networks of innervation exist in ticks that may be unique adaptations to a blood-feeding lifestyle (Šimo et al. 2014). One of these is the innervations of the salivary glands. Salivary gland acini II and III are innervated by neurons that secrete either myoinhibitory peptide (MIP) or SIFamide (Šimo et al. 2009b). SIFamide functions in the olfactory system and regulate the flow of food from the foregut to the midgut in crustaceans and sexual behaviour in flies, while MIP functions as inhibitor of locust heartbeat, juvenile hormone production in crickets, ecdysone secretion and spontaneous hindgut peristaltic contractions in silk moths and control of ecdysis (Šimo et al. 2014, 2009b). In ixodid salivary glands, MIP and SIFamide probably regulate dopamine secretion from the basal acinar cells of acini II and III into the acinar lumen, where dopamine then binds to the 
dopamine D1 receptor to stimulate secretion of secretory granules (Šimo et al. 2014, 2012, 2011, 2009b). In this regard, injection of argasids and ixodids with cholinergic stimulants, such as pilocarpine and carbachol induces salivation (Howell, 1966; Kaufman, 1978; Tatchell, 1967a). Cholinergic stimulants do not act on isolated salivary glands of hard or soft ticks (Kaufman, 1978; Mans, 2002; Maritz-Olivier, 2005), suggesting that they act on the central nervous system, whereas stimulation of isolated argasid and ixodid salivary glands with dopamine induces secretion (Kaufman, 1977; Mans, 2002; Maritz-Olivier, 2005). Sequence homologs for the receptor for SIFamide (sifa-r) have been detected in salivary gland transcriptomes of ixodid and argasid ticks, suggesting that the SIFamide-dopamine system may be conserved in all ticks (Egekwu et al. 2016; Šimo et al. 2013; B.J. Mans, unpublished observation). Differences in expression levels and profiles of neuropeptides and their receptors do exist in hard and soft ticks, especially with regard to respondes to feeding biology (Egekwu et al. 2016). Again, this points to exaptation and modification with descent in response to specific lifestyles at the Edges of Life.

Even so, differences in salivary gland biology between argasids and ixodids do exist, suggesting that lineage specific adaptations occurred. Ixodids have two types of granular acini (II and III) in females and three in males (II, III and IV), while argasids only have a single granular secretory type (II) (Balashov, 1972; Coons and Alberti, 1999). Prostaglandin E2 (PGE2) synthesis occurs in ixodid salivary glands from dietary arachidonic acid, which cannot be synthesized de novo in ticks (Bowman et al. 1996). PGE2 acts as an autocrine or paracrine stimulator of protein secretion in ixodids (Sauer et al. 2000), and is secreted into the tick feeding site to act as immunomodulator and vasodilator (Oliveira et al. 2011). PGE2 is also needed for secretion of bloodmealderived water during feeding via the f-cells in granular acini III (Bowman et al. 1996). 
No PGE2 has been detected in argasid saliva, nor does it stimulate salivary secretion, suggesting that it does not exist in soft ticks (Astigarraga et al. 1997; Mans, 2014; Maritz-Olivier et al. 2005). This correlates with the secretion of bloodmeal-derived water via the coxal glands and the absence of acini III in argasids ticks (Balashov, 1972; Coons and Alberti, 1999). However, prostaglandins play an important role in egg laying, immune defenses and chloride transport in arthropods (Stanley and Kim, 2011). Prostaglandin synthesis is also conserved to some extent between arthropods and mammals, starting with liberation of arachidonic acid from membrane phospholipids by phospholipase A2. Cyclooxygenase-1 (COX-1) then convert arachidonic acid to prostaglandin $\mathrm{H} 2$ (PGH2) which is converted to PGE2 via PGE2 specific synthases, belonging to the Sigma class gluthatione transferases (Eichner et al. 2015). BLAST analysis using confirmed arthropod PGE2 synthases (Hansen et al. 2014; Yamamoto et al. 2013), retrieved a single sequence from I. scapularis (GI: 241751467) (E-value $=10^{-}$ $\left.{ }^{93}\right)$. Analysis using this sequence retrieved orthologs $\left(E-v a l u e=10^{0}\right)$ from salivary gland transcriptomes of I. ricinus (Schwarz et al. 2013), A. maculatum (Karim et al. 2011), A. cajennense and A. parvum (Garcia et al. 2014) and R. pulchellus (Tan et al. 2015). Phylogenetic analysis showed that PGE2 synthases from diverse arthropods (including ticks) recapitulate expected relationships (Eichner et al. 2015). BLASTP analysis of Argasidae and Nuttalliella salivary gland transcriptomes (B.J. Mans, unpublished observation) also retrieved PGE2 synthase orthologs with significant E-values $\left(10^{-179}\right)$. Orthologs for soluble and membrane bound PLA2 were also found in argasids and ixodids (B.J. Mans, unpublished observation) and inhibition of PLA2 activity affected secretion in argasids (Maritz-Olivier et al. 2005). It is therefore not clear why PGE2 does not play a role in argasid salivary gland secretion or why argasids do not secrete PGE2. A possibility exists in the diversity observed for 7-transmembrane G-protein coupled 
receptors, which are presumably the receptors that bind PGE2 (Stanley and Kim, 2011). A number of other blood-feeding diptera also possess PGE2 synthase, but do not secrete PGE2 in their saliva (Eichner et al. 2015). The function of PGE2 in salivary gland biology may as such be a lineage specific exaptation in ixodids.

\section{Minimizing water loss in terrestrial arthropods}

A large part of the body plan of terrestrial arthropods deal with measures to minimize water loss. Chitinized exoskeletons are sealed with a waxy epicuticle. Ticks have a well-developed epicuticular system (Ecdysozoan heritage) in both hard and soft bodied ticks (Hackman, 1982). Ticks also have a specialized mechanism to prevent water loss in the type I agranular salivary gland acini that functions as salt secretory glands to absorb moisture from the air (Balashov, 1972; Needham and Teel, 1986; Needham et al. 1990). This acinar system is found in argasids, ixodids (Coons and Alberti, 1999; Needham et al. 1990), presumably in N. namaqua, but not in other Parasitiformes (Alberti and Coons, 1999), supporting the monophy of ticks. This is a lineage specific adaptation related to the evolution of hematophagy and parasitism that allow ticks to survive for prolonged periods between feeding events.

\section{The arthropod respiratory system}

The respiratory systems of terrestrial arthropods are internal and are composed of either book lungs (considered ancestral), or internal tracheal networks that are considered to have evolved numerous times independently, even though all possess spiracles (Garwood and Edgecombe, 2011; Klok et al. 2002). The general tracheal arrangement is conserved in parasitiform mites (Alberti and Coons, 1999). The respiratory system ends in surface spiracles, where water loss from evaporation is 
regulated via the intricate morphology of the spiracular plates (Pugh, 1997). Most larvae lack spiracles in the Parasitiformes (Alberti and Coons, 1999). The morphologies and location on the body differ between various parasitiform lineages and have been used to differentiate species and lineages (Pugh, 1997). Spiracles generally occur between coxae II and III in the Opilioacarida, Holothyrida and some Mesostigmata (Alberti and Coons, 1999; Pugh, 1997). However, the position of the spiracles in the Gamasida may be found between, the II/III, III/IV or posterior to the IV coxae. Spiracular position in the Ixodida has therefore been considered secondary and not phylogenetic informative (Pugh, 1997). Spiracles in argasids occur between the III/IV coxae, posterior to coxae IV in ixodids and posterolaterally to coxae IV in N. namaqua (Pugh, 1997). Argasids and N. namaqua have small spiracles with a controllable ostium between a flexible anterior macula and posterior curved sieveplate, with a uniform inter-pedicellar airspace interspersed with solid, rounded pedicels and no sub-atrial ducts. The larger ixodid spiracles possess inflexible macula and a closed ostium surrounded by an inflexible flat sieveplate, with the atrial chambers of the labyrinth clearly delimited by hollow, flanged pedicels with some sub-atrial ducts present (Pugh, 1997). Nuttalliella namaqua has a unique fenestrated sieveplate and a button-like baseplate. A cladistic analysis based on 29 spiracle characters indicated that the Ixodida is monophyletic with regard to the Mesostigamata, with Nuttalliella and Argasidae closer related than Nuttalliella and the Ixodidae (Pugh, 1997).

\section{Osmoregulation}

Arthropods utilize the Malpighian system for further prevention of water loss by concentrating waste in the form of solid uric acid and guanine and readsorbing water into the body (Garwood and Edgecombe, 2011). Waste products are secreted into the 
post-colon. Ticks utilize this system to deal with excess ammonia from the blood meal, but have also adapted this system in a remarkable manner to deal with excess blood meal derived water in N. namaqua by secretion via the anal valves (Mans et al. 2012). Concentration of blood meal derived water allows ticks to ingest larger volumes of red blood cells. Soft ticks feed fast and expand rapidly ingesting $>10$ times their body weight in blood (Balashov, 1972). Excess water is secreted via the coxal organs located between coxae I and II (Lavoipierre and Riek, 1955; Lees, 1946). Initial lysis of some red blood cells occurs, but the majority is not immediately lysed (Balashov, 1972; Coons et al. 1986). About, $40-50 \%$ of bloodmeal derived water and ions are secreted via the coxal organs (Sonenshine, 1991) and correlate with the excluded volume left when red blood cells are packed, explaining the limited concentration that may be achieved in argasids. Nuttalliella namaqua also feeds rapidly, ingests $\sim 10$ fold its body weight in blood and does not lyse red blood cells, but secretes excess water via the Malpighian tubules and anal valves (Mans et al. 2012). This character is unique in the Ixodida and was only recently discovered (Video 1). The amount of blood meal concentration is similar to soft ticks. Malpighian secretion has been observed in soft ticks, but is generally not considered a major form of secretion (Jupp et al. 1987). It does suggest that this form of secretion may have been ancestral to ticks, since it is also found in other arthropods (Garwood and Edgecombe, 2011). Conversely, coxal organs are also found in other Acari and arthropods and function as osmoregulatory organs (Alberti and Coons, 1999; Garwood and Edgecombe, 2011), with the implication that these also had ancestral precedence and were lost in the Ixodidae and Nuttalliellidae. Ixodids retain an accessory coxal gland present in argasids, thought to function during ecdysis (Binnington, 1975). Hard ticks feed for prolonged periods and lyse red blood cells during feeding (Coons et al. 1986). This allows concentration of the blood meal to a much larger extent of up to 
$>100 \mathrm{X}$ their body weight, since excess water is secreted via the salivary glands via cell type f cells located in granular acini III (Fawcett et al. 1981; Meredith and Kaufman, 1973; Tatchell, 1967b). This form of water secretion is considered unique to ixodids and a lineage specific innovation. The degree to which water is secreted by ticks during feeding (40-50\% in argasids and Nuttalliella, $70-80 \%$ in ixodids) is far larger than any other parasitiform mite and in each family point to modification of existing organ structures in specific response to a blood-feeding lifestyle. It also suggests that different tick families, to some extent, found independent strategies to adapt to a blood-feeding lifestyle. Even so, all arthropods utilize aquaporins in water secretion and regulation and several members have been identified in ticks to date, notably PRIP/AQP2, BlB and an acarine specific clade (Benoit et al. 2014). The molecular mechanisms of water transport are probably conserved in all arthropods while their specific regulation may be limited to organ specific expression. In this regard, the neuropeptides and receptors involved in diuresis (Calcitonin/DH, calcitonin/DH receptor, CRF receptor, CAPA/pyrokinin receptor) are upregulated in ixodids and argasids before water secretion (Egekwu et al. 2016). Calcitonin/DH, CRF and CAPA/pyrokinin all function in water and salt elimination via the Malpighian tubules in insects, implicating these in water secretion by $N$. namaqua, but also indicating exaptation in other organs such as the coxal and salivary glands.

\section{Digestion of the blood meal}

Arthropods had well developed digestive systems at least since the Cambrian period (Vannier et al. 2014). The midgut and midgut caeca observed for ticks can be traced back to this body plan, while the digestive cells are similar to that of other arachnids (Balashov, 1972). An important difference between ticks and other arthropods, is that the 
tick gut may also be used as a storage organ for haemoglobin, or even undigested red blood cells in the case of argasids and N. namaqua (Mans, 2014; Sonenshine and Roe, 2014). Hemoglobin is specifically taken up via receptor-mediated endocytosis and targeted to endosomes for digestion before heme is targeted to the hemosome (Coons et al. 1986; Lara et al. 2005; Sojka et al. 2013). In ixodids, digestion occurs via a sequential cascade of proteolytic enzymes that include aspartic (cathepsin D), cysteine (cathepsin B, $\mathrm{C}$ and L) and legumain-type asparaginyl peptidases that show differential expression patterns during feeding (Franta et al. 2010; Horn et al. 2009; Sojka et al. 2008). These peptidases seem to be conserved in prostriates and metastriates (Mans, 2014). In the argasid $O$. moubata, cathepsin B, cathepsin $\mathrm{C}$ and legumain-type asparaginyl peptidases were detected but not cathepsin D or L (Grunclová et al. 2006). A proteomics study of the midgut of the argasid $O$. erraticus detected cathepsin D, legumain-type asparaginyl and metallopeptidases (Oleaga et al. 2015). It is therefore not clear whether ixodids and argasids utilize the same proteolytic cascades for digestion. Dynamics of digestion also differ due to the long feeding and continuous digestion observed for ixodids versus the short feeding and prolonged digestion in argasids. Cysteine and aspartic proteases, capable of digesting hemoglobin have been found in free-living and ecto-parasitic mites (Nisbet and Billingsley, 2000), indicating that the basic digestive machinery was present in the ancestral tick lineage. Whereas, convergent evolution occurred for the proteolytic systems of various blood-feeding parasites (Sojka et al. 2013, 2008), in ticks differences between the families may be due to gene loss or differential expression patterns.

\section{The Ixodida and their relationships to other Arachnida}

While most lineages within the Arachnida are well defined, their relationships to each other are not clear, since morphological and molecular data do not support 
similar phylogenies (Dunlop, 2010; Edgecombe et al. 2011; Edgecombe and Legg, 2014; Giribet and Edgecombe, 2012; Legg et al. 2013; Philippe et al. 2009; Shultz, 2007). The sister group to the Acari (Acariformes and Parasitiformes) has been considered to be the Ricinulei (Shultz, 2007; Wheeler and Hayashi, 1998), unresolved (Edgecombe and Legg, 2014; Giribet and Edgecombe, 2012; Klompen et al. 2007), or the Palpigradi and Pycnogonida (Giribet et al. 2002). Additionally, a number of morphological and molecular studies have suggested that the Acari is not monophyletic (Borner et al. 2014; Dunlop, 2010; Dunlop and Selden, 2009; Garwood and Dunlop, 2014; Ovchinnikov and Masta, 2012; Pepato et al. 2010; Regier et al. 2010; Sharma et al. 2014; Shultz, 2007; van der Hammen, 1989). The relationship between Parasitiformes and other arachnids is also not clear, since it has been considered a sister group of the Solifugae (Borner et al. 2014), Pseudoscorpiones (Regier et al. 2010), basal to a clade formed by the (Pycnogonida, (Acariformes and Pseudoscorpiones) (Ovchinnikof and Masta, 2012), or within different clades: the (Ricinulei, (Parasitiformes, (Solifugae, Acariformes) (Garwood and Dunlop, 2014), or the (Pseudoscorpiones, Acariformes), (Parasitiformes, other Chelicerata) (Sharma et al. 2014). In most cases, these proposed relationships show branch support less than $60 \%$.

The most that may be said with confidence is that the Parasitiformes belong to the Arachnida, and that the defining Lineage of Life features that bind these lineages are the presence of six legs in larvae and eight legs in adults. One possible explanation for the unresolved nature of the relationships between the major arachnid lineages, lies in the ancient origin of all arachnids and the possibility that several ancient lineages went extinct, resulting in taxon deficiency at this level (Giribet and Edgecombe, 2012).

The Arachnida as venomous animals 
The poorly supported affinity of the Acari and Parasitiformes to other arachnid lineages poses problems when character traits are transferred from other arachnid lineages to ticks. It has been suggested for example, that the ancestral tick lineage (and by extension all Parasitiformes), derived from a much more ancient arachnid lineage that was venomous and that this may explain various forms of tick toxicoses and paralysis (Cabezas-Cruz and Valdés, 2014; Cordeiro et al. 2015). Given our lack of certainty regarding the sister group of the Parasitiformes and the generalized recognition that toxins evolved independently in different arachnid lineages (Cordeiro et al. 2015; Fry et al. 2009), it would be premature to derive conclusions of this nature until the molecular correlates of all toxins have been established. Furthermore, the structure of holocyclotoxin-1 has been determined to resemble a cysteine knot motif, but no closely related structures are present in the protein databank, leading the authors to conclude that this toxin possess a novel fold and showed convergent evolution of the cysteine knot motif in plants, animals and arthropods (Vink et al. 2014).

Many arthropods are considered venomous (Casewell et al. 2013; Fry et al. 2009). Venom has been defined as: "a secretion, produced in a specialised gland in one animal and delivered to a target animal through the infliction of a wound (regardless of how tiny it could be), which contains molecules that disrupt normal physiological or biochemical processes so as to facilitate feeding or defence by the producing animal" (Casewell et al. 2013; Fry et al. 2009). This new definition has gained popularity and has been used to designate arthropod lineages, such as ticks, venomous (Cabezas-Cruz and Valdés, 2014). As the definition stands it is not difficult to designate a venomous lineage, since it by default include all blood-feeding arthropods such as ticks, flies, fleas, assassin bugs, moths, bed bugs, mites and has been used to expand our count of venomous organisms and their venoms (Fry et al. 2009). Inclusion of the blood-feeding 
arthropods has been omitted in more recent reviews on the topic (Casewell et al. 2013), but given the stated definition could still be included. The definition to some extent, obscures meaning when a distinction between benign (those that does not cause debilitating toxicoses) and toxic arthropods is necessary, or when the evolutionary origins and causes of toxicoses are considered (Mans et al. 2004). Irrespective of the definition, most authors recognize that convergent evolution of venoms occurred in all arthropod and arachnid lineages (Casewell et al. 2013; Fry et al. 2009; von Reumont et al. 2014).

The status of "venomous" has been assigned based on the fact that venoms have the same characteristics that include: all toxins are secretory, all toxins are disulphide bond rich, toxins from diverse organisms belong to the same secretory protein families where they perform similar functions, toxins function rapidly and toxin diversity is characterized by gene duplication and expansion by hypermutation of surface exposed residues (Fry et al. 2009). However, it is in the nature of secretions to contain secretory proteins and these are generally disulphide bond rich (Wong et al. 2011). It may not be surprising that the same families reappear in different "venoms" since these are the secretory protein families available to arthropods which are by necessity the raw materials of evolution (Mans, 2011). In many families canonical functionalities are linked with specific folds and will recur again and again, due to exaptation of existing similar functions. As such, the bovine pancreatic trypsin inhibitor (BPTI), serpin and cystatin folds act as inhibitors, the enzymes apyrase, chitinase, hyaluronidase and proteases perform the same functions, due to conserved active site residues, even if their targets differ and the lipocalins are scavengers as dictated by their beta-barrel structure (Mans, 2011). Gene duplication linked with lineage specific expansion and diversification of function is a universal established evolutionary strategy, not only for 
venomous organisms (Demuth and Hahn, 2009). Lineage specific expansion of certain folds or families may be linked with the ancestral lifestyles of organisms, whether predatory, scavengers, parasitic or symbiotic (Mans, 2011). Rather than lumping secretory molecules collectively as toxins, a narrow view allow distinction of benign and therapeutical useful molecules that allows modulation of vertebrate defences (antihemostatics and immunomodulators), against those who exhibit a specific toxic effect and phenotypic outcome (anaphylactic shock, edema, necrosis, pain or paralysis). It also allow distinction between toxic adaptive responses (predation and defense) and hostparasite arms races that facilitate dissection of lineage specific evolution with more precision.

\section{Dates of origin for the Acari and Parasitiformes}

The relationships of the Acari, Acariformes and Parasitiformes with other arachnids are important since it impacts on potential ancestral reconstruction scenarios. If the Acari are monophyletic, the lowest estimate for origin of the Acariformes, based on fossil evidence place the Acari at 410 million years ago (MYA) (Dunlop and Selden, 2009) and by extension the Parasitiformes as its sister group. This is very close to the origin proposed for all arachnids as well as their terrestrialization $(\sim 501-418$ MYA) (Dunlop and Selden, 2009; Edgecombe et al. 2011; Wheat and Wahlberg, 2013). If all Acari are monophyletic, it may be likely that ticks evolved in the Devonian ( 360 MYA) and evolved a blood-feeding lifestyle on amphibian tetrapods during vertebrate terrestrialization in the Australasian region as previously proposed (Barker and Murrell, 2004, 2002; Barker et al. 2014). However, if the Acari are paraphyletic, then the older age proposed for the Acariformes does not impact on the origin of the Parasitiformes. Molecular clock analysis and fossil dating have estimated the origin of the Parasitiformes 
in the Carboniferous ( 250-350 MYA) (Dunlop, 2010; Jeyaprakash and Hoy, 1999b; Mans et al. 2012). This younger date corresponds with a possible origin in the Karoo basin of Gondwanaland during the Late Carboniferous ( 320 MYA) or Early Permian ( 290 MYA), and evolution of a blood-feeding lifestyle on early therapsid, diapsid or synapsid hosts (Mans et al. 2012, 2011). Even if the Acari evolved in the Devonian ( 410 MYA), time for divergence of the basal parasitiform lineages (Opilioacarida, Holothyrida) are still necessary for the emergence of the tick lineage. This would still place the origin of ticks in the Carboniferous or Permian (Palopoli et al. 2014), making this timeframe more probable than the proposed Devonian origin in our opinion.

\section{Edges of Life processes}

The Ixodida and their relationships to other Acari

The Parasitiformes can be divided into the Holothyrida, Ixodida, Mesostigmata and Opilioacarida (Klompen et al. 2007; Lindquist et al. 2009; Murrell et al. 2005). Relationships between these groups have indicated a relative consensus of morphological and molecular data, with Opilioacarida being the most basal lineage, Holothyrida sharing a sister group relationship with the Ixodida and the Mesostigmata as their sister group (Klompen, 2010; Klompen et al. 2015, 2007; Lehtinen, 1991). Even so, a study has indicated a closer relationship between Ixodida and Mesostigmata (Burger et al. 2014a). It should be noted that Haller's organ is unique to the Holothyrida and Ixodida (Lehtinen, 1991). This organ is located on the tarsi of the forelegs and functions in ticks in host detection via numerous olfactory sensilla (Hess and Vlimant, 1986). It is not clear what function Haller's organ performs in the Holothyrida, but it may be assumed to play a role in the sensing of food sources. One of the main molecules sensed by ticks for host detection is carbon dioxide (Sonenshine, 2004). No homologs to 
the carbon dioxide receptors found in insects have been found in tick genome data suggesting that this detection system evolved independently in various arthropod lineages (Robertson and Kent, 2009). If orthologs for the carbon dioxide receptor exist in the various tick families it would be considered important proof that host-detection capabilities evolved in the ancestral tick lineage (Mans, 2014).

The relationship of the sister group to ticks is important, since it may give clues to the origin and nature of the ancestral tick lineage before adaptation to a bloodfeeding environment. While the Parasitiformes have been named due to the extensive number of parasitic species, more than $50 \%$ of Mesostigmata are non-parasitic with early lineages being predators, while blood-feeding are found in more derived lineages (Klompen et al. 2007; Walter and Proctor, 1999, 1998). The Opilioacarida and Holothyrida are scavengers of particulates or fluids (van der Hammen, 1989; Walter and Proctor, 1998). As such, the ancestral parasitiform lineage were most probably nonparasitic and non-predatory scavengers (Walter and Proctor, 1998), suggesting that blood-feeding evolved independently within the tick and Dermanyssina (including Parasitina) lineages (Bochkov et al. 2008; Mans, 2011; Radovsky, 1969; Walter and Proctor, 1999). In this scenario, ticks would have adapted from an ancestor that may have scavenged from vertebrate wounds (Walter and Proctor, 1998), first as a lymph feeder and later as blood-feeder. An ancestral lineage with a primary scavenging lifestyle has several interesting implications. It negates a venomous ancestral lineage that was maintained into the tick lineage. It also implies that the functions selected for Edges of Life processes were at first primarily concerned with scavenging behaviour. This would include enzymes involved in extra-cellular digestion and anti-microbial peptides to prevent infection during ingestion (Mans, 2011). 


\section{Geographic origins of the Ixodida}

The sister lineages of the Ixodida could have important implications for the geographic origin of the ancestral tick lineage. An origin for ticks in the African part of Gondwanaland during the Late Carboniferous or Early Permian was proposed based on the limited distribution of the monotypic species $N$. namaqua and molecular clock estimates from mitochondrial data (Mans et al. 2012, 2011). An alternative origin in the Australasian region of Gondwanaland has been proposed based on the limited distribution of the Holothyrida in this region and the fact that "basal" lineages of the Ixodidae, the Australian prostriate (Ixodes) and Metastriates (Bothriocrotoninae) also occur exclusively in this region (Barker and Murrell, 2004, 2002; Barker et al. 2014). However, the Holothyrida has a Gondwanean distribution that may include the Australasian, South and Central American, Caribbean and Indian Ocean islands and also the coastal regions of East Africa (Lehtinen, 1991). It is therefore likely that the historic distribution of the Holothyrida (and the holothyrid-tick ancestral lineage) was across most of Gondwana. Further, the extant ecology of the Holothyrida suggests a preference for tropical climates (Lehtinen, 1991). Such humid, wet and warm conditions were present in the Karoo basin during the Late Carboniferous or Early Permian, resulting in modern day coal deposits of southern Africa (Visser, 1995). Extant N. namaqua favour drier semi-desert climates which were present in the Karoo basin of southern Africa since the Early Permian (Mans et al. 2011; Visser, 1995). This could suggest the emergence of the tick lineage once drier climates were introduced, while the range of the Holothyrida shrunk to those regions in Gondwanaland that retained a tropical climate, with a possible mass extinction event as the African continent became more xeric (Visser, 1995). 
The basal position of the Bothriocrotoninae was based on analysis of the $18 \mathrm{~S}$ rRNA and morphological data (Dobson and Barker, 1999; Klompen et al. 2002, 1997). More recent analyses based on mitochondrial genomes does not support the basal position of Bothriocroton in relation to other Metastriata (Burger et al. 2013, 2012). Conversely, 18S rRNA analyses indicated that non-Australian Ixodes group basal to Australian Ixodes (Burger et al. 2013, 2012), suggesting that the prostriate lineage originated outside Australia. Alternatively, mitochondrial data indicate that nonAustralian and Australian Ixodes are sister groups (Burger et al. 2012). The argument for an origin of the Ixodidae in Australia during the Devonian is, therefore, not well supported with current data. An origin for the Ixodidae in the Antarctic region should be considered (Mans et al. 2012), with dispersal to the rest of the world, including Australia. This large landmass showed an impressive fauna during the Permian and Triassic and basal lineages that ended up in Australia would have suffered mass extinction events during its glaciation (McLoughlin, 2001). This may explain the relatively small numbers of extant species in the Australian tick lineages, as well as their limited distributions (Mans et al. 2012).

\section{The importance of $N$. namaqua in ancestral reconstruction}

The question may be asked why $N$. namaqua and its relationship to the other tick families are so important for the study of tick evolution. The answer to this lies in the implications that the sister-group relationship of this species have for the evolution of blood-feeding behaviour in the tick lineage. Based on the lifestyle differences of the hard and soft tick families, as well as their different salivary gland functional repertoires, it has been proposed that hematophagous lifestyles evolved independently in the argasid and ixodid lineages, even though they are considered to be monophyletic (Mans and 
Neitz, 2004a; Mans et al. 2008a, 2002a). Until recently, there was little evidence to challenge this hypothesis, but it was acknowledged that $N$. namaqua might hold the key to the resolution of this paradox (Mans and Neitz, 2004a). That was because N. namaqua was historically considered the "missing link" between the hard and soft tick families, particularly because it possesses morphological features from both families, including a leathery integument as observed for argasids and a pseudoscutum similar to the true scutum found in ixodids (Bedford, 1931; El Shoura, 1990). The position of N. namaqua relative to the other tick families also remained unresolved and impacted on hypotheses regarding the ancestral tick lineage (Barker and Murrell, 2004, 2002).

Several possibilities exist with regard to the relationship of $N$. namaqua and the argasid and ixodid families. Nuttalliella namaqua may have a closer relationship to one of the other parasitiform lineages. Recent analysis of the 12S rRNA gene placed $N$. namaqua between the Holothyrida and the Mesostigamata (Burger et al. 2014a). This would make the Ixodida paraphyletic and would still result in a juxtaposition of the two major families with the implication that blood-feeding behaviour evolved independently. Nuttalliella namaqua could also group with argasids as suggested by analysis of the $18 \mathrm{~S}$ and 28S rRNA genes, or morphology of the spiracles (Burger et al. 2013; Pugh, 1997), or with ixodids as suggested by mitochondrial genome analysis (Burger et al. 2014a). In both these cases, N. namaqua would be incorporated into the respective families, with no resolution to their disparate lifestyle histories. Nuttalliella namaqua may also group basal to the argasid and ixodid families thereby retaining the three tick families as well as the monophyletic nature of the Ixodida, as was observed for $18 \mathrm{~S}, 18 \mathrm{~S}-28 \mathrm{~S}$ rRNA and mitochondrial genome analysis (Chen et al. 2014; Gu et al. 2014; Mans et al. 2015, 2012, 2011). Parsimony considerations of the latter position on the tick tree suggest a monophyletic origin for hematophagy in ticks (Mans et al. 2011). This permits ancestral 
reconstruction using characters that are shared by $N$. namaqua and the respective tick families (Mans et al. 2012), allowing a perspective that brings the families together that was not previously possible. In this sense $N$. namaqua is truly a missing link (as intended originally by Bedford, 1931), and not in the sense where the term "missing link" was considered as a remnant from a more romantic and philosophic era (Barker et al. 2014).

The question is raised as to which of these four evolutionary possibilities may be the most likely. It should be noted that the placement of $N$. namaqua at the base of the tick tree could not be rejected (Burger et al. 2014a). It should also be noted that the nuclear dataset analysis did not correlate in all studies, notably because incomplete 18S28S rRNA datasets were used in some studies (Burger et al. 2014a, 2013), while inclusion of a complete $18 \mathrm{~S}-28 \mathrm{~S}$ dataset for $N$. namaqua supports its basal position (Mans et al. 2015). Nuclear ribosomal genes are generally considered more informative at family and subfamily level, while mitochondrial data may be better at resolving intrageneric and intraspecific relationships (Durden and Beati, 2014; Mans et al. 2015). It should also be acknowledged that nuclear and mitochondrial datasets do not necessarily result in congruent phylogenies (Giribet and Edgecombe, 2012), and that mitochondrial analysis has its own pitfalls and does not necessarily represent true phylogenetic relationships even if mitogenomic analysis is a popular systematic approach (Dávalos et al. 2012; Pisani et al. 2013). In this regard, mitogenomic analyses of relationships among ixodid lineages could not yet come to a consensus, since the relationships among genera changes as more taxa is added (Burger et al. 2014a, 2013, 2012). The relationships among the argasid genera are also contentious with little consensus between morphological and molecular data, creating paraphyletic genera in their taxonomic classification, within and between the Argasinae and Ornithodorinae 
(Burger et al. 2014a; Estrada-Peña et al. 2010; Guglielmone et al. 2010; Klompen and Oliver, 1993; Nava et al. 2009).

Incomplete taxon sampling may bias phylogenies (Wiens and Morrill, 2011) and this may be a fundamental problem in tick systematics, since only five basal lineages can be recognized (Nuttalliellidae, Argasinae, Ornithodorinae, Prostriata and Metastriata) (Mans et al. 2015). The possibility exists that significant lineage specific extinctions occurred, within extant lineages and even among basal lineages (Mans et al. 2014, 2011). If this is indeed the case, incomplete taxon sampling due to mass extinction at the deeper levels of phylogeny (that result in long branch attraction phenomena), will preclude any accurate reconstruction and may explain the relatively low branch support observed for the relationships among the tick families.

\section{A framework for reconstruction of ancestral characters evolved for blood-feeding}

A basal position for $N$. namaqua provides a framework for ancestral reconstruction. It supports the monophyly of the Ixodida and maintains three distinct families. It implies that hematophagy evolved in the last common ancestral tick lineage and that some characters evolved specifically for blood-feeding should be conserved among the tick lineages (Fig. 3).

The most distinct character unique to the Ixodida is their gnathostoma which is composed of cutting chelicera and the hypostome. Chelicera are a conserved feature of the Chelicerata, but in ticks have been modified as cutting organs. The hypostome, a teethed appendage, is unique in the Ixodida and found in all three families (Coons and Alberti, 1999; Sonenshine, 1991; Sonenshine and Roe, 2014). The hypostome is used for anchoring ticks during feeding and may be one of the few characters involved in feeding that is conserved among all tick families and indicative of a common origin of 
Figure 3: External morphology of representative species from the Holothyrida, Nuttalliellidae, Argasidae and Ixodidae. Indicated are dorsal and ventral perspectives. Asc: alloscutum, Ds: dorsal shield, Gn: gnathostoma, Gp: genital pore, Pg: preanal groove, Psc: pseudoscutum, Sc: scutum.

Haplothyrus expolitissimus (Holothyrida)
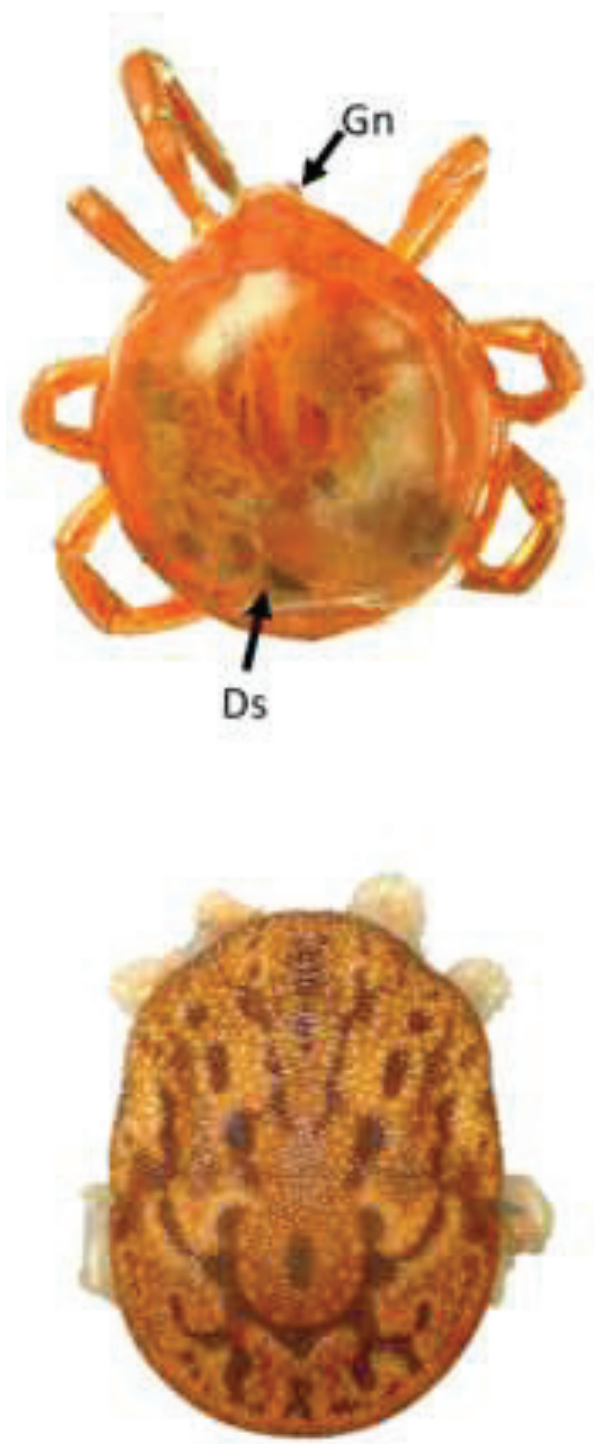

Ornithodoros savignyi (Ixodida: Argasidae)
Nuttalliella namaqua (lxodida: Nuttalliellidae)
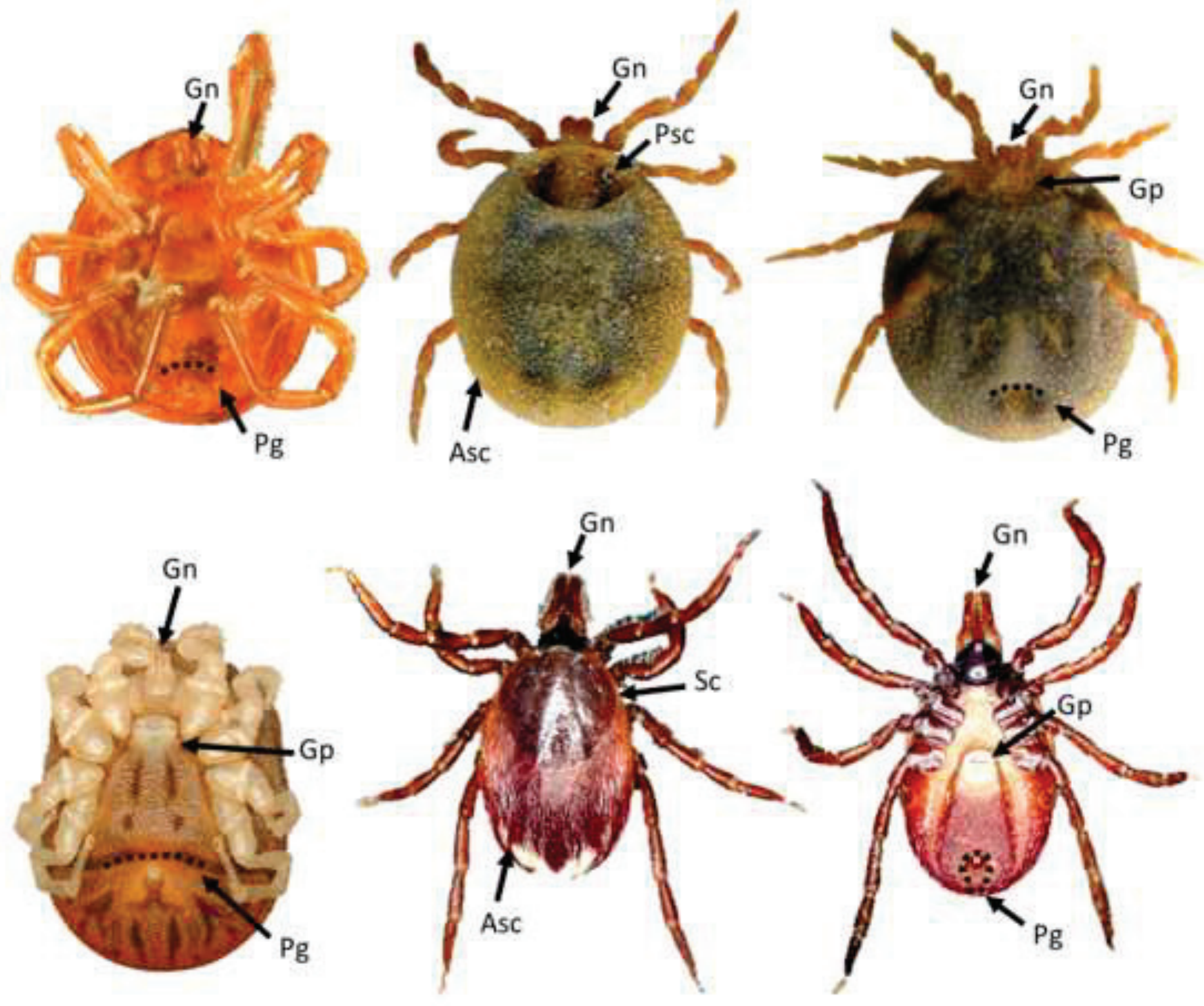

Ixodes pilosus (Ixodida: Ixodidae) 
hematophagy in the ancestral tick lineage (Mans, 2014). There is significant variation in hypostome length, form and number of teeth, which is associated with feeding time duration, but in all species that feed on vertebrates it serves the purpose of cutting into the dermis and anchoring the tick during feeding (Nuttall, 1911). The fast feeding stages of argasids and $N$. namaqua have hypostomes with rudimentary teeth, while slow feeding stages and species have well developed hypostomes (Nuttall, 1911). Exceptions occur for non-hematophagous life stages from some species where the hypostome may be significantly reduced. This is found in some males from Ixodes and some argasid species where the nymphal or adult stages do not feed such as Antricola, Nothoaspis and Otobius (Oliver, 1989). It may also hold for N. namaqua where the male hypostome is significantly reduced (Latif et al. 2012), although non-feeding has not yet been confirmed. Sexual dimorphism with regard to hypostome armature occurs in Ixodes and N. namaqua (Arthur, 1962; Latif et al. 2012; Nuttall, 1911). It should be noted that reduced hypostome morphology cannot be used to infer homologous relationships, since non-feeding behaviour is probably derived in different lineages and should be considered a synapomorphy. Reduction of hypostome armature was also correlated with off-host mating which is considered an ancestral trait (Nuttall, 1911). In N. namaqua, the hypostome is generally reduced, apical rounded with only 10-15 denticles arranged into two poorly defined rows (Latif et al. 2012). Compared to argasids and ixodids the hypostome may be considered rudimentary and if this is an ancestral features suggests that the hypostome developed to a greater extent in derived lineages, probably as ticks adapted to new hosts.

The position of the gnathostoma has been an important and easy taxonomic feature to distinguish argasids (ventral) and ixodids (terminal), since inspection of any tick specimen from above allow classification by determining whether the hypostome 
can be observed or not (Durden and Beati, 2013; Sonenshine, 1991). In N. namaqua it was originally described as terminal, similar to ixodids, since it may be observed from above (Bedford, 1931). However, close inspection indicated that the hypostome and basis capituli is not contiguous with the scutum as observed for ixodids, but is rather subterminal, similar to the gnathostoma of the Holothyrida. The nuttaliellid hypostome therefore occupies an ancestral position, intermediate between the positions observed in argasids and ixodids (Mans et al. 2011).

Closely linked with the hypostome, is the secretion of cement by ticks to help with anchoring. It has been recognized that soft ticks do not secrete cement due to their short feeding periods (Balashov, 1972). This will also hold for nymphal and adult Nuttalliella (Mans et al. 2012). It was further evident that some Ixodes species secrete less cement, while metastriates secrete significant quantities (Kemp et al. 1982). This has been linked to the high abundance of cement proteins secreted from the salivary glands. The cement proteins are glycine and proline rich proteins that are found in all tick transcriptomes described to date (Table 1), except that of the non-feeding adult stages of Antricola delacruzi. Cement proteins have also been found in a salivary transcriptome of N. namaqua (B.J. Mans, unpublished observation). It has been argued that cement may be secreted in argasid and nuttallielid larvae that feed for prolonged periods similar to ixodids (Mans et al. 2012). The prolonged feeding of argasid and nuttallielid larvae also leads to a $>100$ fold increase in body weight, similar to ixodids and is accompanied by red blood cell lysis (Moorhouse et al. 1975). It was suggested that in both cases, excess water is secreted via the salivary glands since argasid larvae do not possess coxal organs (Mans et al. 2012; Moorhouse, 1975). Prolonged feeding is a unique adaptation in ticks not generally observed in other blood-feeding arthropods (Mans, 2011), and is one of the reasons for the success of ixodids as vectors of pathogenic organisms. The hypostome, 
cement proteins and prolonged larval feeding would have been present in the ancestral tick lineage, and provide a rationale for the prolonged feeding observed in ixodids. Prolonged larval feeding allow small-bodied ticks to gain enough size with the first feeding event, to obtain larger engorged blood volumes in subsequent life stages, which finally results in larger egg masses and progeny numbers.

The larvae from $N$. namaqua possess a scutum similar to those of ixodids (Latif et al. 2012). It has been argued that the scutum is an ancestral feature of ticks derived from the dorsal shield present in other parasitiform mites (Coons and Alberti, 1999; Mans et al. 2012). The dorsal shield is still present in argasid larvae and as pseudoscutum in Nothoaspis ticks (Keirans and Clifford, 1975). The pseudoscutum from nymphal and adult $N$. namaqua is a mixture of sclerotized epidermis and leathery integument, pointing to a developmental pathway not fully differentiated, that may lead to either loss as observed in argasids or fully sclerotized as observed in ixodids. Furthermore, the pseudoscutum from male N. namaqua and the scutum from male ixodids represent the holodorsal shields observed in holothyrids and mesostigmata that cover the full dorsal cuticle. Conversely, the pseudoscutum from female and nymphal $N$. namaqua, adult Nothoaspis, larval argasids and the scutums from N. namaqua larvae, ixodid larvae, nymphs and females resemble podonotal shields from mesostigmata (Coons and Alberti, 1999). This implies that a sclerotized scutum (ixodid) and leathery integument (argasid) were present in the ancestral tick lineage. The leathery integument favors rapid engorgement, a feature observed for argasids and $N$. namaqua nymphs and adults. In ixodids and larvae, developmental changes in cuticle elasticity allows incredible expansion to occur, that results in the uptake of blood $>100 \mathrm{X}$ the body volume (Balashov, 1972). However, rapid engorgement and a leathery cuticle only allow expansion 10-15X the body volume, since the leathery integument has an intrinsic 
rigidity. The rapidity of feeding is also probably too fast for efficient red blood cell lysis. Both argasids and N. namaqua do not immediately lyse red blood cells and red blood cells may be maintained for months after feeding with slow digestion (Mans et al. 2012). This is a good strategy in environments where hosts are scarce and where ticks need to survive for months to years without finding hosts and feeding. This would imply that rapid feeding in nymphs and adults were present in the ancestral tick lineage.

From the above reconstruction, it should be clear that the ancestral tick lineage had an argasid-like biology (fast feeding, small numerous egg batches, multiple nymphal stages, limited red blood cell lysis). However, there were also ixodid features present (a scutum for protection, prolonged feeding in larvae, secretion of cement and secretion of water via the salivary glands). The ancestral lineage therefore possessed many of the features that distinguish the argasid and ixodid families (Fig. 3). These features were refined in the different lineages according to classic modification with descent theory. Without the contribution of $N$. namaqua, that is arguably the closest extant taxon to the ancestral lineage, this reconstruction was previously impossible given the differences in argasids and ixodid biology (Mans and Neitz, 2004a). In this regard, N. namaqua has been termed a living fossil, since it is monotypic and has been living in the Karoo basin, where the ecology had not changed since the Permian (Mans et al. 2011; Visser, 1995). The term "living fossil" has been introduced by Darwin to describe species that had not changed much over the course of evolution (Darwin, 1859). Recently this term has been under scrutiny, since even living fossils show evolutionary change (Mathers, 2013). However, evolutionary stasis may be expected in higher-level taxonomic groups with relatively low speciation rates and has been incorporated into a number of evolutionary models, even if these are the exception rather than the rule (Benton and Pearson, 2001; Cavalier-Smith 2006; Eldredge and Gould, 1972; Garwood and Edgecombe, 2011; 
Figure 4: Reconstruction of blood-feeding characteristics in the Ixodida. Indicated are the date estimates for various nodes of the Ixodida and corresponding major events in evolution. Blood feeding characters proposed to be present in ancestral and extant lineages are indicated by numbers at the different nodes and include: 1) Haller's organ for host detection and hypostome for feeding. 2) Prolonged feeding in larvae and secretion of water via the salivary glands. 3) Prolonged feeding in nymphs and adults with water secretion via the salivary glands. 4) Rapid digestion of blood meal with lysis of red blood cells during engorgement. 5) One larval and nymphal molt. 6) Adult stages feed once and lay one large egg batch. 7) Presence of scutum. 8) Presence of pseudo scutum. 9) Little or no cement. 10) Cement. 11) Fast feeding in nymphs and adults with water secretion via the Malpighian tubules. 12) Fast feeding in nymphs and adults with water secretion via the coxal organs. 13) Slow digestion of blood meal with little initial red blood cell lysis. 14) One larval and several nymphal molting stages. 15) Adult stages feed more than once and lay several small egg batches. 16) Loss of heme synthesizing capability and mechanisms to deal with heme toxicity. Dates and data adapted from Mans et al. (2012).

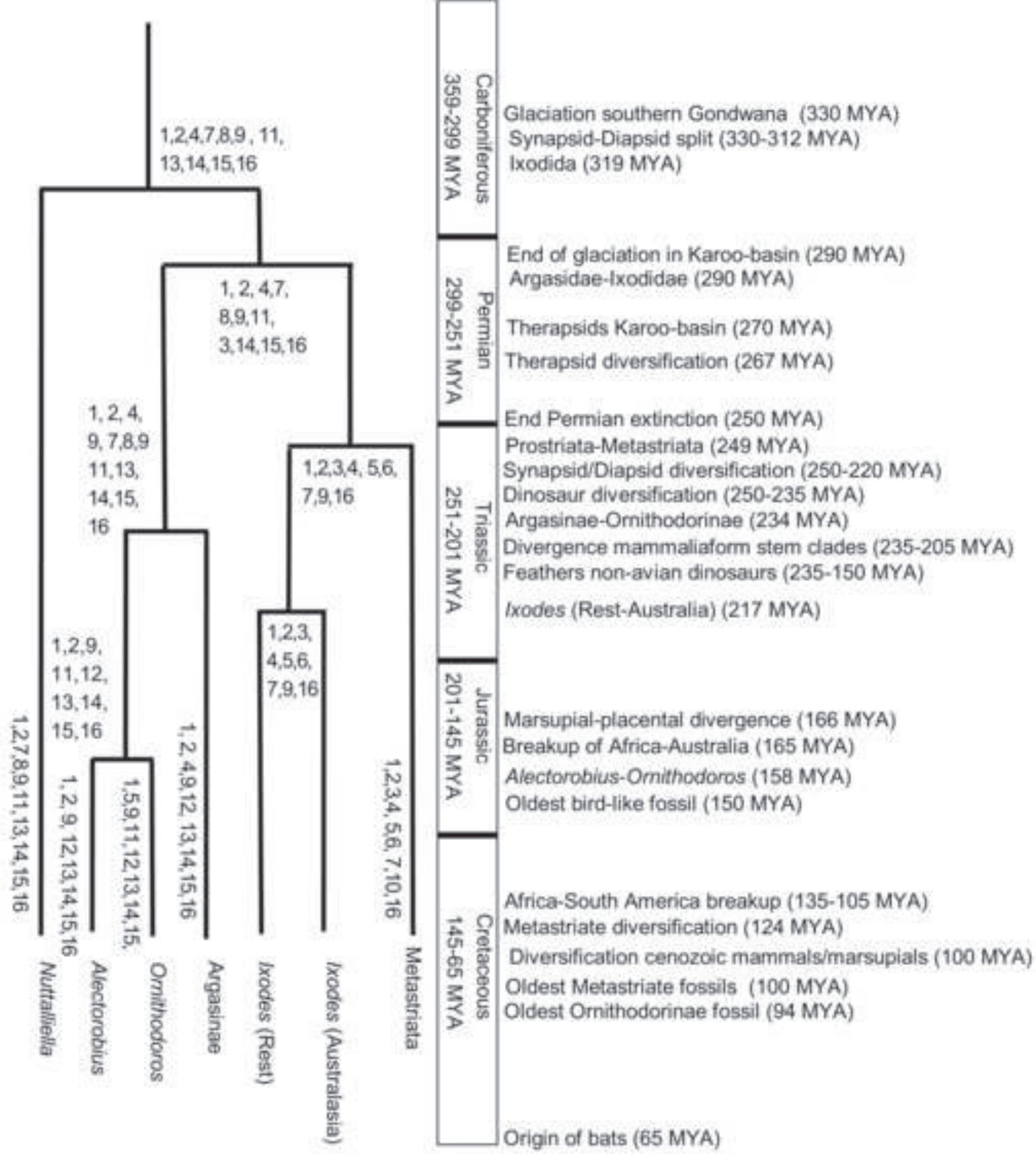


Gould, 2002; Sheldon, 1996). We are fortunate that N. namaqua survived this long without significant morphological or physiological changes, since this species may truly have been the missing link necessary for ancestral reconstruction. This does not deny that $N$. namaqua also evolved and has its own unique molecular signatures and lineage specific adaptations (Werth and Shear, 2014), but with the use of comparative biology, those characters shared in the ancestral tick lineage may be reconstructed (Fig. 4). This recapitulate the central themes observed for the Core of Life, Lineages of Life and Edges of Life phenomena that emphasize conservation of characters, but recognize lineage specific change.

The salivary glands as unique blood-feeding character

Except for the hypostome whose evolution for feeding purposes can be traced back to the ancestral lineage, the other organ in ticks evolved for feeding purposes are the salivary glands. In other parasitiform mites, multiple secretory glands exist, none specifically resembling those from ticks (Alberti and Coons, 1999), while the glands from the Astigmata are part of a podocephalic system with the coxal glands. Other prosomal glands also exist, but are not considered homologous to tick salivary glands (Alberti and Coons, 1999; Filimonova and Amosova, 2015). All ticks have one set of paired salivary glands constructed of agranular and granular acini. In soft ticks there is a single granular acini (Coons and Alberti, 1999). In hard ticks, two types of granular acini occur in females, type III possess the f cells that develop into water transporting cells during feeding. Ixodid males possess an additional type IV granular acini important for the mating factor secreted into females during mating that facilitate rapid engorgement. Ultrastructural studies of $N$. namaqua salivary glands have not yet been performed, but given its similar fast feeding behaviour to argasids, a similar morphology may be 
expected. Both hypostome and salivary glands play a role in tick-host interaction at the feeding site: the hypostome as piercing and anchoring device and the salivary glands as vehicle for all molecules secreted in the saliva. It has been argued that secretory proteins expressed in the salivary glands, evolved as part of the adaptation to a blood-feeding lifestyle (Mans and Neitz, 2004a). Conversely, it has been argued that immune pressure from the vertebrate host led to extensive diversification of salivary gland protein function after divergence of the main families, making ancestral reconstruction problematic (Mans, 2014). Even so, comparative analysis of salivary gland derived proteins can give insight into lineage specific adaptation as well as conserved functions evolved in the ancestral tick lineage.

\section{A brief history of salivary gland secretions and secretory proteins}

The potential of ticks to modulate their host's defence responses via salivary secretions has been recognized for more than a 115 years. Sabbatani (1899) showed that whole body extracts from I. ricinus prevented blood clotting and suggested that all blood-feeding organisms secrete anti-hemostatics. Christophers (1906) indicated that coxal fluid from Ornithodoros savignyi prevented blood clotting, while Nuttall and Strickland (1908) expanded this observation to show that salivary gland (SGE) and gut extracts from Argas persicus inhibited blood clotting. Cornwall and Patton (1914) confirmed the studies on $A$. persicus and suggested that after salivary glands secreted their anti-hemostatics needed to be "refilled" after feeding. A hiatus in salivary gland research followed that was only revived once work on tick toxicoses commenced. Ross (1926) confirmed the presence of anticoagulants in SGE of I. holocyclus in search of toxins. Hoeppli and Feng (1933), as part of studies into tick toxicoses and paralysis used male SGE from Dermacentor sinicus and Hyalomma detritum (=H. scupense) to confirm 
the presence of anticoagulants. Pilocarpine induced saliva was first collected by Howell (1966), and the first saliva derived protein and toxin was isolated (Neitz et al. 1969) and amino acid sequences determined for ticks (Neitz, 1976; Neitz et al. 1983). The first studies on targeting of specific host molecules followed and included the presence of anti-thrombin (Hellman and Hawkins, 1967; Hoffmann et al. 1991), hyaluronidase (Neitz, 1976; Neitz et al. 1978), histamine (Chinery and Ayitey-Smith, 1977), apyrase (Ribeiro et al. 1991, 1985), $\mathrm{PGE}_{2}$ and bradykininase (Ribeiro et al. 1985), anaphylatoxin (Ribeiro and Spielman, 1986) and complement C3 inhibitor (Ribeiro, 1987). Tick anticoagulant peptide (TAP) that targeted factor Xa (fXa) was the first salivary gland derived protein for which a full-length sequence was reported (Waxman et al. 1990). In the last 25 years biochemical and functional characterization of salivary gland components have virtually exploded and include platelet aggregation inhibitors (Table 2), blood clotting inhibitors (Table 3 ) and immuno-modulatory molecules (Table 4), the majority which have sequence data associated with these functions.

The data from these studies showed that soft and hard tick salivary glands possess similar protein families, notably basic tail secretory proteins (BTSP), kunitzBPTI, lipocalins and metalloproteases (Mans et al. 2008b). The transcriptome of $N$. namaqua also possess the same protein families (B.J. Mans, unpublished observation), suggesting that these protein families were present in the ancestral tick lineage. Nextgeneration sequencing of the predatory mite M. occidentalis (Hoy et al. 2013) and the blood-feeding poultry mite (Dermanyssus gallinae) (Schicht et al. 2014), both Parasitiformes, indicate that while the major tick salivary gland protein families are present, they do not show the same degree of lineage specific expansion. This also holds for the acariform mite, Sarcoptes scabiei (Rider et al. 2015) (Table 1). This suggests that the tick families specifically underwent lineage specific expansion during blood-feeding 
evolution, probably because they retained signals for salivary gland expression that were maintained after gene duplication (Mans, 2011). Retaining tissue specific differential expression signals may be an important way to prevent gene death after gene duplication, especially for secretory proteins which might escape the effects of functionally deleterious mutations until adaptive selection finds a new function. This may also be a reason why lineage specific expansions are prevalent in secretory families (Mans, 2011).

Whereas the basic protein families or folds may be conserved between the tick families), similar functions in salivary proteins are generally encoded by nonhomologous proteins (Table 2, 3 and 4), suggesting that these functions evolved independently in these lineages (Mans and Neitz, 2004a). More than ten years later, these observations still remain valid, even though more functions and proteins have been described. However, it may be prudent to discuss some specific examples in relation to ancestral reconstruction.

\section{Orthologous secretory proteins in tick lineages}

Orthologous genes will generally have similar functions and mechanisms, will be reciprocal best hits in BLAST analysis and will cluster in well supported monophyletic clades (Gabaldón and Koonin, 2013). A number of genes found in both the Argasinae and Ornithodorinae display these features, suggesting that they evolved specifically in the ancestral argasid lineage. This include platelet aggregation inhibitors (savignygrin, disagregin and monogrin) that target integrin $\alpha_{\mathrm{IIb}} \beta_{3}$ and present the integrin RGD recognition motif on the substrate-binding presenting loop of the Kunitz-BPTI fold (Karczewski et al. 1994; Mans et al. 2008a, 2002b), double-domain Kunitz-BPTI thrombin inhibitors (monobin, ornithodorin and savignin) that insert their N-terminal residues into the thrombin active site and bind to the thrombin fibrinogen-binding exosite 
with the C-terminal $\alpha$-helix (Mans et al. 2008a, 2002c; van de Locht et al. 1996), and leukotriene $\mathrm{C}_{4}\left(\mathrm{LTC}_{4}\right)$ scavengers that bind $\mathrm{LTC}_{4}$ inside the lipocalin barrel (Mans and Ribeiro, 2008a). No orthologs were detected in a salivary transcriptome of $N$. namaqua (B.J. Mans, personal observation) or in ixodids.

In ixodids, a group of double domain Kunitz-BPTI proteins of non-salivary gland origin (amblin, boophilin, ixophilin, hemalin), that targets thrombin has been characterized and shows superficial similarities in mechanism to the ornithodorin group (Lai et al. 2004; Liao et al. 2009; Macedo-Ribeiro et al. 2008; Narasimhan et al. 2013). However, superposition of structures indicated that non-homologous positions in the different inhibitors are involved in thrombin interaction (Macedo-Ribeiro et al. 2008). Phylogenetic analysis also did not support a monophyletic origin (Mans et al. 2008a). The conclusion that follows is that these functions evolved convergently in the argasid and ixodid lineages and that no Kunitz-double domain thrombin inhibitory function was present in the ancestral tick lineage. Molecular clock estimates indicate that the Argasinae and Ornithodorinae diverged $\sim 234 \pm 25$ MYA (Mans et al. 2012). This means that a number of functions involved in regulation of host defences have been maintained for millions of years in both argasids and ixodids. Some of these such as the histamine binding proteins, apyrase and savignygrins are immunogenic and even show protective responses during vaccination (Díaz-Martín et al. 2015; Oleaga et al. 2007). Host immune pressure can therefore not completely account for salivary gland diversity observed, but stochastic gene duplication and losses and host specificity must also have played a role. In the case of ixodids, host immunity may play a larger role, given their prolonged attachment to the host (Francischetti et al. 2009). However, argasids that are host borrowing and feed on a daily basis when hosts are present will arguably stimulate the host's immune system as much as ixodids. 
Functions unique to the genus Ornithodoros include thromboxane $\mathrm{A}_{2}\left(\mathrm{TXA}_{2}\right)$ and leukotriene $\mathrm{B}_{4}\left(\mathrm{LTB}_{4}\right)$ scavenging and complement $\mathrm{C} 5$ inhibition by lipocalins from the moubatin clade (Mans and Ribeiro, 2008b), and fXa inhibition by single domain Kunitz-BPTI proteins (TAP/fXaI) (Mans et al. 2008a). Their absence in the Argasinae would suggest that these functions evolved within the Ornithodoros lineage, although a larger taxonomic sampling would be necessary to confirm this. No orthologs to these functions were found in a N. namaqua salivary transcriptome (B.J. Mans, personal observation). In the hard tick I. ricinus, $\mathrm{LTB}_{4}$ scavenging by a lipocalin was observed (Beaufays et al. 2008a), but these does not show monophyletic clustering with the Ornithodoros lipocalins (Beaufays et al. 2008b), suggesting independent origins for this function.

Similarly to the argasid picture, a number of functions are unique to ixodids. These include platelet aggregation inhibitors from prostriate and metastriate ticks, that targets integrin $\alpha_{\text {IIb }} \beta_{3}$, but do not belong to the Kunitz-BPTI fold, but a fold termed the ixodegrins (Francischetti et al. 2005; Tang et al. 2015; Wang et al. 1996). Prostriates possess complement $\mathrm{C} 3$ inhibitors that belong to the Isac family and fXa inhibitors that belong to the basic tail secretory family (Narasimhan et al. 2002; Valenzuela et al. 2000). Prostriates possess a number of multi-domain kunitz-BPTI proteins that target fXa-TF complexes (Francischetti et al. 2004, 2002). Metastriates possess the evasins that belong to their own unique fold (Déruaz et al. 2008; Frauenschuh et al. 2007). Orthologs for these proteins have not been found in a $N$. namaqua salivary transcriptome (B.J. Mans, personal observation). Again this suggests that these particular functions evolved independently in the different tick families and even in the prostriates and metastriates.

Functions that are conserved between argasids and ixodids include biogenic amine binding lipocalins (Mans et al. 2008c), apyrase activity (Stutzer et al. 2009) and 
metalloprotease activity (Mans et al. 2008b). These are also found in a salivary gland transcriptome of N. namaqua (B.J. Mans, personal observation). This would suggest that a core set of salivary gland derived functions were present in the ancestral tick lineage. These functions may have been housekeeping before exaptation for a blood-feeding lifestyle (Mans, 2011). It therefore remains difficult to use these common functions as evidence for a common origin of blood-feeding, even though the systematic support for the monophyly of hematophagous behaviour in ticks suggests that they may have been exapted in the ancestral tick lineage.

These observations are to a large extent anecdotal due to the small number of taxons sampled to date. Large-scale comparative analysis will be necessary in future to systematically determine those orthologs conserved in various ancestral lineages. It is therefore useful to discuss the impact that transcriptomic analysis had on elucidation of salivary gland complexity and challenges that will be faced in the future.

\section{Transcriptomics and ancestral reconstruction}

The numbers of functionally characterized molecules before the millennium remained in the lower tens and the relatively simple protein patterns observed in salivary gland extracts supported this (Table 1). However, the complexity of salivary glands became apparent with the advent of conventional transcriptomics, when numbers of secretory proteins detected in the salivary glands jumped to hundreds (Francischetti et al. 2008a, 2008b, 2005; Mans et al. 2008b; Ribeiro et al. 2006; Valenzuela et al. 2002). The introduction of next-generation sequencing technologies caused a jump to hundreds of genes for each major protein family (Karim et al. 2011). Even so, less than 150 molecules and less than 100 functions have been described empirically (Table 2-4). This 
implies that extensive functions remain unknown or that extensive redundancy exists in tick sialomes.

The number of salivary gland and other transcriptomes characterized has exploded in the last 15 years (Table 1). This has immense potential for ancestral reconstruction, given all the data generated on genes present and expressed in a given species. However, significant challenges are faced in using this data since a number of important factors impact on the usefulness of this data. A number of transcriptomes have been described using conventional cDNA library sequencing approaches (Table 1). Representation in these libraries is generally restricted to highly abundant transcripts and the sequence depth of these libraries limited by sequencing of only a few thousand clones. All orthologs and paralogs are not recovered for a given species, making inferences of lineage specific expansions and losses difficult.

The advent of next-generation sequencing technologies has promise to address the under representation problem due to its sequence depth, but may introduce the problem of over representation, resulting in multiple gene models for single genes. This may be legitimate allelic variation since multiple individuals are generally pooled or may be due to artefacts of the assembly process, resulting in chimeric, miss-assembled or truncated sequences (Martin and Wang, 2011). For example, the current number of 28636 nucleotide sequences in Genbank for I. ricinus can be reduced to 20260 when clustered at 95\% identity and potential chimeric and duplicate sequences are removed (B.J. Mans, personal observation).

The computational effort that is needed to analyse and annotate transcriptomes also led to short-cuts in data submission, so that only nucleotide or expressed sequence tags (EST) data is submitted, without submitting the protein sequences to the databank (Table 1, species marked with *). This opens the opportunity of re-analysis by third 
parties (Ribeiro et al. 2011), but requires an investment of time and effort to effectively repeat the same work again. In some cases the raw reads or no reads at all are submitted, without submitting any assembled contigs (Table 1, those transcriptomes showing no data). This means that assemblies need to be repeated de novo from the raw data and given variation in bioinformatic parameters, may not produce the assemblies reported in papers. This effectively excludes these sequences from protein database analysis and requires much greater effort for comparative transcriptomics.

Similarly, many transcriptomes are submitted into databases with noninformative annotations such as "hypothetical secretory protein". This is partly due to the proliferation of orphan genes in tick transcriptomes (Gibson et al. 2013; Ribeiro and Francischetti, 2003), but also due to poor annotation or mass submission of sequences. The problem that this creates in subsequent analysis and annotation of new transcriptomes, is that of self-propagation, in that the best BLAST hits remain hypothetical unknowns with regard to functional annotation (DeWoody et al. 2013). While this may not be a problem for the experienced bioinformatician, it does miss the point of creating accessible and well annotated databases available to the whole scientific community.

The large numbers of orphan genes found in different tick species also remain problematic (Gibson et al. 2013), although this may be alleviated as our taxonomic breadth increases and closer related species are analysed (Francischetti et al. 2009). However, few described transcriptomes to date have integrated and performed in-depth comparative analysis, but remains descriptive species specific gene list reports. Many genes deposited in the databases are also truncated, due to the historic limitations of conventional cDNA library synthesis methods or due to incomplete assembly using nextgeneration sequencing data. Truncated genes may be useful to confirm the presence of a 
gene family, or for primer design for cloning the full-length transcript for further analysis, but is rarely useful for downstream bioinformatic analyses (multiple alignments, phylogenetic analysis, structure modelling and ancestral reconstruction), since homologous characters or informative regions may be missing. The construction and curation of well-maintained tick specific sequence databases needs to be a priority in the future if they will be useful for ancestral reconstruction.

Another problem that will be faced in future relates to the systematics of ticks. As more geographic localities are sampled and deeper systematic analysis performed, increased numbers of cryptic or distinct species are being uncovered. An example of this is the case of $R$. microplus and $R$. australis Fuller 1899, where the latter Australasian strain of $R$. microplus has been reinstated as a unique species (Estrada-Peña et al. 2012; Labruna et al. 2009), while at least another unique clade (species?) has been associated with the name R. microplus (Barker and Walker, 2014; Burger et al. 2014b). Rhipicephalus australis and $R$. microplus has been extensively characterized and genome sequencing efforts on both species are well advanced and data indicate that significant differences exist with regard to gene coverage (Bellgard et al. 2012). As such, all studies that report sequences of an Australasian origin should probably be considered to be $R$. australis, for example, the serpins that targets thrombin (Rodriguez-Valle et al. 2015; Xu et al. 2016). In those instances where sequences exist in the database under the incorrect species designation, it will definitely impact on future bioinformatical analysis and ancestral reconstruction efforts, by confounding the analysis of orthologous and paralogous relationships of protein genes. A possible solution to this may be that all studies that reports on functional or transcriptomic data should also submit or report at least a 16S, Cytb or COX1 voucher sequence that derive from their specimens to enable species confirmation in future. Additionally, Genbank submissions known to represent 
erroneous species should be corrected to the appropriate species designation (Barker and Walker, 2014).

\section{Protein family specific analysis: characterizing paralogs}

A number of studies aimed to investigate the evolution of specific tick protein families and functions using phylogenetic analysis. This included studies of the BTSP family (Mans et al. 2008a), the Kunitz/BPTI family (Dai et al. 2012; Louw et al. 2013; Mans and Neitz, 2004b; Mans et al. 2008a, 2003b; 2002a; Schwarz et al. 2014b), the lipocalin family (Beaufays et al. 2008b; Mans, 2005; Mans and Neitz, 2004c; Mans and Ribeiro, 2008a, 2008b; Mans et al. 2008a, 2008c, 2003a) and the apyrases (Stutzer et al. 2009). These studies suggested that argasid BPTI anti-hemostatic factors share a common evolutionary pathway; that biogenic amine binding lipocalins and $\mathrm{TXA}_{2} / \mathrm{LTB}_{4}$ scavenging lipocalins are closely related; that the biogenic amine binding site is probably ancestral; that tick lipocalins share a monophyletic origin with lipocalins from other metazoan and that apyrase activity probably evolved a single time in the ancestral tick lineage.

A variety of transcriptome studies also report phylogenetic trees, but these are generally descriptive in nature, aiming to depict the diversity of family members and the number of clades that may be distinguished without making specific conclusions regarding evolution (Table 1). In many cases members from other species may be included for assignment of potential function to clades. In the majority of cases, no function can be assigned to the species specific clades and these studies mostly serve to indicate that lineage specific expansions (species or genus specific gene duplications) are prevalent. Since species specific family members have been analysed in most cases without applying functional knowledge, construction of evolutionary scenarios remain 
problematic since it is difficult to determine which genes are true lineage specific innovations, which have deeper phylogenetic relationships to other tick lineages or species and which represent novel functional innovation or diversification. In this regard, closely related proteins have been shown to possess different functions even if these functions have some similarity. As such, a general biogenic amine binding function (histamine or serotonin) may be assigned to lipocalins with the biogenic amine binding motif, but it is not possible to predict which molecule will be scavenged until empirically tested (Mans et al. 2008c). Members of the moubatin clade may bind $\mathrm{TXA}_{2}, \mathrm{LTB}_{4}$ or inhibit complement C5 and some of the molecular correlates of these functions have been elucidated and can be used for functional prediction (Mans and Ribeiro, 2008a). Molecular modelling has even been used to predict potential binding partners for $\mathrm{LTC}_{4}$ scavengers (Mans and Ribeiro, 2008c), while the canonical folds of the Kunitz-BPTI and lipocalin families have been successfully used to predict inhibitory or scavenging functions that was then empirically tested (Mans, 2011). However, bioinformatical analysis without empirical testing remains a dangerous approach to assign functions to clades, even if some members of a clade have known functions (Valdés and Moal, 2014). This will remain one of the central challenges of ancestral reconstruction of functional evolution for tick protein families, since very few proteins have been assigned empirically confirmed functions (Table 2, 3 and 4). Linked to this is the expansion of the major tick protein families with every transcriptome that is sequenced, which add more and more diverse protein family members. As these are added, it becomes increasingly difficult to obtain phylogenetically informative multiple sequence alignments and phylogenetic trees with good nodal support, since for the major protein families such as the Kunitz-BPTI, lipocalin and BTSP, the percentage sequence similarity overall lies well within the twilight zone (20-30\% sequence identity) (Rost, 1999). This will 
necessitate new methods of analysis and representation (Chan and Ragan, 2013). As an example of this, the tick lipocalin family had 1 member in 1993 (Keller et al. 1993), 4 in 1999 (Paesen et al. 1999), 5 in 2002 (Sangamnatdej et al. 2002), 20 in 2003 (Mans et al. 2003a), 38 in 2005 (Mans, 2005), 300 in 2008 (Mans et al. 2008c), 584 added from the first next-generation sequencing project (Karim et al. 2011) and 3867 in the current database. If current trends in the description of transcriptomes continue, in 20 years there will be more lipocalins in the database than proteins encoded in the genome of $I$. scapularis. This means that it is already impossible to analyse all lipocalins as one family using one alignment, since the alignments are not reliable anymore due to low sequence similarity among family members. This observation also holds for other major tick protein families including the BPTI, BTSP and metalloproteases. In the future, these families will need to be classified as super families, containing subfamilies with shared ancestry and clade specific expression and function. This will be aided as more empirical functional studies become available.

\section{Molecular clock dating and salivary protein families}

A few studies have attempted to date the divergences of the protein families using molecular clock approaches (Louw et al. 2013; Schwarz et al. 2014b). However, due to low sequence similarity among family members, the trees obtained give contradictory results and general low branch support. As such, even though molecular clock estimates place the divergence of the tick families at >240 MYA and divergence of Argas/Ornithodoros and prostriate/metastriate at >200 MYA (Jeyaprakash and Hoy, 2009b; Mans et al. 2012), clades that possess both argasid and ixodid sequences are dated $<150$ MYA, or clades that possess Argas/Ornithodoros or prostriate/metastriate sequences are dated <120 MYA (Schwarz et al. 2014b). This would either imply that 
molecular clock estimates based on mitochondrial data are over estimated, or that convergent and divergent evolution give untrustworthy results for these multi-paralogous protein families due to the non-clock like behaviour of proteins under positive selection.

Analysis restricted to BPTI sequences from a single species (R. microplus), yielded estimates for different clades between 1-11 MYA (Louw et al. 2013). These were interpreted as recent duplications, but are almost as old as the estimates for the origin of the Rhipicephalinae 14 MYA (Barker and Murrel, 2004), suggesting that most of these duplications did not originate in $R$. microplus, but before diversification of a number of lineages. Since no sequences from other species were used in the analysis, it is difficult to determine whether these duplications are lineage specific or whether orthologs exist for them. The study also concluded that a genome duplication occurred $\sim 150$ MYA to give rise to two major clades of BPTI inhibitors in $R$. microplus, suggesting that this specific clade structure will be prevalent among all metastriates. Again, the exclusion of sequences from other species makes this statement difficult to assess. It is likely that this study also suffered from the same problems stated before, namely non-clock like behaviour for rapidly evolving sequences.

The problem with molecular clock dating of salivary gland protein families is likely to increase as transcriptome studies expand the number of divergent protein family members. This may be remedied once enough lineages have been sampled to accurately identify orthologs, paralogs and functional clades, and fill in the phylogenetic space that prevent the characterization of robust clades. Once this state of taxon sampling has been achieved, ancestral reconstruction of protein families may become more robust. Until then, in-depth study of the evolution of tick salivary gland protein families will remain restricted. 


\section{Conclusions}

Both certainties and uncertainties remain in the reconstruction of ancestral tick lineages. At almost all levels of the ancestral lineages that lead to the Ixodida, there are certainties and uncertainties. We know that ticks are Eukaryotes and belong to the Bilateria, even though the relationships among the basal eukaryotic lineages remain obscure. We know that ticks are arthopods, chelicerates and arachnids even though we cannot with certainty define the basal relationships in each level. We know that ticks are acarids and belong to the Parasitiformes, even though the monophyly of the Acari is not certain. We are fairly confident about the relationships within the Parasitiformes and that ticks are monophyletic, but the exact relationship between the three tick families remain contentious. We are confident regarding the major groupings in the soft (Argasinae and Ornithodorinae) and hard tick (prostriata and metastriata) families, but much uncertainty remains with regard to the relationships and monophyly of genera and sub-genera. Even so, broad reconstructions can be made in relation to the ancestral lineages that lead to extant tick families, genera and species. Conservation of Core of Life, Lineage of Life and even Edges of Life phenomena can be delineated. Lineage specific exaptation and innovation of conserved processes occur on all levels, implying that comparative biology of these phenomena will continue to yield surprises and remain a worthwhile exercise. However, it should be clear that ancestral reconstruction of the tick lineage is still in its infancy, even though extensive data has been generated for tick biology over the last 150 years. Focus areas in the future will still revolve around systematics, transcriptomics, proteomics and functional genomics and will continue until representative datasets that cover the taxonomic breadth of the Arthropoda, Arachnida, Parasitiformes and Ixodida have been generated. While $N$. namaqua (and some other taxonomically important species), have no economic importance, their study will continue to play a central role to 
further our understanding of tick biology and evolution. Taxonomic important species may easily be neglected and include all that do not transmit major diseases, but represent distinct lineages such as Antricola, Bothriocroton, Carios, Cosmiomma, Margaropus, Nosomma, Nothoaspis, Ogadenus, Otobius, Reticulinasus, Rhipicentor, Secretargas and closer relatives to species that are major vectors. Until we understand tick biology in general, we might not appreciate to the fullest extent those character traits that distinguish economically important ticks from their more benign relatives.

\section{Acknowledgements}

This project was funded by the Joy Liebenberg Trust (21/19/JT02) allocated to BM, incentive funding for rated researchers grant from the National Research Foundation of South Africa (NRF-Mans 76499), and the ARC Tick Vaccine project (30/01/V010). 


\section{References}

Adl, S.M., Simpson, A.G., Lane, C.E., Lukeš, J., Bass, D., Bowser, S.S., Brown, M.W., Burki, F., Dunthorn, M., Hampl, V., Heiss, A., Hoppenrath, M., Lara, E., Le Gall, L., Lynn, D.H., McManus, H., Mitchell, E.A., Mozley-Stanridge, S.E., Parfrey, L.W., Pawlowski, J., Rueckert, S., Shadwick, R.S., Schoch, C.L., Smirnov, A., Spiegel, F.W., 2012. The revised classification of eukaryotes. J. Eukaryot. Microbiol. 59, 429-493.

Aguinaldo, A.M.A., Turbeville, J.M., Linford, L.S., Rivera, M.C., Garey, J.R., Raff, R.A., Lake, J.A., 1997. Evidence for a clade of nematodes, arthropods and other moulting animals. Nature 387, 489-493.

Alarcon-Chaidez, F.J., Sun, J., Wikel, S.K., 2007. Transcriptome analysis of the salivary glands of Dermacentor andersoni Stiles (Acari: Ixodidae). Insect Biochem. Mol. Biol. 37, 48-71.

Alberti, G., Coons, L.B., 1999. Acari: mites, in: F.W. Harrison, F.W., Foelix, R.F. (Eds.), Microscopic Anatomy of Invertebrates, Vol. 8C: Chelicerate Arthopoda. Wiley-Liss, New York, pp. 515-1265.

Aljamali, M.N., Hern, L., Kupfer, D., Downard, S., So, S., Roe, B.A., Sauer, J.R., Essenberg, R.C., 2009. Transcriptome analysis of the salivary glands of the female tick Amblyomma americanum (Acari: Ixodidae). Insect Mol. Biol. 18, 129-154.

Anastopoulos, P., Thurn, M.J., Broady, K.W., 1991. Anticoagulant in the tick Ixodes holocyclus. Aust. Vet. J. 68, 366-367.

Anatriello, E., Ribeiro, J.M., de Miranda-Santos, I.K., Brandão, L.G., Anderson, J.M., Valenzuela, J.G., Maruyama, S.R., Silva, J.S., Ferreira, B.R., 2010. An insight into the sialotranscriptome of the brown dog tick, Rhipicephalus sanguineus. BMC Genomics 11, 450.

Anderson, J.M., Sonenshine, D.E., Valenzuela, J.G., 2008. Exploring the mialome of ticks: an annotated catalogue of midgut transcripts from the hard tick, Dermacentor variabilis (Acari: Ixodidae). BMC Genomics 9, 552.

Anguita, J., Ramamoorthi, N., Hovius, J.W., Das, S., Thomas, V., Persinski, R., Conze, D., Askenase, P.W., Rincón, M., Kantor, F.S., Fikrig, E., 2002. Salp15, an Ixodes scapularis salivary protein, inhibits CD4(+) T cell activation. Immunity 16, 849-859.

Anisuzzaman, Islam, M.K., Alim, M.A., Miyoshi, T., Hatta, T., Yamaji, K., Matsumoto, Y., Fujisaki, K., Tsuji, N., 2011. Longistatin, a plasminogen activator, is key to the availability of blood meals for ixodid ticks. PLoS Pathog. 7, e1001312.

Anisuzzaman, Islam, M.K., Alim, M.A., Miyoshi, T., Hatta, T., Yamaji, K., Matsumoto, Y., Fujisaki, K., Tsuji, N., 2012. Longistatin is an unconventional serine protease and induces protective immunity against tick infestation. Mol. Biochem. Parasitol. 182, 45-53. 
Arolas, J.L., Lorenzo, J., Rovira, A., Castellà, J., Aviles, F.X., Sommerhoff, C.P., 2005a. A carboxypeptidase inhibitor from the tick Rhipicephalus bursa: isolation, cDNA cloning, recombinant expression, and characterization. J. Biol. Chem. 280, 3441-3448.

Arolas, J.L., Popowicz, G.M., Lorenzo, J., Sommerhoff, C.P., Huber, R., Aviles, F.X., Holak, T.A., 2005b. The three-dimensional structures of tick carboxypeptidase inhibitor in complex with A/B carboxypeptidases reveal a novel double-headed binding mode. J. Mol. Biol. 350, 489-498.

Artavanis-Tsakonas, S., Rand, M.D., Lake, R.J., 1999. Notch signaling: cell fate control and signal integration in development. Science 284, 770-776.

Arthur, D.R., 1962. Ticks and Disease. Row, Peterson and Company, Evanston.

Astigarraga, A., Oleaga-Pérez, A., Pérez-Sánchez, R., Baranda, J.A., EncinasGrandes, A., 1997. Host immune response evasion strategies in Ornithodoros erraticus and O. moubata and their relationship to the development of an antiargasid vaccine. Parasite Immunol. 19, 401-410.

Balashov, Y.S., 1972. Bloodsucking ticks (Ixodideae) — vectors of disease of man and animals. Misc. Pub. Entomol. Soc. Amer. 8, 161-376.

Barker, S.C., Murrell, A., 2002. Phylogeny, evolution and historical zoogeography of ticks: a review of recent progress. Exp. Appl. Acarol. 28, 55-68.

Barker, S.C., Murrell, A., 2004. Systematics and evolution of ticks with a list of valid genus and species names. Parasitol. 129, S15-S36.

Barker, S.C., Walker, A.R., 2014. Ticks of Australia. The species that infest domestic animals and humans. Zootaxa 3816, 1-144.

Barker, S.C., Walker, A.R., Campelo, D., 2014. A list of the 70 species of Australian ticks; diagnostic guides to and species accounts of Ixodes holocyclus (paralysis tick), Ixodes cornuatus (southern paralysis tick) and Rhipicephalus australis (Australian cattle tick); and consideration of the place of Australia in the evolution of ticks with comments on four controversial ideas. Int. J. Parasitol. 44, 941-953.

Bastiani, M., Hillebrand, S., Horn, F., Kist, T.B., Guimarães, J.A., Termignoni, C., 2002. Cattle tick Boophilus microplus salivary gland contains a thiol-activated metalloendopeptidase displaying kininase activity. Insect Biochem. Mol. Biol. 32, 1439-1446.

Batista, I.F., Ramos, O.H., Ventura, J.S., Junqueira-de-Azevedo, I.L., Ho, P.L., Chudzinski-Tavassi, A.M., 2010. A new Factor Xa inhibitor from Amblyomma cajennense with a unique domain composition. Arch. Biochem. Biophys. 493, 151156.

Beaufays, J., Adam, B., Menten-Dedoyart, C., Fievez, L., Grosjean, A., Decrem, Y., Prévôt, P.P., Santini, S., Brasseur, R., Brossard, M., Vanhaeverbeek, M., Bureau, F., 
Heinen, E., Lins, L., Vanhamme, L., Godfroid, E., 2008a. Ir-LBP, an Ixodes ricinus tick salivary LTB4-binding lipocalin, interferes with host neutrophil function. PLoS One 3, e3987.

Beaufays, J., Adam, B., Decrem, Y., Prévôt, P.P., Santini, S., Brasseur, R., Brossard, M., Lins, L., Vanhamme, L., Godfroid, E., 2008b. Ixodes ricinus tick lipocalins: identification, cloning, phylogenetic analysis and biochemical characterization. PLoS One 3, e3941.

Bedford, G.A.H., 1931. Nuttalliella namaqua, a new genus and species of tick. Parasitol. 23, 230-232.

Bellgard, M.I., Moolhuijzen, P.M., Guerrero, F.D., Schibeci, D., Rodriguez-Valle, M., Peterson, D.G., Dowd, S.E., Barrero, R., Hunter, A., Miller, R.J., Lew-Tabor, A.E., 2012. CattleTickBase: an integrated Internet-based bioinformatics resource for Rhipicephalus (Boophilus) microplus. Int. J. Parasitol. 42, 161-169.

Benoit, J.B., Hansen, I.A., Szuter, E.M., Drake, L.L., Burnett, D.L., Attardo, G.M., 2014. Emerging roles of aquaporins in relation to the physiology of blood-feeding arthropods. J. Comp. Physiol. B. 184, 811-825.

Benton, M.J., Pearson, P.N., 2001. Speciation in the fossil record. Trends Ecol. Evol. $16,405-411$.

Bergman, D.K., Ramachandra, R.N., Wikel, S.K., 1998. Characterization of an immunosuppressant protein from Dermacentor andersoni (Acari: Ixodidae) salivary glands. J. Med. Entomol. 35, 505-509.

Bergman, D.K., Palmer, M.J., Caimano, M.J., Radolf, J.D., Wikel, S.K., 2000. Isolation and molecular cloning of a secreted immunosuppressant protein from Dermacentor andersoni salivary gland. J. Parasitol. 86, 516-525.

Binnington, K.C., 1975. Secretory coxal gland, active during apolysis in ixodid and argasid ticks (Acarina). Int. J. Insect Morph. Embr. 4, 183-191.

Bissinger, B.W., Donohue, K.V., Khalil, S.M., Grozinger, C.M., Sonenshine, D.E., Zhu, J., Roe, R.M., 2011. Synganglion transcriptome and developmental global gene expression in adult females of the American dog tick, Dermacentor variabilis (Acari: Ixodidae). Insect Mol. Biol. 20, 465-491.

Black, W.C. 4th, Klompen, J.S., Keirans, J.E., 1997. Phylogenetic relationships among tick subfamilies (Ixodida: Ixodidae: Argasidae) based on the $18 \mathrm{~S}$ nuclear rDNA gene. Mol. Phylogenet. Evol. 7, 129-144.

Bochkov, A.V., Connor, B.M., Wauthy, G., 2008. Phylogenetic position of the mite family Myobiidae within the infraorder Eleutherengona (Acariformes) and origins of parasitism in eleutherengone mites. Zool. Anz. 247, 15-45.

Borner, J., Rehm, P., Schill, R.O., Ebersberger, I., Burmester, T., 2014. A transcriptome approach to ecdysozoan phylogeny. Mol. Phylogenet. Evol. 80, 79-87. 
Bošnjak, I., Bojović, V., Šegvić-Bubić, T., Bielen, A., 2014. Occurrence of protein disulfide bonds in different domains of life: a comparison of proteins from the Protein Data Bank. Protein Eng. Des. Sel. 27, 65-72.

Bowman, A.S., Dillwith, J.W., Sauer, J.R., 1996. Tick salivary prostaglandins: Presence, origin and significance. Parasitol. Today 12, 388-396.

Braz, G.R., Coelho, H.S., Masuda, H., Oliveira, P.L., 1999. A missing metabolic pathway in the cattle tick Boophilus microplus. Curr. Biol. 9, 703-706.

Brown, S.J., 1988. Evidence for regurgitation by Amblyomma americanum. Vet. Parasitol. 28, 335-342.

Burger, T.D., Shao, R., Beati, L., Miller, H., Barker, S.C., 2012. Phylogenetic analysis of ticks (Acari: Ixodida) using mitochondrial genomes and nuclear rRNA genes indicates that the genus Amblyomma is polyphyletic. Mol. Phylogenet. Evol. 64, 4555 .

Burger, T.D., Shao, R., Barker, S.C., 2013. Phylogenetic analysis of the mitochondrial genomes and nuclear rRNA genes of ticks reveals a deep phylogenetic structure within the genus Haemaphysalis and further elucidates the polyphyly of the genus Amblyomma with respect to Amblyomma sphenodonti and Amblyomma elaphense. Ticks Tick Borne Dis. 4, 265-274.

Burger, T.D., Shao, R., Labruna, M.B., Barker, S.C., 2014a. Molecular phylogeny of soft ticks (Ixodida: Argasidae) inferred from mitochondrial genome and nuclear rRNA sequences. Ticks Tick Borne Dis. 5, 195-207.

Burger, T.D., Shao, R., Barker, S.C., 2014b. Phylogenetic analysis of mitochondrial genome sequences indicates that the cattle tick, Rhipicephalus (Boophilus) microplus, contains a cryptic species. Mol. Phylogenet. Evol. 76, 241-253.

Cabezas-Cruz, A., Valdés, J.J., 2014. Are ticks venomous animals? Front. Zool. 11, 47.

Cao, Z., Yu, Y., Wu, Y., Hao, P., Di, Z., He, Y., Chen, Z., Yang, W., Shen, Z., He, X., Sheng, J., Xu, X., Pan, B., Feng, J., Yang, X., Hong, W., Zhao, W., Li, Z., Huang, K., Li, T., Kong, Y., Liu, H., Jiang, D., Zhang, B., Hu, J., Hu, Y., Wang, B., Dai, J., Yuan, B., Feng, Y., Huang, W., Xing, X., Zhao, G., Li, X., Li, Y., Li, W., 2013. The genome of Mesobuthus martensii reveals a unique adaptation model of arthropods. Nat. Commun. 4, 2602.

Casewell, N.R., Wüster, W., Vonk, F.J., Harrison, R.A., Fry, B.G., 2013. Complex cocktails: the evolutionary novelty of venoms. Trends Ecol. Evol. 28, 219-229.

Cavalier-Smith, T., 2006. Cell evolution and Earth history: stasis and revolution. Philos. Trans. R. Soc. Lond. B. Biol. Sci. 361, 969-1006.

Chan, C.X., Ragan, M.A., 2013. Next-generation phylogenomics. Biol. Direct. 8, 3. 
Chen, D.S., Jin, P.Y., Zhang, K.J., Ding, X.L., Yang, S.X., Ju, J.F., Zhao, J.Y., Hong, X.Y., 2014. The complete mitochondrial genomes of six species of Tetranychus provide insights into the phylogeny and evolution of spider mites. PLoS ONE 9, e110625.

Cheng, Y., Wu, H., Li, D., 1999. An inhibitor selective for collagen-stimulated platelet aggregation from the salivary glands of hard tick Haemaphysalis longicornis and its mechanism of action. Sci. China C Life Sci. 42, 457-464.

Chiabrando, D., Vinchi, F., Fiorito, V., Mercurio, S., Tolosano, E., 2014. Heme in pathophysiology: a matter of scavenging, metabolism and trafficking across cell membranes. Front. Pharmacol. 5, 61.

Chinery, W.A., Ayitey-Smith, E., 1977. Histamine blocking agent in the salivary gland homogenate of the tick Ripicephalus sanguineus sanguineus. Nature 265, 366367.

Chmelar, J., Anderson, J.M., Mu, J., Jochim, R.C., Valenzuela, J.G., Kopecký, J., 2008. Insight into the sialome of the castor bean tick, Ixodes ricinus. BMC Genomics 9, 233.

Chmelar, J., Oliveira, C.J., Rezacova, P., Francischetti, I.M., Kovarova, Z., Pejler, G., Kopacek, P., Ribeiro, J.M., Mares, M., Kopecky, J., Kotsyfakis, M., 2011. A tick salivary protein targets cathepsin $\mathrm{G}$ and chymase and inhibits host inflammation and platelet aggregation. Blood 117, 736-744.

Christie, A.E., 2008. Neuropeptide discovery in Ixodoidea: an in silico investigation using publicly accessible expressed sequence tags. Gen. Comp. Endocrinol. 157, 17485 .

Christophers, S.R., 1906. The anatomy and histology of Ticks. Scientific Memoirs by Officers of the Medical and Sanitary Departments of the Government of India, New Series, No. 23.

Ciprandi, A., de Oliveira, S.K., Masuda, A., Horn, F., Termignoni, C., 2006. Boophilus microplus: its saliva contains microphilin, a small thrombin inhibitor. Exp. Parasitol. 114, 40-46.

Connat, J.L., 1991. Demonstration of regurgitation of gut content during blood meals of the tick Ornithodoros moubata. Possible role in the transmission of pathogenic agents. Parasitol. Res. 77, 452-454.

Coons, L.B., Roshdy, M.A., 1981. Ultrastructure of granule secretion in salivary glands of Argas (Persicargas) arboreus during feeding. Parasitol. Res. 65, 225-234.

Coons, L.B., Rosell-Davis, R., Tarnowski, B.I., 1986. Bloodmeal digestion in ticks, in: Sauer, J.A., Hair, J.A. (Eds.), Morphology, physiology, and behavioral biology of ticks. Ellis Horwood Lmtd, Chichester, pp 248-279. 
Coons, L.B., Alberti, G., 1999. Acari: ticks. in: Harrison, F.W., Foelix, R.F. (Eds.), Microscopic Anatomy of Invertebrates, Volume 8B: Chelicerate Arthopoda. WileyLiss, New York , pp. 267-514.

Cordeiro, F.A., Amorim, F.G., Anjolette, F.A., Arantes, E.C., 2015. Arachnids of medical importance in Brazil: main active compounds present in scorpion and spider venoms and tick saliva. J. Venom. Anim. Toxins. Incl. Trop. Dis. 21, 24.

Cornwall, J.W., Patton, W.S., 1914. Some observations on the salivary secretion of the commoner blood-sucking insects and ticks. Indian J. Med. Res. 2, 569-593.

Cunningham, C.W., Omland, K.E., Oakley, T.H., 1998. Reconstructing ancestral character states: a critical reappraisal. Trends Ecol. Evol. 13, 361-366.

Dai, S.X., Zhang, A.D., Huang, J.F., 2012. Evolution, expansion and expression of the Kunitz/BPTI gene family associated with long-term blood feeding in Ixodes scapularis. BMC Evol. Biol. 12, 4.

Dávalos, L.M., Cirranello, A.L., Geisler, J.H., Simmons, N.B., 2012. Understanding phylogenetic incongruence: lessons from phyllostomid bats. Biol. Rev. 87, 991-1024.

Darwin, C., 1859. On the Origin of Species by Means of Natural Selection, or the Preservation of Favoured Races in the Struggle for Life. London: John Murray.

de Castro, M.H., de Klerk, D., Pienaar, R., Latif, A.A., Rees, D.J.G., Mans, B.J. 2016. De novo assembly and annotation of the salivary gland transcriptome of Rhipicephalus appendiculatus male and female ticks during blood feeding. Ticks Tick-borne Dis. doi:10.1016/j.ttbdis.2016.01.014.

Decrem, Y., Rath, G., Blasioli, V., Cauchie, P., Robert, S., Beaufays, J., Frère, J.M., Feron, O., Dogné, J.M., Dessy, C., Vanhamme, L., Godfroid, E., 2009. Ir-CPI, a coagulation contact phase inhibitor from the tick Ixodes ricinus, inhibits thrombus formation without impairing hemostasis. J. Exp. Med. 206, 2381-2395.

de la Fuente, J., Estrada-Peña, A., Cabezas-Cruz, A., Brey, R., 2015. Flying ticks: anciently evolved associations that constitute a risk of infectious disease spread. Parasit. Vectors 8, 538.

Demuth, J.P., Hahn, M.W., 2009. The life and death of gene families. Bioessays 31, 29-39.

Déruaz, M., Frauenschuh, A., Alessandri, A.L., Dias, J.M., Coelho, F.M., Russo, R.C., Ferreira, B.R., Graham, G.J., Shaw, J.P., Wells, T.N., Teixeira, M.M., Power, C.A., Proudfoot, A.E., 2008. Ticks produce highly selective chemokine binding proteins with antiinflammatory activity. J. Exp. Med. 205, 2019-2031.

DeWoody, J.A., Abts, K.C., Fahey, A.L., Ji, Y., Kimble, S.J., Marra, N.J., Wijayawardena, B.K., Willoughby, J.R., 2013. Of contigs and quagmires: nextgeneration sequencing pitfalls associated with transcriptomic studies. Mol. Ecol. Resour. 13, 551-558. 
Díaz-Martín, V., Manzano-Román, R., Oleaga, A., Encinas-Grandes, A., PérezSánchez, R., 2013a. Cloning and characterization of a plasminogen-binding enolase from the saliva of the argasid tick Ornithodoros moubata. Vet. Parasitol. 191, 301214.

Díaz-Martín, V., Manzano-Román, R., Valero, L., Oleaga, A., Encinas-Grandes, A, Pérez-Sánchez, R., 2013b. An insight into the proteome of the saliva of the argasid tick Ornithodoros moubata reveals important differences in saliva protein composition between the sexes. J. Proteomics 80, 216-235.

Díaz-Martín, V., Manzano-Román, R., Oleaga, A., Pérez-Sánchez, R., 2015. New salivary anti-haemostatics containing protective epitopes from Ornithodoros moubata ticks: Assessment of their individual and combined vaccine efficacy. Vet. Parasitol. 212, 336-349.

Dobson, S.J., Barker, S.C., 1999. Phylogeny of the hard ticks (Ixodidae) inferred from $18 \mathrm{~S}$ rRNA indicates that the genus Aponomma is paraphyletic. Mol. Phylogenet. Evol. $11,288-295$.

Dobzhansky, T., 1973. Nothing in biology males sense except in the light of evolution. Am. Biol. Teach. 35, 125-129.

Donohue, K.V., Khalil, S.M., Sonenshine, D.E., Roe, R.M., 2009. Heme-binding storage proteins in the Chelicerata. J. Insect Physiol. 55, 287-296.

Donohue, K.V., Khalil, S.M., Ross, E., Grozinger, C.M., Sonenshine, D.E., Roe, M.R., 2010. Neuropeptide signaling sequences identified by pyrosequencing of the American dog tick synganglion transcriptome during blood feeding and reproduction. Insect Biochem. Mol. Biol. 40, 79-90.

Dunlop, J.A., Selden, P.A., 2009. Calibrating the chelicerate clock: a paleontological reply to Jeyaprakash and Hoy. Exp. Appl. Acarol. 48, 183-197.

Dunlop, J.A., 2010. Geological history and phylogeny of Chelicerata. Arthropod Struct. Dev. 39, 124-142.

Durden, L.A., Beati, L., 2014. Modern tick systematics, in: Sonenshine, D.E, Roe, R.M. (Eds.), Biology of Ticks, Volume 1, Second Edition. Oxford University Press, New York, pp. 17-58.

Edgecombe, G.D., 2010. Arthropod phylogeny: An overview from the perspectives of morphology, molecular data and the fossil record. Arth. Struct. Dev. 39, 74-87.

Edgecombe, G.D., Giribet, G., Dunn, C.W., Hejnol, A., Kristensen, R.M., Neves, R.C., Rouse, G.W., Worsaae, K. Sørensen, W.V., 2011. Higher-level metazoan relationships: recent progress and remaining questions. Org. Divers. Evol. 11, 151172. 
Edgecombe, G.D., Legg, D.A., 2014. Origins and early evolution of arthropods. Palaeontology 57, 457-468.

Egekwu, N., Sonenshine, D.E., Bissinger, B.W., Roe, R.M., 2014. Transcriptome of the female synganglion of the black-legged tick Ixodes scapularis (Acari: Ixodidae) with comparison between Illumina and 454 systems. PLoS One 9, e102667.

Egekwu, N., Sonenshine, D.E., Garman, H., Barshis, D.J., Cox, N., Bissinger, B.W., Zhu, J., Roe, M.R., 2016. Comparison of synganglion neuropeptides, neuropeptide receptors and neurotransmitter receptors and their gene expression in response to feeding in Ixodes scapularis (Ixodidae) vs. Ornithodoros turicata (Argasidae). Insect Mol. Biol. 25, 72-92.

Ehebauer, M.T., Mans, B.J., Gaspar, A.R., Neitz, A.W., 2002. Identification of extrinsic blood coagulation pathway inhibitors from the tick Ornithodoros savignyi (Acari: Argasidae). Exp. Parasitol. 101, 138-148.

Eichner, C., Øvergård, A.C., Nilsen, F., Dalvin, S., 2015. Molecular characterization and knock-down of salmon louse (Lepeophtheirus salmonis) prostaglandin E synthase. Exp. Parasitol. 159, 79-93.

El Shoura, S.M., 1990. Nuttalliella namaqua (Acarina: Ixodoidea: Nuttalliellidae) redescription of the female morphology in relation to the families Argasidae and Ixodidae. Acarologia 31, 349-355.

Eldredge, N., Gould, S.J., 1972. Punctuated equilibria: an alternative to phyletic gradualism, in: Schopf T.J., (Ed.), Models in paleobiology. Freeman, Cooper \& Co., San Francisco, pp. 82-115.

Estrada-Peña, A., Mangold, A.J., Nava, S., Venzal, J.M., Labruna, M., Guglielmone, A.A., 2010. A review of the systematics of the tick family Argasidae (Ixodida). Acarologia 50, 317-333.

Estrada-Peña, A., Venzal, J. M., Nava, S., Mangold, A., Guglielmone, A. A., Labruna, M. B. \& de la Fuente, J., 2012. Reinstatement of Rhipicephalus (Boophilus) australis (Acari: Ixodidae) with redescription of the adult and larval stages. J. Med. Entomol. 49, 794-802.

Farkaš, R., 2015. Apocrine secretion: New insights into an old phenomenon. Biochim. Biophys. Acta 1850, 1740-1750.

Fawcett, D.W., Doxsey, S., Büscher, G., 1981. Salivary gland of the tick vector $(R$. appendiculatus) of East Coast fever. II. Cellular basis for fluid secretion in the type III acinus. Tissue Cell. 13, 231-253.

Filimonova, S.A., Amosova, L.I., 2015. Peculiar salivary glands in a silk-producing mite Bakericheyla chanayi (Cheyletidae). J. Morphol. 276, 772-786.

Francischetti, I.M., Valenzuela, J.G., Andersen, J.F., Mather, T.N., Ribeiro, J.M., 2002. Ixolaris, a novel recombinant tissue factor pathway inhibitor (TFPI) from the 
salivary gland of the tick, Ixodes scapularis: identification of factor X and factor Xa as scaffolds for the inhibition of factor VIIa/tissue factor complex. Blood 99, 36023612 .

Francischetti, I.M., Mather, T.N., Ribeiro, J.M., 2003. Cloning of a salivary gland metalloprotease and characterization of gelatinase and fibrin(ogen)lytic activities in the saliva of the Lyme disease tick vector Ixodes scapularis. Biochem. Biophys. Res. Commun. 305, 869-875.

Francischetti, I.M., Mather, T.N., Ribeiro, J.M., 2004. Penthalaris, a novel recombinant five-Kunitz tissue factor pathway inhibitor (TFPI) from the salivary gland of the tick vector of Lyme disease, Ixodes scapularis. Thromb. Haemost. 91, 886-898.

Francischetti, I.M., My Pham, V., Mans, B.J., Andersen, J.F., Mather, T.N., Lane, R.S., Ribeiro, J.M., 2005. The transcriptome of the salivary glands of the female western black-legged tick Ixodes pacificus (Acari: Ixodidae). Insect Biochem. Mol. Biol. 35, 1142-1161.

Francischetti, I.M., Mans, B.J., Meng, Z., Gudderra, N., Veenstra, T.D., Pham, V.M., Ribeiro, J.M., 2008a. An insight into the sialome of the soft tick, Ornithodorus parkeri. Insect Biochem. Mol. Biol. 38, 1-21.

Francischetti, I.M., Meng, Z., Mans, B.J., Gudderra, N., Hall, M., Veenstra, T.D., Pham, V.M., Kotsyfakis, M., Ribeiro, J.M., 2008b. An insight into the salivary transcriptome and proteome of the soft tick and vector of epizootic bovine abortion, Ornithodoros coriaceus. J. Proteomics 71, 493-512.

Francischetti, I.M., Sa-Nunes, A., Mans, B.J., Santos, I.M., Ribeiro, J.M., 2009. The role of saliva in tick feeding. Front. Biosci. 14, 2051-2088.

Francischetti, I.M., Anderson, J.M., Manoukis, N., Pham, V.M., Ribeiro, J.M., 2011. An insight into the sialotranscriptome and proteome of the coarse bontlegged tick, Hyalomma marginatum rufipes. J. Proteomics. 74, 2892-2908.

Franta, Z., Frantová, H., Konvičková, J., Horn, M., Sojka, D., Mareš, M., Kopáček, P., 2010. Dynamics of digestive proteolytic system during blood feeding of the hard tick Ixodes ricinus. Parasit. Vectors 3, 119.

Frauenschuh, A., Power, C.A., Déruaz, M., Ferreira, B.R., Silva, J.S., Teixeira, M.M., Dias, J.M., Martin, T., Wells, T.N., Proudfoot, A.E., 2007. Molecular cloning and characterization of a highly selective chemokine-binding protein from the tick Rhipicephalus sanguineus. J. Biol. Chem. 282, 27250-27258.

Fry, B.G., Roelants, K., Champagne, D.E., Scheib, H., Tyndall, J.D., King, G.F., Nevalainen, T.J., Norman, J.A., Lewis, R.J., Norton, R.S., Renjifo, C., de la Vega, R.C., 2009. The toxicogenomic multiverse: convergent recruitment of proteins into animal venoms. Annu. Rev. Genomics Hum. Genet. 10, 483-511. 
Gabaldón, T., Koonin, E.V., 2013. Functional and evolutionary implications of gene orthology. Nat. Rev. Genet. 14, 360-366.

Garcia, G.R., Gardinassi, L.G., Ribeiro, J.M., Anatriello, E., Ferreira, B.R., Moreira, H.N., Mafra, C., Martins, M.M., Szabó, M.P., de Miranda-Santos, I.K., Maruyama, S.R., 2014. The sialotranscriptome of Amblyomma triste, Amblyomma parvum and Amblyomma cajennense ticks, uncovered by 454-based RNA-seq. Parasit Vectors 7, 430.

Garwood, R.J., Edgecombe, G.D., 2011. Early Terrestrial Animals, Evolution, and Uncertainty. Evo. Edu. Outreach 4, 489-501.

Garwood, R.J., Dunlop, J., 2014. Three-dimensional reconstruction and the phylogeny of extinct chelicerate orders. PeerJ. 2, e641.

Gaspar, A.R., Joubert, A.M., Crause, J.C., Neitz, A.W., 1996. Isolation and characterization of an anticoagulant from the salivary glands of the tick, Ornithodoros savignyi (Acari: Argasidae). Exp. Appl. Acarol. 20, 583-598.

Geer, L.Y., Marchler-Bauer, A., Geer, R.C., Han, L., He, J., He, S., Liu, C., Shi, W., Bryant, S.H., 2010. The NCBI BioSystems database. Nucleic Acids Res. 38: D492D496.

Gibson, A.K., Smith, Z., Fuqua, C., Clay, K., Colbourne, J.K., 2013. Why so many unknown genes? Partitioning orphans from a representative transcriptome of the lone star tick Amblyomma americanum. BMC Genomics 14, 135.

Gill, H.S., Walker, A.R., 1987. The salivary glands of Hyalomma anatolicum anatolicum: structural changes during attachment and feeding. Int. J. Parasitol. 17, 1381-1392.

Giribet, G., Edgecombe, G.D., Wheeler, W.C., Babbitt, C., 2002. Phylogeny and systematic position of Opiliones: a combined analysis of chelicerate relationships using morphological and molecular data. Cladistics 18, 5-70.

Giribet, G., Edgecombe, G.D., 2012. Reevaluating the arthropod tree of life. Annu. Rev. Entomol. 57, 167-186.

Gong, H., Zhou, J., Liao, M., Hatta, T., Harnnoi, T., Umemiya, R., Inoue, N., Xuan, X., Fujisaki, K., 2007. Characterization of a carboxypeptidase inhibitor from the tick Haemaphysalis longicornis. J. Insect Physiol. 53, 1079-1087.

Gould, S.J. (2002) The structure of evolutionary theory. Belknap, Cambridge.

Grunclová, L., Horn, M., Vancová, M., Sojka, D., Franta, Z., Mares, M., Kopácek, P., 2006. Two secreted cystatins of the soft tick Ornithodoros moubata: differential expression pattern and inhibitory specificity. Biol. Chem. 387, 1635-1644. 
Gu, X.B., Liu, G.H., Song, H.Q., Liu, T.Y., Yang, G.Y., Zhu, X.Q., 2014. The complete mitochondrial genome of the scab mite Psoroptes cuniculi (Arthropoda: Arachnida)provides insights into Acari phylogeny. Parasit. Vectors 7, 340.

Guerrero, F.D., Miller, R.J., Rousseau, M.E., Sunkara, S., Quackenbush, J., Lee, Y., Nene, V., 2005. BmiGI: a database of cDNAs expressed in Boophilus microplus, the tropical/southern cattle tick. Insect Biochem. Mol. Biol. 35, 585-595.

Guglielmone, A.A., Robbins, R.G., Apanaskevich, D.A., Petney, T.N., Estrada-Peña, A., Horak, I.G., Shao, R., Barker, S.C., 2010. The Argasidae, Ixodidae and Nuttalliellidae (Acari: Ixodida) of the world: a list of valid species names. Zootaxa 2528, 1-28.

Guo, X., Booth, C.J., Paley, M.A., Wang, X., DePonte, K., Fikrig, E., Narasimhan, S., Montgomery, R.R., 2009. Inhibition of neutrophil function by two tick salivary proteins. Infect. Immun. 77, 2320-2329.

Hackman, R.H., 1982. Structure and function in tick cuticle. Annu. Rev. Entomol. 27, 75-95.

Hackman, R.H., Filshie, B.K., 1982. The Tick Cuticle, in: Obenchain, F.D., Galun, R. (Eds.), Physiology of Ticks. Pergamon Press, Oxford, New York, Toronto, Sydney, Paris, Frankfurt, pp. 1-42.

Hansen, K., Varvas, K., Järving, I., Samel, N., 2014. Novel membrane-associated prostaglandin E synthase-2 from crustacean arthropods. Comp. Biochem. Physiol. B Biochem. Mol. Biol. 174, 45-52.

Heekin, A.M., Guerrero, F.D., Bendele, K.G., Saldivar, L., Scoles, G.A., Gondro, C., Nene, V., Djikeng, A., Brayton, K.A., 2012. Analysis of Babesia bovis infectioninduced gene expression changes in larvae from the cattle tick, Rhipicephalus (Boophilus) microplus. Parasit. Vectors 5, 162.

Heekin, A.M., Guerrero, F.D., Bendele, K.G., Saldivar, L., Scoles, G.A., Dowd, S.E., Gondro, C., Nene, V., Djikeng, A., Brayton, K.A., 2013a. Gut transcriptome of replete adult female cattle ticks, Rhipicephalus (Boophilus) microplus, feeding upon a Babesia bovis-infected bovine host. Parasitol. Res. 112, 3075-3090.

Heekin, A.M., Guerrero, F.D., Bendele, K.G., Saldivar, L., Scoles, G.A., Dowd, S.E., Gondro, C., Nene, V., Djikeng, A., Brayton, K.A., 2013b. The ovarian transcriptome of the cattle tick, Rhipicephalus (Boophilus) microplus, feeding upon a bovine host infected with Babesia bovis. Parasit. Vectors 6, 276.

Hellman, K., Hawkins, R.I., 1967. The action of tick extracts on blood coagulation and fibrinolysis. Thromb. Diathes. Haemorrh. 18, 617-625.

Hess, E., Vlimant, M., 1986. Leg sense organs of ticks, in: Sauer, J.R., Hair, J.A. (Eds.), Morphology, Physiology, and Behavioral Biology of Ticks. Ellis Horwood Lmtd., Chichester, pp. 361-390. 
Hoeppli, R., Feng, L.C., 1933. Experimental studies on ticks. Chin. Med. J. 47, 2943.

Hoffman, A., Walsmann, P., Riesner, G., Paintz, M., Markwardt, F., 1991. Isolation and characterization of a thrombin inhibitor from the tick Ixodes ricinus. Pharmazie 46, 209-212.

Hoogstraal, H., 1985. Argasid and Nuttalliellid ticks as parasites and vectors. Adv. Parasitol. 24, 135-238.

Horak, I.G., Lutermann, H., Medger, K., Apanaskevich, D.A., Matthee, C.A., 2012. Natural hosts of the larvae of Nuttalliella sp. (N. namaqua?) (Acari: Nuttalliellidae). Onderstepoort J. Vet. Res. 79, E1-2.

Horn, F., dos Santos, P.C., Termignoni, C., 2000. Boophilus microplus anticoagulant protein: an antithrombin inhibitor isolated from the cattle tick saliva. Arch. Biochem. Biophys. 384, 68-73.

Horn, M., Nussbaumerová, M., Sanda, M., Kovárová, Z., Srba, J., Franta, Z., Sojka, D., Bogyo, M., Caffrey, C.R., Kopácek, P., Mares, M., 2009. Hemoglobin digestion in blood-feeding ticks: mapping a multipeptidase pathway by functional proteomics. Chem. Biol. 16, 1053-1063.

Hosler, J.P., Ferguson-Miller, S., Mills, D.A., 2006. Energy transduction: proton transfer through the respiratory complexes. Annu. Rev. Biochem. 75, 165-187.

Howell, C.J., 1966. Collection of salivary gland secretion from the argasid Ornithodoros savignyi (Audouin) (1827) by the use of a pharmacological stimulant. J. S. Afr. Vet. Med. Assoc. 37, 236-239.

Hoy, M.A., Yu, F., Meyer, J.M., Tarazona, O.A., Jeyaprakash, A., Wu, K., 2013. Transcriptome sequencing and annotation of the predatory mite Metaseiulus occidentalis (Acari: Phytoseiidae): a cautionary tale about possible contamination by prey sequences. Exp. Appl. Acarol. 59, 283-296.

Ibrahim, M.A., Ghazy, A.H., Maharem, T., Khalil, M., 2001a. Isolation and properties of two forms of thrombin inhibitor from the nymphs of the camel tick Hyalomma dromedarii (Acari: Ixodidae). Exp. Appl. Acarol. 25, 675-698.

Ibrahim, M.A., Ghazy, A.H., Maharem, T.M., Khalil, M.I., 2001b. Factor Xa (FXa) inhibitor from the nymphs of the camel tick Hyalomma dromedarii. Comp. Biochem. Physiol. B Biochem. Mol. Biol. 130, 501-512.

Imamura, S., da Silva Vaz Junior, I., Sugino, M., Ohashi, K., Onuma, M., 2005. A serine protease inhibitor (serpin) from Haemaphysalis longicornis as an anti-tick vaccine. Vaccine 23, 1301-1311.

Iwanaga, S., Okada, M., Isawa, H., Morita, A., Yuda, M., Chinzei, Y., 2003. Identification and characterization of novel salivary thrombin inhibitors from the ixodidae tick, Haemaphysalis longicornis. Eur. J. Biochem. 270, 1926-1934. 
Iwanaga, S., Isawa, H., Yuda, M., 2014. Horizontal gene transfer of a vertebrate vasodilatory hormone into ticks. Nat. Commun. 5, 3373.

Jablonka, W., Kotsyfakis, M., Mizurini, D.M., Monteiro, R.Q., Lukszo, J., Drake, S.K., Ribeiro, J.M., Andersen, J.F., 2015. Identification and Mechanistic Analysis of a Novel Tick-Derived Inhibitor of Thrombin. PLoS One 10, e0133991.

Jarmey, J.M., Riding, G.A., Pearson, R.D., McKenna, R.V., Willadsen, P., 1995. Carboxydipeptidase from Boophilus microplus: a "concealed" antigen with similarity to angiotensin-converting enzyme. Insect Biochem. Mol. Biol. 25, 969-974.

Jaworski, D.C., Jasinskas, A., Metz, C.N., Bucala, R., Barbour, A.G., 2001. Identification and characterization of a homologue of the pro-inflammatory cytokine Macrophage Migration Inhibitory Factor in the tick, Amblyomma americanum. Insect Mol. Biol. 10, 323-331.

Jaworski, D.C., Zou, Z., Bowen, C.J., Wasala, N.B., Madden, R., Wang, Y., Kocan, K.M., Jiang, H., Dillwith, J.W., 2010. Pyrosequencing and characterization of immune response genes from the American dog tick, Dermacentor variabilis (L.). Insect Mol. Biol. 19, 617-630.

Jeffers, L.A., Roe, R.M., 2008. The movement of proteins across the insect and tick digestive system. J. Insect Phys. 54, 319-332.

Jeyaprakash, A., Hoy, M.A., 2009a. The nuclear genome of the phytoseiid Metaseiulus occidentalis (Acari: Phytoseiidae) is among the smallest known in arthropods. Exp. Appl. Acarol. 47, 263-273.

Jeyaprakash, A., Hoy, M.A., 2009b. First divergence time estimate of spiders, scorpions, mites and ticks (subphylum: Chelicerata) inferred from mitochondrial phylogeny. Exp. Appl. Acarol. 47, 1-18.

Joubert, A.M., Crause, J.C., Gaspar, A.R., Clarke, F.C., Spickett, A.M., Neitz, A.W., 1995. Isolation and characterization of an anticoagulant present in the salivary glands of the bont-legged tick, Hyalomma truncatum. Exp. Appl. Acarol. 19, 79-92.

Joubert, A.M., Louw, A.I., Joubert, F., Neitz, A.W., 1998. Cloning, nucleotide sequence and expression of the gene encoding factor Xa inhibitor from the salivary glands of the tick, Ornithodoros savignyi. Exp. Appl. Acarol. 22, 603-619.

Jupp, P.G., Joubert, J.J., Cornel, A.J., Swanevelder, C., Prozesky, O.W., 1987. An experimental assessment of the tampan tick Ornithodoros moubata as vector of hepatitis B virus. Med. Vet. Entomol. 1, 361-368.

Karczewski, J., Endris, R., Connolly, T.M., 1994. Disagregin is a fibrinogen receptor antagonist lacking the Arg-Gly-Asp sequence from the tick, Ornithodoros moubata. J. Biol. Chem. 269, 6702-6708. 
Karczewski, J., Waxman, L., Endris, R.G., Connolly, T.M., 1995. An inhibitor from the argasid tick Ornithodoros moubata of cell adhesion to collagen. Biochem. Biophys. Res. Commun. 208, 532-541.

Karim, S., Singh, P., Ribeiro, J.M., 2011. A deep insight into the sialotranscriptome of the gulf coast tick, Amblyomma maculatum. PLoS One 6, e28525.

Karim, S., Ribeiro, J.M., 2015. An Insight into the Sialome of the Lone Star Tick, Amblyomma americanum, with a Glimpse on Its Time Dependent Gene Expression. PLoS One 10, e0131292.

Kato, N., Iwanaga, S., Okayama, T., Isawa, H., Yuda, M., Chinzei, Y., 2005. Identification and characterization of the plasma kallikrein-kinin system inhibitor, haemaphysalin, from hard tick, Haemaphysalis longicornis. Thromb. Haemost. 93, 359-367.

Kaufman, W.R., 1977. The influence of adrenergic agonists and their antagonists on isolated salivary glands of ixodid ticks. Eur. J. Pharmacol. 45, 61-68.

Kaufman, W.R., 1978. Actions of some transmitters and their antagonists on salivary secretion in a tick. Am. J. Physiol. 235, R76-R81.

Kaufmann, W.R., 2014. Integument and Ecdysis, in: Sonenshine, D.E, Roe, R.M. (Eds.), Biology of Ticks, Volume 1, Second Edition. Oxford University Press, New York, pp. 99-121.

Kazimírová, M., Jancinová, V., Petríková, M., Takác, P., Labuda, M., Nosál', R. 2002. An inhibitor of thrombin-stimulated blood platelet aggregation from the salivary glands of the hard tick Amblyomma variegatum (Acari: Ixodidae). Exp. Appl. Acarol. 28, 97-105.

Keirans, J.E., Clifford, C.M., 1975. Nothoaspis reddelli, new genus and new species (Ixodoidea: Argasidae), from bat cave in Mexico. Ann. Entomol. Soc. Am. 68, 81-85.

Keirans, J.E., Clifford, C.M., Hoogstraal, H., Easton, E.R., 1976. Discovery of Nuttalliella namaqua Bedford (Acarina: Ixodoidea: Nuttalliellidae) in Tanzania and redescription of the female based on scanning electron microscopy. Ann. Entomol. Soc. Amer 69, 926-932.

Keller, P.M., Waxman, L., Arnold, B.A., Schultz, L.D., Condra, C., Connolly, T.M., 1993. Cloning of the cDNA and expression of moubatin, an inhibitor of platelet aggregation. J. Biol. Chem. 268, 5450-5456.

Kemp, D.H., Stone, B.F., Binnington, K.C., 1982. Tick attachment and feeding: Role of the mouthparts, feeding apparatus, salivary gland secretions, and the host response, in: Obenchain, F.D., Galun, R. (Eds.), Physiology of Ticks. Pergamon Press, Oxford, New York, Toronto, Sydney, Paris, Frankfurt, pp. 119-167.

Kim, T.K., Tirloni, L., Radulovic, Z., Lewis, L., Bakshi, M., Hill, C., da Silva Vaz, I. Jr., Logullo, C., Termignoni, C., Mulenga, A., 2015. Conserved Amblyomma 
americanum tick Serpin19, an inhibitor of blood clotting factors Xa and XIa, trypsin and plasmin, has anti-haemostatic functions. Int. J. Parasitol. 45, 613-627.

Klok, C.J., Mercer, R.D., Chown, S.L., 2002. Discontinuous gas-exchange in centipedes and its convergent evolution in tracheated arthropods. J. Exp. Biol. 205, 1019-1029.

Klompen, J.S.H., Oliver, J.H., 1993. Systematic relationships in the soft ticks (Acari: Ixodida: Argasidae). Sys. Entomol. 18, 313-331.

Klompen, J.S., Black, W.C. 4th, Keirans, J.E., Oliver, J.H. Jr., 1996a. Evolution of ticks. Annu. Rev. Entomol. 41, 141-161.

Klompen, H., Keirans, J.E., Filippova, N.A., Oliver, J.H. Jr., 1996b. Idiosomal lyrifissures, setae, and small glands as taxonomic characters and potential indicators of ancestral segmentation patterns in larval Ixodidae (Acari: Ixodida). Int. J. Acarol. $22,113-134$.

Klompen, J.S.H., Oliver, J.H., Jr., Keirans, J.E., Homsher, P.J., 1997. A re-evaluation of relationships in the Metastriata (Acari: Parasitiformes: Ixodidae). Syst. Parasitol. $38,1-24$.

Klompen, H., 2000. A preliminary assessment of the utility of elongation factor1alpha in elucidating relationships among basal Mesostigmata. Exp. Appl. Acarol. 24, 805-820.

Klompen H., Dobson, S.J., Barker, S.C., 2002. A new subfamily, Bothriocrotoninae n. subfam., for the genus Bothriocroton Keirans, King \& Sharrad, 1994 status amend. (Ixodida: Ixodidae), and the synonymy of Aponomma Neumann, 1899 with Amblyomma Koch, 1844. Syst. Parasitol. 53: 101-117.

Klompen, H., Lekveishvili, M., Black, W.C. 4th., 2007. Phylogeny of parasitiform mites (Acari) based on rRNA. Mol. Phylogenet. Evol. 43, 936-951.

Klompen, H., 2010. Holothyrids and ticks: New insights from larval morphology and DNA sequencing, with the description of a new species of diplothyrus (parasitiformes: Neothyridae). Acarologia 50, 269-285.

Klompen, H., Vázquez, M.M., Bernardi, L.F., 2015. Post-embryonic development in the mite suborder Opilioacarida, with notes on segmental homology in Parasitiformes (Arachnida). Exp. Appl. Acarol. 67, 183-207.

Koh, C.Y., Kazimirova, M., Trimnell, A., Takac, P., Labuda, M., Nuttall, P.A., Kini, R.M., 2007. Variegin, a novel fast and tight binding thrombin inhibitor from the tropical bont tick. J. Biol. Chem. 282, 29101-29113.

Koonin, E.V., Fedorova, N.D., Jackson, J.D., Jacobs, A.R., Krylov, D.M., Makarova, K.S., Mazumder, R., Mekhedov, S.L., Nikolskaya, A.N., Rao, B.S., Rogozin, I.B., Smirnov, S., Sorokin, A.V., Sverdlov, A.V., Vasudevan, S., Wolf, Y.I., Yin, J.J., 
Natale, D.A., 2004. A comprehensive evolutionary classification of proteins encoded in complete eukaryotic genomes. Genome Biol. 5, R7.

Koonin, E.V., 2015. Origin of eukaryotes from within archaea, archaeal eukaryome and bursts of gene gain: eukaryogenesis just made easier? Philos. Trans. R. Soc. Lond. B Biol. Sci. 370, 20140333.

Kořený, L., Oborník, M., Lukeš, J., 2013. Make it, take it, or leave it: heme metabolism of parasites. PLoS Pathog. 9, e1003088.

Kotsyfakis, M., Sá-Nunes, A., Francischetti, I.M., Mather, T.N., Andersen, J.F., Ribeiro, J.M., 2006. Antiinflammatory and immunosuppressive activity of sialostatin L, a salivary cystatin from the tick Ixodes scapularis. J. Biol. Chem. 281, 2629826307.

Kotsyfakis, M., Karim, S., Andersen, J.F., Mather, T.N., Ribeiro, J.M., 2007. Selective cysteine protease inhibition contributes to blood-feeding success of the tick Ixodes scapularis. J. Biol. Chem. 282, 29256-29263.

Kotsyfakis, M., Schwarz, A., Erhart, J., Ribeiro, J.M., 2015a. Tissue- and timedependent transcription in Ixodes ricinus salivary glands and midguts when blood feeding on the vertebrate host. Sci Rep. 5, 9103.

Kotsyfakis, M., Kopáček, P., Franta, Z., Pedra, J.H., Ribeiro, J.M., 2015b. Deep Sequencing Analysis of the Ixodes ricinus Haemocytome. PLoS Negl. Trop. Dis. 9, e0003754.

Labruna, M.B., Naranjo, V., Mangold, A.J., Thompson, C., Estrada-Peña, A., Guglielmone, A.A., Jongejan, F., de la Fuente, J., 2009. Allopatric speciation in ticks: genetic and reproductive divergence between geographic strains of Rhipicephalus (Boophilus) microplus. BMC Evol. Biol. 9: 46.

Lai, R., Takeuchi, H., Jonczy, J., Rees, H.H., Turner, P.C., 2004. A thrombin inhibitor from the ixodid tick, Amblyomma hebraeum. Gene 342, 243-149.

Lara, F.A., Lins, U., Paiva-Silva, G., Almeida, I.C., Braga, C.M., Miguens, F.C., Oliveira, P.L., Dansa-Petretski, M., 2003. A new intracellular pathway of haem detoxification in the midgut of the cattle tick Boophilus microplus: aggregation inside a specialized organelle, the hemosome. J. Exp. Biol. 206, 1707-1715.

Lara, F.A., Lins, U., Bechara, G.H., Oliveira, P.L., 2005. Tracing heme in a living cell: hemoglobin degradation and heme traffic in digest cells of the cattle tick Boophilus microplus. J. Exp. Biol. 208, 3093-3101.

Latif, A.A., Putterill, J.F., de Klerk, D.G., Pienaar, R., Mans, B.J., 2012. Nuttalliella namaqua (Ixodoidea: Nuttalliellidae): first description of the male, immature stages and re-description of the female. PLoS One 7, e41651. 
Lavoipierre, M.M., Riek, R.F., 1955. Observations on the feeding habits of argasid ticks and on the effect of their bites on laboratory animals, together with a note on the production of coxal fluid by several of the species studies. Ann. Trop. Med. Parasitol. 49, 96-113.

Lees, A.D., 1946. Chloride regulation and the function of the coxal glands in ticks. Parasitol. 37, 172-184.

Legg, D.A., Sutton, M.D., Edgecombe GD., 2013. Arthropod fossil data increase congruence of morphological and molecular phylogenies. Nat. Commun. 4, 2485.

Lehtinen, P.T., 1991. Phylogeny and zoogeography of the Holothyrida, in: Dusabek, F., Bukva, V. (Eds.), Modern Acarology, Volume 2. SPB Academic Publishers, The Hague, pp. 101-113.

Liao, M., Zhou, J., Gong, H., Boldbaatar, D., Shirafuji, R., Battur, B., Nishikawa, Y., Fujisaki, K., 2009. Hemalin, a thrombin inhibitor isolated from a midgut cDNA library from the hard tick Haemaphysalis longicornis. J. Insect Physiol. 55, 164-173.

Liberles, D.A., 2007. Ancestral Sequence Reconstruction. Oxford University Press, New York.

Limo, M.K., Voigt, W.P., Tumbo-Oeri, A.G., Njogu, R.M., ole-MoiYoi, O.K., 1991. Purification and characterization of an anticoagulant from the salivary glands of the ixodid tick Rhipicephalus appendiculatus. Exp. Parasitol. 72, 418-429.

Lindquist, E.E., Krantz, G.W., Walter, D.E., 2009. Classification, in: Krantz, G.W., Walter, D.E. (Eds.), A Manual of Acarology, Third Edition. Texas Tech University Press, Lubbock, pp. 97-103.

Loesel, R., Wolf, H., Kenning, M., Harzsch, S., Sombke, A., 2013. Architectural principles and evolution of the arthropod central nervous system. in: Minelli, A., Boxhall, G., Fusco, G. (Eds.), Arthropod Biology and Evolution: Molecules, Development, Morphology. Spinger, Heidelberg, New York, Dordrecht, London, pp. 299-342.

Louw, E., van der Merwe, N.A., Neitz, A.W., Maritz-Olivier, C., 2013. Evolution of the tissue factor pathway inhibitor-like Kunitz domain-containing protein family in Rhipicephalus microplus. Int. J. Parasitol. 43, 81-94.

Macedo-Ribeiro, S., Almeida, C., Calisto, B.M., Friedrich, T., Mentele, R., Stürzebecher, J., Fuentes-Prior, P., Pereira, P.J., 2008. Isolation, cloning and structural characterisation of boophilin, a multifunctional Kunitz-type proteinase inhibitor from the cattle tick. PLoS One 3, e1624.

Mans, B.J., Gaspar, A.R., Louw, A.I., Neitz, A.W., 1998a. Apyrase activity and platelet aggregation inhibitors in the tick Ornithodoros savignyi (Acari: Argasidae). Exp. Appl. Acarol. 22, 353-366. 
Mans, B.J., Gasper, A.R., Louw, A.I., Neitz, A.W., 1998b. Purification and characterization of apyrase from the tick, Ornithodoros savignyi. Comp. Biochem. Physiol. B Biochem. Mol. Biol. 120, 617-624.

Mans, B.J., 2002. Functional perspectives on the evolution of argasid tick salivary gland protein superfamilies. PhD thesis, University of Pretoria, Pretoria, South Africa.

Mans, B.J., Louw, A.I., Neitz, A.W., 2002a. Evolution of hematophagy in ticks: common origins for blood coagulation and platelet aggregation inhibitors from soft ticks of the genus Ornithodoros. Mol. Biol. Evol. 19, 1695-1705.

Mans, B.J., Louw, A.I., Neitz, A.W., 2002b. Savignygrin, a platelet aggregation inhibitor from the soft tick Ornithodoros savignyi, presents the RGD integrin recognition motif on the Kunitz-BPTI fold. J. Biol. Chem. 277, 21371-21378.

Mans, B.J., Louw, A.I., Neitz, A.W., 2002c. Amino acid sequence and structure modeling of savignin, a thrombin inhibitor from the tick, Ornithodoros savignyi. Insect Biochem. Mol. Biol. 32, 821-828.

Mans, B.J., Louw, A.I., Neitz, A.W., 2003a. The major tick salivary gland proteins and toxins from the soft tick, Ornithodoros savignyi, are part of the tick Lipocalin family: implications for the origins of tick toxicoses. Mol. Biol. Evol. 20, 1158-1167.

Mans, B.J., Louw, A.I., Neitz, A.W., 2003b. The influence of tick behavior, biotope and host specificity on concerted evolution of the platelet aggregation inhibitor savignygrin, from the soft tick Ornithodoros savignyi. Insect Biochem. Mol. Biol. 33, 623-629.

Mans, B.J., Neitz, A.W., 2004a. Adaptation of ticks to a blood-feeding environment: evolution from a functional perspective. Insect Biochem. Mol. Biol. 34, 1-17.

Mans, B.J., Neitz, A.W., 2004b. The mechanism of alphaIIbbeta3 antagonism by savignygrin and its implications for the evolution of anti-hemostatic strategies in soft ticks. Insect Biochem. Mol. Biol. 34, 573-584.

Mans, B.J., Neitz, A.W., 2004c. Exon-intron structure of outlier tick lipocalins indicate a monophyletic origin within the larger lipocalin family. Insect Biochem. Mol. Biol. 34: 585-594.

Mans, B.J., Gothe, R., Neitz, A.W., 2004. Biochemical perspectives on paralysis and other forms of toxicoses caused by ticks. Parasitol. 129, S95-S111.

Mans, B.J., 2005. Tick histamine-binding proteins and related lipocalins: potential as therapeutic agents. Curr. Opin. Investig. Drugs 6, 1131-1135.

Mans, B.J., Andersen, J.F., Schwan, T.G., Ribeiro, J.M., 2008a. Characterization of anti-hemostatic factors in the argasid, Argas monolakensis: implications for the evolution of blood-feeding in the soft tick family. Insect Biochem. Mol. Biol. 38, 2241. 
Mans, B.J., Andersen, J.F., Francischetti, I.M., Valenzuela, J.G., Schwan, T.G., Pham, V.M., Garfield, M.K., Hammer, C.H., Ribeiro, J.M., 2008b. Comparative sialomics between hard and soft ticks: implications for the evolution of blood-feeding behavior. Insect Biochem. Mol. Biol. 38, 42-58.

Mans, B.J., Ribeiro, J.M., Andersen, J.F., 2008c. Structure, function, and evolution of biogenic amine-binding proteins in soft ticks. J. Biol. Chem. 283, 18721-18733.

Mans, B.J., Ribeiro, J.M., 2008a. A novel clade of cysteinyl leukotriene scavengers in soft ticks. Insect Biochem. Mol. Biol. 38, 862-870.

Mans, B.J., Ribeiro, J.M., 2008b. Function, mechanism and evolution of the moubatin-clade of soft tick lipocalins. Insect Biochem. Mol. Biol. 38, 841-852.

Mans, B.J., 2011. Evolution of vertebrate hemostatic and inflammatory control mechanisms in blood-feeding arthropods. J. Innate Immun. 3, 41-51.

Mans, B.J., de Klerk, D., Pienaar, R., Latif, A.A., 2011. Nuttalliella namaqua: a living fossil and closest relative to the ancestral tick lineage: implications for the evolution of blood-feeding in ticks. PLoS One 6, e23675.

Mans, B.J., de Klerk, D., Pienaar, R., de Castro, M.H., Latif, A.A., 2012. The mitochondrial genomes of Nuttalliella namaqua (Ixodoidea: Nuttalliellidae) and Argas africolumbae (Ixodoidae: Argasidae): estimation of divergence dates for the major tick lineages and reconstruction of ancestral blood-feeding characters. PLoS One 7, e49461.

Mans, B.J., de Klerk, D.G., Pienaar, R., Latif, A.A., 2014. The host preferences of Nuttalliella namaqua (Ixodoidea: Nuttalliellidae): a generalist approach to surviving multiple host-switches. Exp. Appl. Acarol. 62, 233-240.

Mans, B.J., 2014. Heme processing and the evolution of hematophagy, in: Sonenshine, D.E, Roe, R.M. (Eds.), Biology of Ticks, Volume 1, Second Edition. Oxford University Press, New York, pp. 220-239.

Mans, B.J., de Klerk, D., Pienaar, R., de Castro, M.H., Latif, A.A., 2015. Nextgeneration sequencing as means to retrieve tick systematic markers, with the focus on Nuttalliella namaqua (Ixodoidea: Nuttalliellidae). Ticks Tick Borne Dis. 6, 450-462.

Maritz-Olivier, C., Louw, A.I., Neitz, A.W., 2005. Similar mechanisms regulate protein exocytosis from the salivary glands of ixodid and argasid ticks. J. Insect Physiol. 51, 1390-1396.

Martin, J.A., Wang, Z., 2011. Next-generation transcriptome assembly. Nat. Rev. Genet. 12, 671-682.

Mathers, T.C., Hammond, R.L., Jenner, R.A., Hänfling, B., Gómez, A., 2013. Multiple global radiations in tadpole shrimps challenge the concept of 'living fossils'. PeerJ 1, e62. 
Maya-Monteiro, C.M., Daffre, S., Logullo, C., Lara, F.A., Alves, E.W., Capurro, M.L., Zingali, R., Almeida, I.C., Oliveira, P.L., 2000. HeLp, a heme lipoprotein from the hemolymph of the cattle tick, Boophilus microplus. J. Biol. Chem. 275, 3658436589.

McLoughlin, S., 2001. The breakup history of Gondwana and its impact on preCenozoic floristic provincialism. Aust. J. Bot. 49, 271-300.

Meredith, J., Kaufman, W.R., 1973. A proposed site of fluid secretion in the salivary gland of the ixodid tick Dermacentor andersoni. Parasitol. 67, 205-217.

Moorhouse, D.E., 1975. Studies on the feeding of larval Argas persicus Oken. Z. Parasitenk. 48, 65-71.

Motoyashiki, T., Tu, A.T., Azimov, D.A., Ibragim, K., 2003. Isolation of anticoagulant from the venom of tick, Boophilus calcaratus, from Uzbekistan. Thromb. Res. 110, 235-241.

Mudenda, L., Pierlé, S.A., Turse, J.E., Scoles, G.A., Purvine, S.O., Nicora, C.D., Clauss, T.R., Ueti, M.W., Brown, W.C., Brayton, K.A., 2014. Proteomics informed by transcriptomics identifies novel secreted proteins in Dermacentor andersoni saliva. Int. J. Parasitol. 44, 1029-1037.

Mulenga, A., Macaluso, K.R., Simser, J.A., Azad, A.F., 2003. The American dog tick, Dermacentor variabilis, encodes a functional histamine release factor homolog. Insect Biochem. Mol. Biol. 33, 911-919.

Mulenga, A., Kim, T., Ibelli, A.M., 2013. Amblyomma americanum tick saliva serine protease inhibitor 6 is a cross-class inhibitor of serine proteases and papain-like cysteine proteases that delays plasma clotting and inhibits platelet aggregation. Insect Mol. Biol. 22, 306-319.

Murrell, A., Dobson, S.J., Walter, D.E., Campbell, N.J.H., Shao, R., Barker, S.C., 2005. Relationships among the three major lineages of the Acari (Arthropoda: Arachnida) inferred from small subunit rRNA: paraphyly of the parasitiformes with respect to the opilioacariformes and relative rates of nucleotide substitution. Invert. Syst. 19, 383-389.

Nakajima, C., Imamura, S., Konnai, S., Yamada, S., Nishikado, H., Ohashi, K., Onuma, M., 2006. A novel gene encoding a thrombin inhibitory protein in a cDNA library from Haemaphysalis longicornis salivary gland. J. Vet. Med. Sci. 68, 447-452.

Narasimhan, S., Koski, R.A., Beaulieu, B., Anderson, J.F., Ramamoorthi, N., Kantor, F., Cappello, M., Fikrig, E., 2002. A novel family of anticoagulants from the saliva of Ixodes scapularis. Insect Mol. Biol. 11, 641-650.

Narasimhan, S., Perez, O., Mootien, S., DePonte, K., Koski, R.A., Fikrig, E., Ledizet, M., 2013. Characterization of Ixophilin, a thrombin inhibitor from the gut of Ixodes scapularis. PLoS One 8, e68012. 
Nava, S., Guglielmone, A.A., Mangold, A.J., 2009. An overview of systematics and evolution of ticks. Front. Biosci. 14, 2857-2877.

Needham, G.R., Teel, P.D., 1986. Water balance by ticks between blood meals, in: (Sauer, J.R., Hair, J.A. (Eds.), Morphology, Physiology and Behavioral Biology of Ticks ). Ellis Horwood, Chichester, pp. 100-151.

Needham, G.R., Rosell, R., Greenwald, L., 1990. Ultrastructure of type-I salivarygland acini in four species of ticks and the influence of hydration states on the type-I acini of Amblyomma americanum. Exp. Appl. Acarol. 10, 83-104.

Neitz, A.W.H., Howell, C.J., Potgieter, D.J.J., 1969. Purification of the toxic component in the oral secretion of the sand tampan Ornithodoros savignyi (Audouin) (1827). J. S. Afr. Chem. Ind. 22, 142-149.

Neitz, A.W.H., 1976. Biochemical investigation into the toxic salivary secretion of the tick Ornithodoros savignyi. D.Sc. thesis, University of Pretoria.

Neitz, A.W., Howell, C.J., Potgieter, D.J., Bezuidenhout, J.D., 1978. Proteins and free amino acids in the salivary secretion and haemolymph of the tick Amblyomma hebraeum. Onderstepoort J. Vet. Res. 45, 235-240.

Neitz A.W.H., Bezuidenhout J.D., Vermeulen N.M.J., Potgieter D.J.J., Howell C.J., 1983. In search of the causal agents of tick toxicoses. Toxicon S3, 317-320.

Nene, V., Lee, D., Quackenbush, J., Skilton, R., Mwaura, S., Gardner, M.J., Bishop, R., 2002. AvGI, an index of genes transcribed in the salivary glands of the ixodid tick Amblyomma variegatum. Int. J. Parasitol. 32, 1447-1456.

Nene, V., Lee, D, Kang'a, S., Skilton, R., Shah, T., de Villiers, E., Mwaura, S., Taylor, D., Quackenbush, J., Bishop, R., 2004. Genes transcribed in the salivary glands of female Rhipicephalus appendiculatus ticks infected with Theileria parva. Insect Biochem. Mol. Biol. 34, 1117-11128.

Neupert, S., Russell, W.K., Predel, R., Russell, D.H., Strey, O.F., Teel, P.D., Nachman, R.J., 2009. The neuropeptidomics of Ixodes scapularis synganglion. J. Proteomics 72, 1040-1045.

Nienaber, J., Gaspar, A.R., Neitz, A.W., 1999. Savignin, a potent thrombin inhibitor isolated from the salivary glands of the tick Ornithodoros savignyi (Acari: Argasidae). Exp. Parasitol. 93, 82-91.

Nijhout, H.F., 2013. Arthopod developmental endocrinology, in: Minelli, A., Boxhall, G., Fusco, G. (Eds.), Arthopod Biology and Evolution. Springer, Heidelberg, New York, Dortrecht, London. pp. 123-148.

Nisbet, A.J., Billingsley, P.F., 2000. A comparative survey of the hydrolytic enzymes of ectoparasitic and free-living mites. Int. J. Parasitol. 30, 19-27. 
Nunn, M.A., Sharma, A., Paesen, G.C., Adamson, S., Lissina, O., Willis, A.C., Nuttall, P.A., 2005. Complement inhibitor of C5 activation from the soft tick Ornithodoros moubata. J. Immunol. 174, 2084-2091.

Nuttall, G.H.F., Strickland, C., 1908. On the presence of an anticoagulin in the salivary glands and intestines of Argas persicus. Parasitol. 1, 302-310.

Nuttall, G.H.F., 1911. On the adaptation of ticks to the habits of their hosts. Parasitol. 4, 46-67.

Ogata, H., Goto, S., Sato, K., Fujibuchi, W., Bono, H., Kanehisa, M., 1999. KEGG: Kyoto Encyclopedia of Genes and Genomes. Nucleic Acids Res. 27, 29-34.

Oleaga, A., Escudero-Población, A., Camafeita, E., Pérez-Sánchez, R., 2007. A proteomic approach to the identification of salivary proteins from the argasid ticks Ornithodoros moubata and Ornithodoros erraticus. Insect Biochem. Mol. Biol. 37, 1149-1159.

Oleaga, A., Obolo-Mvoulouga, P., Manzano-Román, R., Pérez-Sánchez, R., 2015. Midgut proteome of an argasid tick, Ornithodoros erraticus: a comparison between unfed and engorged females. Parasit. Vectors 8, 525.

Oliveira, C.J., Sa-Nunes, A., Francischetti, I.M., Carregaro, V., Anatriello, E., Silva, J.S., Santos, I.K., Ribeiro, J.M., Ferreira, B.R., 2011. Deconstructing tick saliva: nonprotein molecules with potent immunomodulatory properties. J. Biol. Chem. 286, 10960-10969.

Oliveira, C.J., Anatriello, E., de Miranda-Santos, I.K., Francischetti, I.M., Sá-Nunes, A., Ferreira, B.R., Ribeiro, J.M., 2013. Proteome of Rhipicephalus sanguineus tick saliva induced by the secretagogues pilocarpine and dopamine. Ticks Tick Borne Dis. 4, 469-477.

Oliver, J.H., 1989. Biology and systematics of ticks (Acari: Ixodida). Ann. Rev. Ecol. Syst. 20, 397-430.

Ovchinnikov, S., Masta, S.E., 2012. Pseudoscorpion mitochondria show rearranged genes and genome-wide reductions of RNA gene sizes and inferred structures, yet typical nucleotide composition bias. BMC Evol. Biol. 12, 31.

Paesen, G.C., Adams, P.L., Harlos, K., Nuttall, P.A., Stuart, D.I., 1999. Tick histamine-binding proteins: isolation, cloning, and three-dimensional structure. Mol. Cell 3, 661-671.

Paesen, G.C., Siebold, C., Harlos, K., Peacey, M.F., Nuttall, P.A., Stuart, D.I., 2007. A tick protein with a modified Kunitz fold inhibits human tryptase. J. Mol. Biol. 368, 1172-1186.

Paesen, G.C., Siebold, C., Dallas, M.L., Peers, C., Harlos, K., Nuttall, P.A., Nunn, M.A., Stuart, D.I., Esnouf, R.M., 2009. An ion-channel modulator from the saliva of 
the brown ear tick has a highly modified Kunitz/BPTI structure. J. Mol. Biol. 389, 734-747.

Palopoli, M.F., Minot, S., Pei, D., Satterly, A., Endrizzi, J., 2014. Complete mitochondrial genomes of the human follicle mites Demodex brevis and $D$. folliculorum: novel gene arrangement, truncated tRNA genes, and ancient divergence between species. BMC Genomics 15, 1124.

Panek, H., O'Brian, M.R., 2002. A whole genome view of prokaryotic haem biosynthesis. Microbiol. 148, 2273-2282.

Penny, D., Collins, L.J., Daly, T.K., Cox, S.J., 2014. The Relative Ages of Eukaryotes and Akaryotes. J. Mol. Evol. 79, 228-239.

Pepato, A.R., da Rocha, C.E., Dunlop, J.A., 2010. Phylogenetic position of the acariform mites: sensitivity to homology assessment under total evidence. BMC Evol. Biol. 10, 235.

Philippe, H., Derelle, R., Lopez, P., Pick, K., Borchiellini, C., Boury-Esnault, N., Vacelet, J., Renard, E., Houliston, E., Quéinnec, E., Da Silva, C., Wincker, P., Le Guyader, H., Leys, S., Jackson, D.J., Schreiber, F., Erpenbeck, D., Morgenstern, B., Wörheide, G., Manuel, M., 2009. Phylogenomics revives traditional views on deep animal relationships. Curr. Biol. 19, 706-712.

Pisani, D., Carton, R., Campbell, L.I., Akanni, W.A., Mulville, E., Rota-Stabelli, O., 2013. An overview of arthropod genomics, mitogenomics, and the evolutionary origins of the arthropod proteome, in: Minelli, A., Boxhall, G., Fusco, G. (Eds.), Arthopod Biology and Evolution. Springer, Heidelberg, New York, Dortrecht, London. pp. 41-62.

Preston, S.G., Majtán, J., Kouremenou, C., Rysnik, O., Burger, L.F., Cabezas Cruz, A., Chiong Guzman, M., Nunn, M.A., Paesen, G.C., Nuttall, P.A., Austyn, J.M., 2013. Novel immunomodulators from hard ticks selectively reprogramme human dendritic cell responses. PLoS Pathog. 9, e1003450.

Prevot, P.P., Adam, B., Boudjeltia, K.Z., Brossard, M., Lins, L., Cauchie, P., Brasseur, R., Vanhaeverbeek, M., Vanhamme, L., Godfroid, E., 2006. Antihemostatic effects of a serpin from the saliva of the tick Ixodes ricinus. J. Biol. Chem. 281, 26361-26369.

Pugh, P.J.A., 1997. Spiracle structure in ticks (Ixodida: Anactinotrichida: Arachnida): Resume, taxonomic and functional significance. Biol. Rev. 72, 549-564.

Radovsky, F.J., 1969. Adaptive radiation in the parasitic mesostigmata. Acarologia $11,450-483$.

Regier, J.C., Shultz, J.W., Zwick, A., Hussey, A., Ball, B., Wetzer, R., Martin, J.W., Cunningham, C.W., 2010. Arthropod relationships revealed by phylogenomic analysis of nuclear protein-coding sequences. Nature 463, 1079-1083. 
Ribeiro J.M.C., Makoul G., Levine J., Robinson D., Spielman A., 1985. Antihemostatic, autoinflammatory and immunosuppressive properties of the saliva of a tick Ixodes dammini. J. Exp. Med. 161, 332-344.

Ribeiro, J.M.C., Spielman, A., 1986. Ixodes dammini: Salivary anaphylatoxin inactivating activity. Exp. Parasitol. 62, 292-297.

Ribeiro, J.M.C., 1987. Ixodes dammini: Salivary anti-complement activity. Exp. Parasitol. 64, 347-353.

Ribeiro, J.M., Mather, T.N., 1998. Ixodes scapularis: salivary kininase activity is a metallo dipeptidyl carboxypeptidase. Exp. Parasitol. 89, 213-221.

Ribeiro J.M.C., Endris T.M., Endris R., 1991. Saliva of the soft tick Ornithodoros moubata, contains anti-platelet and apyrase activity. Comp. Biochem. Physiol. 100, 109-112.

Ribeiro, J.M., Francischetti, I.M., 2003. Role of arthropod saliva in blood feeding: sialome and post-sialome perspectives. Annu. Rev. Entomol. 48, 73-88.

Ribeiro, J.M., Alarcon-Chaidez, F., Francischetti, I.M., Mans, B.J., Mather, T.N., Valenzuela, J.G., Wikel, S.K., 2006. An annotated catalog of salivary gland transcripts from Ixodes scapularis ticks. Insect Biochem. Mol. Biol. 36, 111-129.

Ribeiro, J.M., Anderson, J.M., Manoukis, N.C., Meng, Z., Francischetti, I.M., 2011. A further insight into the sialome of the tropical bont tick, Amblyomma variegatum. BMC Genomics 12, 136.

Ribeiro, J.M., Labruna, M.B., Mans, B.J., Maruyama, S.R., Francischetti, I.M., Barizon, G.C., de Miranda Santos, I.K., 2012. The sialotranscriptome of Antricola delacruzi female ticks is compatible with non-hematophagous behavior and an alternative source of food. Insect Biochem. Mol. Biol. 42, 332-342.

Ricci, C.G., Pinto, A.F., Berger, M., Termignoni, C., 2007. A thrombin inhibitor from the gut of Boophilus microplus ticks. Exp. Appl. Acarol. 42, 291-300.

Rider, S.D. Jr., Morgan, M.S., Arlian, L.G., 2015. Draft genome of the scabies mite. Parasit. Vectors 8, 585.

Robertson, H.M., Kent, L.B., 2009. Evolution of the gene lineage encoding the carbon dioxide receptor in insects. J. Insect Sci. 9, 19.

Rodriguez-Valle, M., Xu, T., Kurscheid, S., Lew-Tabor, A.E., 2015. Rhipicephalus microplus serine protease inhibitor family: annotation, expression and functional characterisation assessment. Parasit. Vectors 8, 7.

Roe, R.M., Donohue, K.V., Khalil, S.M., Bissinger, B.W., Zhu, J., Sonenshine, D.E., 2014. Hormonal regulation of metamorphosis and reproduction in ticks, in: Sonenshine, D.E, Roe, R.M. (Eds.), Biology of Ticks, Volume 1, Second Edition. Oxford University Press, New York, pp. 416-448. 
Ronquist, F., 2004. Bayesian inference of character evolution. Trends Ecol. Evol. 19, 475-481.

Ross, I.C., 1926. An experimental study of tick paralysis in Australia. Parasitol. 18, 410-429.

Rost, B., 1999. Twilight zone of protein sequence alignments. Prot. Eng. 12, 85-94.

Roversi, P., Ryffel, B., Togbe, D., Maillet, I., Teixeira, M., Ahmat, N., Paesen, G.C., Lissina, O., Boland, W., Ploss, K., Caesar, J.J., Leonhartsberger, S., Lea, S.M., Nunn, M.A., 2013. Bifunctional lipocalin ameliorates murine immune complex-induced acute lung injury. J. Biol. Chem. 288, 18789-18802.

Ruppert, E.E., Fox, R.S., Barnes, R.D., 2003. Invertebrate Zoology. 7th Edition. Brooks/Cole, Belmont.

Sabbatani, L., 1899. Fermento anticoagulante dell Ixodes ricinus. Arch. Ital. Biol. 31, $37-53$.

Salát, J., Paesen, G.C., Rezácová, P., Kotsyfakis, M., Kovárová, Z., Sanda, M., Majtán, J., Grunclová, L., Horká, H., Andersen, J.F., Brynda, J., Horn, M., Nunn, M.A., Kopácek, P., Kopecký, J., Mares, M., 2010. Crystal structure and functional characterization of an immunomodulatory salivary cystatin from the soft tick Ornithodoros moubata. Biochem. J. 429, 103-112.

Sangamnatdej, S., Paesen, G.C., Slovak, M., Nuttall, P.A., 2002. A high affinity serotonin- and histamine-binding lipocalin from tick saliva. Insect Mol. Biol. 11, 7986.

Sant'Anna Azzolini, S., Sasaki, S.D., Torquato, R.J., Andreotti, R., Andreotti, E., Tanaka, A.S., 2003. Rhipicephalus sanguineus trypsin inhibitors present in the tick larvae: isolation, characterization, and partial primary structure determination. Arch. Biochem. Biophys. 417, 176-182.

Santos, I.K., Valenzuela, J.G., Ribeiro, J.M., de Castro, M., Costa, J.N., Costa, A.M., da Silva, E.R., Neto, O.B., Rocha, C., Daffre, S., Ferreira, B.R., da Silva, J.S., Szabó, M.P., Bechara, G.H., 2004. Gene discovery in Boophilus microplus, the cattle tick: the transcriptomes of ovaries, salivary glands, and hemocytes. Ann. N.Y. Acad. Sci. $1026,242-246$.

Santos, V.T., Ribeiro, L., Fraga, A., de Barros, C.M., Campos, E., Moraes, J., Fontenele, M.R., Araujo, H.M., Feitosa, N.M., Logullo, C., Nunes da Fonseca, R., 2013. The embryogenesis of the tick Rhipicephalus (Boophilus) microplus: the establishment of a new chelicerate model system. Genesis 51, 803-818.

Sasaki, S.D., Azzolini, S.S., Hirata, I.Y., Andreotti, R., Tanaka, A.S., 2004. Boophilus microplus tick larvae, a rich source of Kunitz type serine proteinase inhibitors. Biochimie 86. 643-649. 
Sauer, J.R., Essenberg, R.C., Bowman, A.S., 2000. Salivary glands in ixodid ticks: control and mechanism of secretion. J. Insect Phys. 46, 1069-1078.

Schicht, S., Qi, W., Poveda, L., Strube, C., 2014. Whole transcriptome analysis of the poultry red mite Dermanyssus gallinae (De Geer, 1778). Parasitol. 141, 336-346.

Schwarz, A., von Reumont, B.M., Erhart, J., Chagas, A.C., Ribeiro, J.M., Kotsyfakis, M., 2013. De novo Ixodes ricinus salivary gland transcriptome analysis using two next-generation sequencing methodologies. FASEB J. 27, 4745-4656.

Schwarz, A., Tenzer, S., Hackenberg, M., Erhart, J., Gerhold-Ay, A., Mazur, J., Kuharev, J., Ribeiro, J.M., Kotsyfakis, M., 2014a. A systems level analysis reveals transcriptomic and proteomic complexity in Ixodes ricinus midgut and salivary glands during early attachment and feeding. Mol. Cell. Proteomics 13, 2725-2735.

Schwarz, A., Cabezas-Cruz, A., Kopecký, J., Valdés, J.J., 2014b. Understanding the evolutionary structural variability and target specificity of tick salivary Kunitz peptides using next generation transcriptome data. BMC Evol. Biol. 14, 4.

Schuijt, T.J., Bakhtiari, K., Daffre, S., Deponte, K., Wielders, S.J., Marquart, J.A., Hovius, J.W., van der Poll, T., Fikrig, E., Bunce, M.W., Camire, R.M., Nicolaes, G.A., Meijers, J.C., van 't Veer, C., 2013. Factor Xa activation of factor V is of paramount importance in initiating the coagulation system: lessons from a tick salivary protein. Circulation 128, 254-266.

Severance, S., Hamza, I., 2009. Trafficking of heme and porphyrins in metazoa. Chem. Rev. 109, 4596-4616.

Sharma, P.P., Kaluziak, S.T., Pérez-Porro, A.R., González, V.L., Hormiga, G., Wheeler, W.C., Giribet, G., 2014. Phylogenomic interrogation of arachnida reveals systemic conflicts in phylogenetic signal. Mol. Biol. Evol. 31, 2963-2984.

Shaw, M.K., Young, A.S., 1995. Differential development and emission of Theileria parva sporozoites from the salivary gland of Rhipicephalus appendiculatus. Parasitol. $111,153-160$.

Sheldon, P., 1996. Plus ça change - a model for stasis and evolution in different environments. Palaeogeogr. Palaeoclimatol. Palaeoecol. 127, 209-227.

Shultz, J.W., 1990. Evolutionary morphology and phylogeny of Arachnida. Cladistics $6,1-38$.

Shultz, J.W., 2007. A phylogenetic analysis of the arachnid orders based on morphological characters. Zool. J. Linn. Soc. 150, 221-265.

Šimo, L., Slovák, M., Park, Y., Žitňan, D., 2009a. Identification of a complex peptidergic neuroendocrine network in the hard tick, Rhipicephalus appendiculatus. Cell Tissue Res. 335, 639-655. 
Šimo, L., Žitňan, D., Park, Y., 2009b. Two novel neuropeptides in innervation of the salivary glands of the black-legged tick, Ixodes scapularis: myoinhibitory peptide and SIFamide. J. Comp. Neurol. 517, 551-563.

Šimo, L., Koči, J., Žitňan, D., Park, Y., 2011. Evidence for D1 dopamine receptor activation by a paracrine signal of dopamine in tick salivary glands. PLoS One 6, e16158.

Šimo, L., Žitňan, D., Park, Y., 2012. Neural control of salivary glands in ixodid ticks. J. Insect Physiol. 58, 459-466.

Šimo, L., Koči, J., Park, Y., 2013. Receptors for the neuropeptides, myoinhibitory peptide and SIFamide, in control of the salivary glands of the blacklegged tick Ixodes scapularis. Insect Biochem. Mol. Biol. 43, 376-387.

Šimo, L., Sonenshine, D.E., Park, Y., Žitňan, D., 2014. Nervous and sensory systems, in: Sonenshine, D.E, Roe, R.M. (Eds.), Biology of Ticks, Volume 1, Second Edition. Oxford University Press, New York, pp. 309-367.

Soares, T.S., Watanabe, R.M., Tanaka-Azevedo, A.M., Torquato, R.J., Lu, S., Figueiredo, A.C., Pereira, P.J., Tanaka, A.S., 2012. Expression and functional characterization of boophilin, a thrombin inhibitor from Rhipicephalus (Boophilus) microplus midgut. Vet. Parasitol. 187, 521-528.

Sojka, D., Franta, Z., Horn, M., Hajdusek, O., Caffrey, C.R., Mares, M., Kopácek, P., 2008. Profiling of proteolytic enzymes in the gut of the tick Ixodes ricinus reveals an evolutionarily conserved network of aspartic and cysteine peptidases. Parasit. Vectors. 1,7 .

Sojka, D., Franta, Z., Horn, M., Caffrey, C.R., Mareš, M., Kopáček, P., 2013. New insights into the machinery of blood digestion by ticks. Trends Parasitol. 29, 276-285.

Sonenshine, D.E., 1991. Biology of ticks. Volume 1. Oxford University Press, Cambridge.

Sonenshine, D.E., 2004. Pheromones and other semiochemicals of ticks and their use in tick control. Parasitol. 129, S405-S425.

Sonenshine, D.E., Roe, R.M., 2014. External and internal anatomy of ticks, in: Sonenshine, D.E, Roe, R.M. (Eds.), Biology of Ticks, Volume 1, Second Edition. Oxford University Press, New York, pp. 74-98.

Stanley, D., Kim, Y., 2011. Prostaglandins and their receptors in insect biology. Front. Endocrinol. (Lausanne) 2, 105.

Stutzer, C., Mans, B.J., Gaspar, A.R., Neitz, A.W., Maritz-Olivier, C., 2009. Ornithodoros savignyi: soft tick apyrase belongs to the 5'-nucleotidase family. Exp. Parasitol. 122, 318-327. 
Tajiri, R., Misaki, K., Yonemura, S., Hayashi, S., 2010. Dynamic shape changes of ECM-producing cells drive morphogenesis of ball-and-socket joints in the fly leg. Development 137, 2055-2063.

Tajiri, R., Misaki, K., Yonemura, S., Hayashi, S., 2011. Joint morphology in the insect leg: evolutionary history inferred from Notch loss-of-function phenotypes in Drosophila. Development 138, 4621-4626.

Tan, K.W., Jobichen, C., Ong, T.C., Gao, Y.F., Tiong, Y.S., Wong, K.N., Chew, F.T., Sivaraman, J., Mok, Y.K., 2012. Crystal structure of Der f 7, a dust mite allergen from Dermatophagoides farinae. PLoS One 7, e44850.

Tan, A.W,. Francischetti, I.M., Slovak, M., Kini, R.M., Ribeiro, J.M., 2015. Sexual differences in the sialomes of the zebra tick, Rhipicephalus pulchellus. J Proteomics $117,120-144$.

Tanaka, A.S., Andreotti, R., Gomes, A., Torquato, R.J., Sampaio, M.U., Sampaio, C.A., 1999. A double headed serine proteinase inhibitor--human plasma kallikrein and elastase inhibitor--from Boophilus microplus larvae. Immunopharmacology 45, 171177.

Tang, J., Fang, Y., Han, Y., Bai, X., Yan, X., Zhang, Y., Lai, R., Zhang, Z., 2015. YY-39, a tick anti-thrombosis peptide containing RGD domain. Peptides 68, 99-104.

Tatchell, R.J., 1967a. A modified method for obtaining tick oral secretion. J. Parasitol. 53, 1106-1107.

Tatchell, R.J., 1967b. Salivary secretion in the cattle tick as a means of water elimination. Nature 213, 940-941.

Tatusov, R.L., Fedorova, N.D., Jackson, J.D., Jacobs, A.R., Kiryutin, B., Koonin, E.V., Krylov, D.M., Mazumder, R., Mekhedov, S.L., Nikolskaya, A.N., Rao, B.S., Smirnov, S., Sverdlov, A.V., Vasudevan, S., Wolf, Y.I., Yin, J.J., Natale, D.A., 2003. The COG database: an updated version includes eukaryotes. BMC Bioinformatics 4, 41.

Telford, M.J., Bourlat, S.J., Economou, A., Papillon, D., Rota-Stabelli, O., 2008. The evolution of the Ecdysozoa. Philos. Trans. R. Soc. Lond. B Biol. Sci. 363, 1529-1537.

Tirloni, L., Reck, J., Terra, R.M., Martins, J.R., Mulenga, A., Sherman, N.E., Fox, J.W., Yates, J.R. 3rd, Termignoni, C., Pinto, A.F., Vaz Ida, S. Jr., 2014. Proteomic analysis of cattle tick Rhipicephalus (Boophilus) microplus saliva: a comparison between partially and fully engorged females. PLoS One 9, e94831.

Tirloni, L., Islam, M.S., Kim, T.K., Diedrich, J.K., Yates, J.R. 3rd, Pinto, A.F., Mulenga, A., You, M.J., Da Silva Vaz, I. Jr., 2015. Saliva from nymph and adult females of Haemaphysalis longicornis: a proteomic study. Parasit Vectors 8, 338. 
Valdés, J.J., Schwarz, A., Cabeza de Vaca, I., Calvo, E., Pedra, J.H., Guallar, V., Kotsyfakis, M., 2013. Tryptogalinin is a tick Kunitz serine protease inhibitor with a unique intrinsic disorder. PLoS One 8, e62562.

Valdés, J.J., Moal, I.H., 2014. Prediction of Kunitz ion channel effectors and protease inhibitors from the Ixodes ricinus sialome. Ticks Tick Borne Dis. 5, 947-950.

Valentine, J.W., Collins, A.G., 2000. The significance of moulting in Ecdysozoan evolution. Evol. Dev. 2, 152-156.

Valenzuela, J.G., Charlab, R., Mather, T.N., Ribeiro, J.M., 2000. Purification, cloning, and expression of a novel salivary anticomplement protein from the tick, Ixodes scapularis. J. Biol. Chem. 275, 18717-18723.

Valenzuela, J.G., Francischetti, I.M., Pham, V.M., Garfield, M.K., Mather, T.N., Ribeiro, J.M., 2002. Exploring the sialome of the tick Ixodes scapularis. J. Exp. Biol. 205, 2843-2864.

van de Locht, A., Stubbs, M.T., Bode, W., Friedrich, T., Bollschweiler, C., Höffken, W., Huber, R., 1996. The ornithodorin-thrombin crystal structure, a key to the TAP enigma? EMBO J. 15, 6011-6017.

Van der Hammen, L., 1989. An introduction to comparative arachnology. SPB Academic Publishing, Leiden.

Vannier, J., Liu, J., Lerosey-Aubril, R., Vinther, J., Daley, A.C., 2014. Sophisticated digestive systems in early arthropods. Nat. Commun. 5, 3641.

Veenstra, J.A., Rombauts, S., Grbić, M., 2012. In silico cloning of genes encoding neuropeptides, neurohormones and their putative G-protein coupled receptors in a spider mite. Insect Biochem. Mol. Biol. 42, 277-295.

Venzal, J.M., Nava, S., Terassini, F.A., Ogrzewalska, M., Camargo, L.M., Labruna, M.B., 2013. Ornithodoros peropteryx (Acari: Argasidae) in Bolivia: an argasid tick with a single nymphal stage. Exp. Appl. Acarol. 61, 231-241.

Vink, S., Daly, N.L., Steen, N., Craik, D.J., Alewood, P.F., 2014. Holocyclotoxin-1, a cystine knot toxin from Ixodes holocyclus. Toxicon 90, 308-317.

Visser, J.N.J., 1995. Post-glacial Permian stratigraphy and geography of southern and central Africa: boundary conditions for climatic modelling. Palaeogeogr. Palaeoclim. Palaeoecol. 118, 213-243.

von Reumont, B.M., Campbell, L.I., Jenner, R.A., 2014. Quo vadis venomics? A roadmap to neglected venomous invertebrates. Toxins (Basel) 6, 3488-3551.

von Siebold C.T., 1848. Lehrbuch der vergleichenden Anatomie der Wirbellosen Thiere. Erster Theil, in: von Siebold, C.T., Stannius, H., (Eds.), Lehrbuch der vergleichenden Anatomie. Verlag von Veit \& Comp., Berlin. 
Walter, D.E., Proctor, H.C., 1998. Feeding behaviour and phylogeny: Observations on early derivative Acari. Exp. Appl. Acarol. 22, 39-50.

Walter, D.E., Proctor, H.C., 1999. Mites: Ecology, Evolution and Behaviour. CABI Publishing, New York.

Wang, H., Nuttall, P.A., 1994. Excretion of host immunoglobulin in tick saliva and detection of IgG-binding proteins in tick haemolymph and salivary glands. Parasitol. $109,525-530$.

Wang, X., Coons, L.B., Taylor, D.B., Stevens, S.E. Jr., Gartner, T.K., 1996. Variabilin, a novel RGD-containing antagonist of glycoprotein IIb-IIIa and platelet aggregation inhibitor from the hard tick Dermacentor variabilis. J. Biol. Chem. 271, 17785-17790.

Wang, H., Paesen, G.C., Nuttall, P.A., Barbour, A.G., 1998. Male ticks help their mates to feed. Nature 391, 753-754.

Waxman L., Smith D.E., Arcuri K.E., Vlasuk P., 1990. Tick anticoagulant peptide (TAP) is a novel inhibitor of blood coagulation factor Xa. Science 248, 593-596.

Waxman, L., Connolly, T.M., 1993. Isolation of an inhibitor selective for collagenstimulated platelet aggregation from the soft tick Ornithodoros moubata. J. Biol. Chem. 268, 5445-5449.

Werth, A.J., Shear, W.A., 2014. The evolutionary truth about living fossils. Amer. Sci. 102, 434-443.

Wheat, C.W., Wahlberg, N., 2013. Phylogenomic insights into the cambrian explosion, the colonization of land and the evolution of flight in arthropoda. Syst. Biol. 62, 93-109.

Wheeler, W.C., Hayashi, C.Y., 1998. The Phylogeny of the Extant Chelicerate Orders. Cladistics 14, 173-192.

Wiens, J.J., Morrill, M.C., 2011. Missing data in phylogenetic analysis: reconcilingresults from simulations and empirical data. Syst. Biol. 60, 719-731.

Wong, J.W.H., Ho, S.Y.W., Hogg, P.J., 2011. Disulfide bond acquisition through eukaryotic protein evolution. Mol. Biol. Evol. 28, 327-334.

Xu, X.L., Cheng, T.Y., Yang, H., Yan, F., Yang, Y., 2015. De novo sequencing, assembly and analysis of salivary gland transcriptome of Haemaphysalis flava and identification of sialoprotein genes. Infect. Genet. Evol. 32, 135-142.

Xu, T., Lew-Tabor, A., Rodriguez-Valle, M., 2016. Effective inhibition of thrombin by Rhipicephalus microplus serpin-15 (RmS-15) obtained in the yeast Pichia pastoris. Ticks Tick Borne Dis. 7, 180-187. 
Yamamoto, K., Suzuki, M., Higashiura, A., Aritake, K., Urade, Y., Uodome, N., Hossain, T., Nakagawa, A., 2013. New insights into the catalytic mechanism of Bombyx mori prostaglandin E synthase gained from structure-function analysis. Biochem. Biophys. Res. Commun. 440, 762-767.

Zhu, K., Bowman, A.S., Brigham, D.L., Essenberg, R.C., Dillwith, J.W., Sauer, J.R., 1997. Isolation and characterization of americanin, a specific inhibitor of thrombin, from the salivary glands of the lone star tick Amblyomma americanum (L.). Exp. Parasitol. 87, 30-38.

Zuckerkandl, E., Pauling, L., 1962. Molecular Disease, Evolution and Genetic Heterogeneity, in: Kasha, M., Pullman, B., (Eds.), Horizons in Biochemistry. Academic Press, New York, pp. 189-225.

Zuckerkandl, E., Pauling, L., 1965a. Molecules as documents of evolutionary history. J. Theor. Biol. 8, 357-366.

Zuckerkandl, E., Pauling, L., 1965b. Evolutionary divergence and convergence in proteins, in: Bryson, V., Vogel, H.J. (Eds.), Evolving Genes and Proteins. Academic Press, New York, pp. 97-166. 